Humberto Rodrigo Sandmann

\title{
Predição não-linear de séries temporais usando sistemas de arquitetura neuro-fuzzy
}

\author{
Dissertação apresentada à Escola \\ Politécnica da Universidade de São \\ Paulo para obtenção do Título de \\ Mestre em Engenharia.
}




\title{
Humberto Rodrigo Sandmann
}

\section{Predição não-linear de séries temporais usando sistemas de arquitetura neuro-fuzzy}

\author{
Dissertação apresentada à Escola \\ Politécnica da Universidade de São \\ Paulo para obtenção do Título de \\ Mestre em Engenharia. \\ Área de concentração: \\ Sistemas Digitais \\ Orientador: \\ Prof. Dr. Marco Túlio Carvalho \\ de Andrade
}


Aos meus pais 


\section{Agradecimentos}

Gostaria de agradecer a todos da Escola Politécnica que me auxiliaram durante este percurso. Em especial o Prof. Dr. Marco Túlio Carvalho de Andrade, meu orientador, o qual me ajudou a trilhar o percurso.

Aos meus familiares por compreenderem todo este tempo as ausências.

Meus amigos que foram cruciais para as idéias e discussões, como o Leandro Augusto da Silva, que sempre esteve disposto a ouvir e discutir as mais mirabolantes idéias, por mais ridículas que parecessem.

Agradeço as pessoas que leram o texto para a revisão e todos aqueles que de alguma forma colaboraram para a finalização deste trabalho. 


\section{Resumo}

SANDMANN, H. Predição não-linear de séries temporais usando sistemas de arquitetura neuro-fuzzy. 2006. 72 p. Dissertação (Mestrado) Escola Politécnica, Universidade de São Paulo, São Paulo, 2006.

Esta dissertação tem como objetivo a aplicação de sistemas com arquitetura neuro-fuzzy na predição de funções que geram séries temporais.

A arquitetura pesquisada é a Adaptive Neuro-Fuzzy Inference System (ANFIS). Esta arquitetura se trata de um Fuzzy Inference Systems (FIS) implementado sob o paradigma das redes neurais artificiais. Ao fazer o uso da tecnologia de redes neurais artificiais, o ANFIS possui a capacidade de aprendizagem dos dados do ambiente no qual está inserido. Da mesma forma, por implementar um FIS, o ANFIS agrega também a competência de processamento lingüístico. Logo, o ANFIS pode ser categorizado como um sistema híbrido.

Ao longo dos capítulos estão expostos alguns conceitos e fundamentos da Teoria Fuzzy, assim como das redes neurais artificiais e sistemas híbridos.

Ao final do trabalho são realizadas algumas discussões, análises e conclusões, as quais permitem a possibilidade de futuras aplicações e extensão deste.

Palavras-chave: Sistemas híbridos. Análise de séries temporais. Redes neurais. Fuzzy. 


\section{Abstract}

SANDMANN, H. Predição não-linear de séries temporais usando sistemas de arquitetura neuro-fuzzy. 2006. 72 p. Dissertation (Mastering) Escola Politécnica, Universidade de São Paulo, São Paulo, 2006.

This master dissertation has as main objetive applies systems of neuro-fuzzy architecture for functions prediction in serie times.

The architecture carried out is the Adaptive Neuro-Fuzzy Inference System (ANFIS). This architecture is a kind of Fuzzy Inference Systems (FIS) implementation under a paradigm of artificial neural networks. Making use of technology of artificial neural networks, the ANFIS has the capacity of learning with environment data that inserted on. As the same, the ANFIS had been implemented to be a FIS. Then it can process simbolic variables. So, an ANFIS can be described like a hibrid system.

All over the chapters are showed some concepts and fundaments of Fuzzy theory, artificial neural networks and hidrid systems.

The purpose of the tests the ANFIS, it were been made from a logistic function and a Mackey-Glass function. This tests were against with an estimation function made by MLP net.

At the end of the work are some discussions, analyses and conclusions that allows futures possibilites of applications and extensions of this work.

Keywords: Hibrid systems. Time series analyse. Neural networks. Fuzzy. 


\title{
Sumário
}

\section{Lista de Figuras}

\author{
Lista de Tabelas
}

\section{Lista de Abreviaturas}

1 Introdução 13

1.1 Objetivo . . . . . . . . . . . . . . . . . . 14

1.2 Organização do Trabalho . . . . . . . . . . . . . . . . . . . . . . . 14

$\begin{array}{llr}2 & \text { Fuzzy } & 15\end{array}$

2.1 Teoria dos Conjuntos Fuzzy . . . . . . . . . . . . . . 15

2.1.1 Relações Básicas em Conjuntos Fuzzy . . . . . . . . . . . . 17

2.1 .2 Regras IF-THEN Fuzzy . . . . . . . . . . . . . . . 20

2.2 Sistema de Inferência Fuzzy . . . . . . . . . . . . . . . . . . . 21

2.2.1 Modelo Fuzzy Mamdani . . . . . . . . . . . . . . . . . . . 22

2.2.2 Modelo Fuzzy Takagi-Sugeno . . . . . . . . . . . . . . 24

2.2 .3 Modelo Fuzzy Tsukamoto . . . . . . . . . . . . . . . . . . 24

2.2.4 Espaço de Particionamento das Variáveis Fuzzy . . . . . . 25

2.3 Sumário . . . . . . . . . . . . . . . . . . . . . . . 27

3 Redes Neurais Artificiais $\quad 28$

3.1 Perceptrons de Múltiplas Camadas (MLP) . . . . . . . . . . 30

3.1.1 Algoritmo de Retropropagação . . . . . . . . . . . . . . 32

3.2 Redes de Função de Base Radial (RBF) . . . . . . . . . . . . . . . 34

3.3 Sumário . . . . . . . . . . . . . . . . . . . . . 36 
$\begin{array}{llr}4 & \text { Sistemas Neuro-Fuzzy } & 37\end{array}$

4.1 Modelos Híbridos . . . . . . . . . . . . . . . . . . . . . . . . . 38

4.1.1 Modelo Concorrente . . . . . . . . . . . . . . 38

4.1.2 Modelo Cooperativo . . . . . . . . . . . . . . . 39

4.1 .3 Modelo Incorporado . . . . . . . . . . . . . . . . . . . . . 39

5 Adaptive Neuro-Fuzzy Inference System (ANFIS) 41

5.1 Arquitetura . . . . . . . . . . . . . . . . . . 42

5.2 Aprendizado........................ 46

5.3 Aproximador Universal de Funções . . . . . . . . . . . . . . . . . 49

5.4 Sumário . . . . . . . . . . . . . . . . . . . . . . . . . . 49

$\begin{array}{lll}6 & \text { Experimentos } & 51\end{array}$

6.1 Função Logística . . . . . . . . . . . . . . . . . . . . . . . 52

6.2 Série de Mackey-Glass . . . . . . . . . . . . . . . . . 58

$\begin{array}{lll}7 & \text { Análise Comparativa e Discussões } & 67\end{array}$

8 Considerações Finais $\quad 69$

8.1 Contribuições do Trabalho . . . . . . . . . . . . . . . . 69

8.2 Trabalhos Futuros . . . . . . . . . . . . . . . . . . 69

$\begin{array}{ll}\text { Referências } & 71\end{array}$ 


\section{Lista de Figuras}

2.1 Conjunto de pertinências de cores de uma variável fuzzy de cor qualquer. . . . . . . . . . . . . . . . . . 16

2.2 Conjunto de pertinências de cores de uma variável fuzzy de cor, através desse gráfico é possível vizualizar as curvas de pertinência das funções vermelho, verde e azul. . . . . . . . . . . . . . . . . . 17

2.3 O conceito de $A \subseteq B$ (JANG; SUN; MIZUTANI, 1997) . . . . . . 18

2.4 Operações lógicas em conjuntos fuzzy: (a) dois conjuntos fuzzy $A$ e $B$; (b) $\bar{A}$; (c) $A \cup B$; (d) $A \cap B$. (JANG; SUN; MIZUTANI, 1997). . 19

2.5 Sistema de Inferência Fuzzy (FIS) (JANG, 1993). . . . . . . . . . . 22

2.6 Modelo fuzzy Mamdani (JANG; SUn; MiZUTAni, 1997). . . . . . . 23

2.7 Modelo fuzzy Takagi-Sugeno (JANG; SUN; MIZUTANI, 1997). . . . . 24

2.8 Modelo fuzzy Tsukamoto (JANG; SUN; MIZUTANI, 1997). . . . . . . 25

2.9 Espaço gerado pela intersecção de duas funções de pertinência de duas variáveis fuzzy distintas (DUDA; HART; STORK, 2000). . . . . 26

2.10 Particionamentos possíveis para o espaço de duas variáveis (AURÉLIO; VELLASCO; LOPES, 1999). . . . . . . . . . . . . . 26

3.1 Modelo de um neurônio artificial (HAYKIN, 1999). . . . . . . . . . 29

3.2 Topologia de uma Rede de Perceptrons de Múltiplas Camadas $(\mathrm{MLP}) \ldots \ldots \ldots \ldots \ldots \ldots \ldots$

3.3 Rede de Função de Base Radial (HAYKIn, 1999) . . . . . . . . . . . 34

4.1 Modelo Neuro-Fuzzy Concorrente, ou Híbrido Seqüencial (AURÉLIO; VELLASCO; LOPES, 1999). . . . . . . . . . . . . . . 38

4.2 Modelo Neuro-Fuzzy Cooperativo, ou Híbrido Auxiliar (AURÉLIO; VELLASCO; LOPES, 1999). . . . . . . . . . . . . . . . . . . 39

4.3 Modelo Neuro-Fuzzy Fused, ou Híbrido Incorporado (AURÉLIO; VELLASCO; LOPES, 1999). . . . . . . . . . . . . . . . . . . 39 
5.1 Arquitetura ANFIS Sugeno com suas cinco camadas (JANG, 1992). 42

5.2 Modelo ANFIS equivalente ao FIS Tsukamoto (JANG; SUN; MIZU-

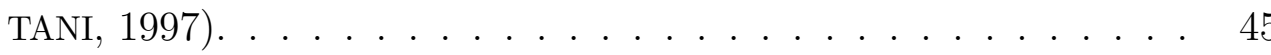

5.3 Modelo ANFIS, equivalente ao FIS Sugeno, com 3 variáveis de entrada, sendo que cada uma possui 2 funções de pertinência. Gerando assim uma lista de regras com 8 combinações. . . . . . .

6.1 Com uma simples variação no parâmetro de bifurcação $\mu$ da função logística $x(n+1)=f(x(n))=\mu x(n)(1-x(n))$ é possível navegar entre comportamentos distintos da função: (a) é o período com apenas um ponto de convergência assintótico (estado estacionário); (b) é o período com dois pontos de oscilação (estado de ciclo-limite com periodicidade 2); (c) é o período com quatro pontos de oscilação (estado de ciclo-limite com periodicidade 4) e (d) é o período com comportamento caótico (estado instável).

6.2 Mapa de bifurcação da função logística 6.1 (DEL-MORALHERNANDEZ, 2003; DEL-MORAL-HERNANDEZ; SANDMANN; SILVA, 2004; GLASS; MACKEY, 1997; BEUTER et al., 2003). . . . . . . . . .

6.3 Estimação da função logística 6.1 com parâmetro de bifurcação $\mu=3,70$ (período caótico) por um ANFIS com números de funções de pertinência por variável de entrada: (a) 2, (b) 3 e (c) 5. . . . .

6.4 Estimação da função logística 6.1 por em rede neural MLP com 2 neurônios na camada oculta. . . . . . . . . . . . . . . . 57

6.5 Estimação da função logística 6.1 por uma rede neural MLP com 3 neurônios na camada oculta. . . . . . . . . . . . . . . . 57

6.6 Estimação da função logística 6.1 por uma rede neural MLP com 5 neurônios na camada oculta. . . . . . . . . . . . . . . . . . . 58

6.7 Uma simples variação no parâmetro de bifurcação $\tau$ da função de Mackey-Glass permite navegar entre comportamentos distintos da função. A coluna da esquerda apresenta a evolução da função ao longo do tempo $(t)$ e a da direita apresenta um diagrama de teia, no qual é notável o número de períodos da função e a evolução entre $x(t)$ e $x(t-\tau)$. A última linha exibe uma função em comportamento caótico. . . . . . . . . . . . . . . . . . . 
6.8 Estimação da função de Mackey-Glass $6.2 \mathrm{com}$ parâmetro de bifurcação $\tau=16$ (ciclo-limite em período 4) por um ANFIS com números de funções de pertinência por variável de entrada: (a) 2, (b) 3 e (c) $5 \ldots \ldots \ldots \ldots \ldots \ldots \ldots$

6.9 Estimação da função de Mackey-Glass 6.2 com parâmetro de bifurcação $\tau=16$ (ciclo-limite em período 4) em uma rede MLP com 2 neurônios na camada oculta. . . . . . . . . . . . 62

6.10 Estimação da função de Mackey-Glass 6.2 com parâmetro de bifurcação $\tau=16$ (ciclo-limite em período 4) em uma rede MLP com 3 neurônios na camada oculta. . . . . . . . . . . . . 62

6.11 Estimação da função de Mackey-Glass 6.2 com parâmetro de bifurcação $\tau=16$ (ciclo-limite em período 4) em uma rede MLP com 5 neurônios na camada oculta. . . . . . . . . . . . .

6.12 Estimação da função de Mackey-Glass 6.2 com parâmetro de bifurcação $\tau=30$ (período instável) por um ANFIS com 2 variáveis de entrada e números de funções de pertinência de entrada (a) 2, (b) 3 e (c) 5 por variável. . . . . . . . . . . . . . . . . . 64

6.13 Estimação da função de Mackey-Glass 6.2 com parâmetro de bifurcação $\tau=16$ (ciclo-limite em período 4) em uma rede MLP com 2 variáveis de entrada e 2 neurônios na camada oculta. . . . . . . .

6.14 Estimação da função de Mackey-Glass 6.2 com parâmetro de bifurcação $\tau=16$ (ciclo-limite em período 4) em uma rede MLP com 2 variáveis de entrada e 3 neurônios na camada oculta. . . . . . .

6.15 Estimação da função de Mackey-Glass $6.2 \mathrm{com}$ parâmetro de bifurcação $\tau=16$ (ciclo-limite em período 4) em uma rede MLP com 2 variáveis de entrada e 5 neurônios na camada oculta. . . . . . . 


\section{Lista de Tabelas}

6.1 Resultados da estimação da função logística 6.1 em um ANFIS. 55

6.2 Resultados da estimação da função logística 6.1 com uma MLP. . 56

6.3 Resultados obtidos com a estimação da função de Mackey-Glass por um ANFIS. . . . . . . . . . . . . . . . . . 60

6.4 Resultados obtidos com a estimação da função de Mackey-Glass por uma rede MLP. . . . . . . . . . . . . . . . . . . . . . 61

6.5 Resultados obtidos com a estimação da função de Mackey-Glass por um ANFIS com duas variáveis de entrada. . . . . . . . . . . . 63

6.6 Resultados obtidos com a estimação da função de Mackey-Glass por um ANFIS com duas variáveis de entrada. . . . . . . . . . . . 64 


\title{
Lista de Abreviaturas
}

\author{
ANFIS Adaptive Neuro-Fuzzy Inference System \\ FIS Sistema de Inferência Fuzzy \\ FP Função de Pertinência \\ MLP Perceptrons de Múltiplas Camadas \\ RBF Rede de Função de Base Radial
}




\section{Introdução}

No dia a dia e no mundo moderno existem diversos problemas que estão relacionados à predição de séries temporais, como por exemplo, a previsão do tempo, estatísticas de trânsito, previsão de ações na bolsa de valores e outros (BROCKWELL; DAVIS, 1991). Logo, a predição de uma série temporal se torna uma funcionalidade de múltiplas aplicabilidades.

A predição de uma série temporal envolve muitas vezes problemas matemáticos complexos, pois, na maioria das vezes, a função que gera a série é desconhecida. Existem algumas técnicas de predição de série utilizadas, por exemplo, as estratégias de busca empregadas em processos estocásticos. Uma outra possibilidade de trabalhar com séries temporais é através de estimadores de funções.

Uma vez que cada instante de tempo de uma série é dado por uma função dependente de um instante passado da mesma, o uso de estimadores se torna mais comum. Na maioria das vezes é desconhecida a função que gera a série temporal. Ao modelar essa função é possível reproduzir a série temporal como se houvesse um conhecimento prévio da função (HAYKIN, 1999; NAUCK et al., 2003; BROCKWELL; DAVIS, 1991). Esse procedimento torna o processo mais ágil e com melhor grau de confiabilidade.

Este trabalho utiliza técnicas de Inteligência Articial para realizar a estimação das funções, como redes neurais artificiais e engenharia fuzzy. As redes neurais tratam o problema de forma exata e precisa, o que não permite uma maleabilidade e ajustes nos seus parâmtros internos. Já com a engenharia fuzzy é possível trabalhar com regras lingüísticas, as quais aproximam o problema do mundo real. Porém, a engenharia fuzzy não possui a capacidade de aprender suas próprias regras e nem de otimizar seus parâmetros para modelar especificamente um problema. Daí, surgem técnicas híbridas que unem as conveniências encontradas em uma rede neural artificial com as de um sistema fuzzy; neste caso, essa arquitetura híbrida é conhecida como neuro-fuzzy (NAUCK et al., 2003). 


\section{$1.1 \quad$ Objetivo}

Este trabalho tem como objetivo apresentar uma técnica baseada em sistemas de arquitetura neuro-fuzzy para predição de uma função. Para realizar os experimentos foram utilizadas duas séries temporais bem particulares: uma função logística e uma função de Mackey-Glass. A função logística foi escolhida por ser de simples entendimento e permitir uma grande exploração de valores para repetição. Já função de Mackey-Glass apresenta grande dificuldade em sua predição, pois ela é representada como uma função em tempo contínuo.

A escolha da função de Mackey-Glass também esta relacionada com a sua origem, pois, assim como as séries temporais existem no mundo real de trabalho, elas também aparecem em sistemas biológicos, no funcionamento de alguns mecanismos do corpo humano. Assim, esta série representa uma modelagem de série temporal existente na própria natureza (BEUTER et al., 2003; GLASS; MACKEY, 1997).

\subsection{Organização do Trabalho}

O trabalho está organizado em quatro partes. A primeira parte apresenta uma breve introdução aos temas que conduziram ao desenvolvimento dos sistemas neuro-fuzzy. O capítulo 2 trata da teoria e engenharia fuzzy, introduzindo conceitos de construção de sistemas que manipulam e realizam cálculos baseandose em variáveis lingüísticas. As redes neurais artificiais são discutidas logo em seguida no capítulo 3, no qual são apresentados modelos, arquiteturas e aprendizagens típicas abordadas pelas redes neurais artificiais.

Na segunda parte do trabalho são abordados os modelos de sistemas híbridos, além da apresentação de uma arquitetura neuro-fuzzy que faz uso dos conhecimentos da primeira parte para fundamentar seu uso e funcionamento.

Já na terceira parte, estão os experimentos realizados com as funções logística e de Mackey-Glass. Neste capítulo são realizados uma bateria de validações e cálculos para auxiliar na análise da predição da série temporal.

Na última parte, os resultados obtidos com os experimentos da predição de séries temporais sobre a arquitetura neuro-fuzzy são comparados e discutidos. $\mathrm{Na}$ seqüência, o trabalho é concluído e são apresentadas possíveis continuidades de trabalhos futuros. 


\section{Fuzzy}

Neste capítulo é apresentada uma breve introdução aos conceitos de conjuntos fuzzy, ou conjuntos nebulosos ${ }^{1}$, além de um resumo das relações básicas possíveis entre eles. Baseado-se nos conceitos fuzzy, mais adiante são apresentados sistemas que trabalham com engenharias do universo de conjuntos fuzzy, permitindo a aplicação da teoria. Para concluir o capítulo, um resumo com os principais pontos sobre os demais capítulos deste trabalho são destacados.

\subsection{Teoria dos Conjuntos Fuzzy}

O conceito de conjuntos fuzzy está vinculado à capacidade de classificação ou categorização de um elemento no contexto do mundo real (ZADEH, 1965; ZADEH, 1996). Nesse contexto, poucas são as vezes nas quais são possíveis definir com precisão uma classe de elementos no qual um elemento isolado pertence. Na maioria das vezes um elemento pertence a mais de uma classe simultaneamente, e esta subjetividade acaba por gerar uma falta de precisão em relação à classificação do elemento, ou então, adiciona um certo grau de incerteza quanto à sua classificação (DUDA; HART; STORK, 2000).

Para classificar um elemento são necessárias informações descriminantes. Cada uma dessas informações são representadas matematicamente por um vetor de dimensionalidade; esses vetores, dentro do universo fuzzy são chamados de variáveis fuzzy. Sendo assim, um único elemento utiliza uma ou mais variáveis fuzzy para ser classificado. Um grande número de variáveis fuzzy para classificar um elemento pode acabar gerando um problema de classificação conhecido como mal da dimensionalidade, o que aumenta a complexidade do sistema em função do seu desempenho (HAYKIN, 1999). Uma abordagem maior do assunto é apresentada na seção 2.2.4.

\footnotetext{
${ }^{1}$ Neste trabalho foi utilizado o termo conjuntos fuzzy pois no idioma português existe uma indefinição quanto a tradução entre conjuntos nebulosos e conjuntos difusos, assim para aumentar o alcance de uma futura possível busca de referência ao trabalho, o termo em inglês é mais normalmente utilizado.
} 
Assim como no mundo real, no universo fuzzy uma variável pode conter um ou mais graus de pertinência (DUBOIS; PRADE; YAGER, 1996). Esses graus de pertinência são os conjuntos domínio de uma variável fuzzy. Por exemplo, ao tentar classificar um elemento quanto à cor podemos recorrer a uma variável fuzzy, na qual é possível encontrar três universos de pertinência, como pode ser observardo na figura 2.1.

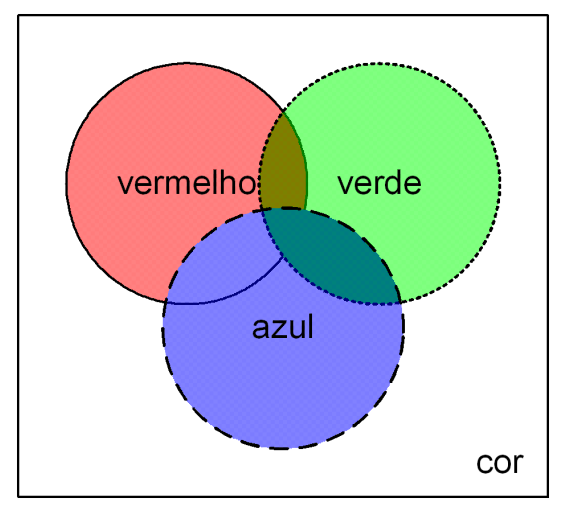

Figura 2.1: Conjunto de pertinências de cores de uma variável fuzzy de cor qualquer.

Os graus de pertinência de uma variável fuzzy são definidos de acordo com sua natureza e necessidade de granularidade da aplicação, sendo que esses graus de pertinência são dados por funções de pertinência. As funções de pertinência representam o valor de inferência de um elemento a ser classificado na curva de pertinência. Assim, uma variável fuzzy genérica $A$ pode ser descrita na forma de

$$
A=\left\{\left(x, \mu_{A}(x)\right) \mid x \in X\right\},
$$

na qual a função $\mu_{A}(x)$ é uma função de pertinência do conjunto A (JANG; SUN; MIZUTANI, 1997).

Uma função de pertinência pode ser expressa por diversas equações. Nas formas mais comuns são equações triangulares, trapezoidais, gaussianas, entre outras. No trabalho estão apresentadas algumas funções normalmente utilizadas para representar uma função de pertinência de uma variável fuzzy $A$ qualquer (JANG, 1992; JANG; SUN; MIZUTANI, 1997).

Uma forma mais comum de visualizar uma variável fuzzy e suas pertinências pode ser expressa pela figura 2.2. Em analogia com a figura 2.1 se torna mais clara a visualização do grau de pertinência do elemento dentro do universo da variável fuzzy.

A teoria fuzzy atua sobre o grau de pertinência de um elemento dentro da variável fuzzy. Como é possível notar pela figura 2.2, dentro de uma variável 


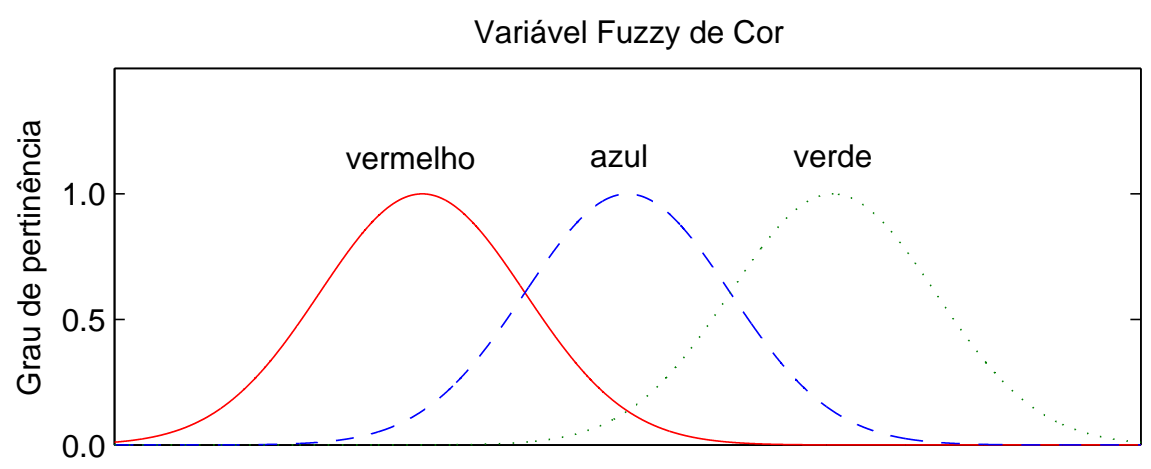

Figura 2.2: Conjunto de pertinências de cores de uma variável fuzzy de cor, através desse gráfico é possível vizualizar as curvas de pertinência das funções vermelho, verde e azul.

fuzzy pode existir um ou mais graus de pertinência para o mesmo elemento. Quando aplicado a um elemento, os graus de pertinência podem ser titulados por rótulos. Logo, como no exemplo acima, uma cor pode ser simultaneamente vermelho e verde, ou até mesmo vermelho, verde e azul, o que descreve uma situação característica do mundo real.

Esse comportamento, quando comparado com os conjuntos clássicos, mostra notória distinção dos conjuntos fuzzy, uma vez que nos conjuntos clássicos o elemento pertence ou não a um conjunto. Já nos conjuntos fuzzy o elemento possui grau de pertinência para cada conjunto, sendo que em alguns casos esse grau de pertinência pode ser até mesmo 0. A figura 2.2 ilustra essa diferença.

Os rótulos atribuítos à cada função de inferência são, na verdade, artifícios ligüísticos que auxiliam na aproximação de uma represenção mais fiel à classe de elementos na qual um elemento pertence.

Na próxima seção são apresentadas as relações básicas entre os conjuntos fuzzy, permitindo a realização de operações simples de conjuntos. Em seguida, a implementação de sistemas para se trabalhar com os conjuntos fuzzy em contextos de sistemas aplicados.

\subsubsection{Relações Básicas em Conjuntos Fuzzy}

Assim como nos conjuntos clássicos, os conjuntos fuzzy também são utilizados em operações lógicas, como as de união, intersecção e complemento de conjuntos fuzzy. Embora essas relações entre conjuntos sejam realizadas de forma bem similar ao comportamento dos conjuntos clássicos (ZADEH, 1965; JANG; SUN; MIZUTANI, 1997), os conjuntos fuzzy apresentam algumas particularidades em seu universo. 
Abaixo são descritas algumas relações básicas realizadas com conjuntos fuzzy.

Conjunto contido ou subconjunto: é quando o conjunto fuzzy $A$ está contido no conjunto fuzzy $B$ (ou equivalentemente, $A$ é um subconjunto de $B$, ou $A$ é menor ou iqual a $B$ ) se e somente se $\mu_{A}(x) \leq \mu_{B}(x)$ para todo $x$. Em símbolos temos que

$$
A \subseteq B \Leftrightarrow \mu_{A}(x) \leq \mu_{B}(x) .
$$

A figura 2.3 ilustra o conceito de $A \subseteq B$.

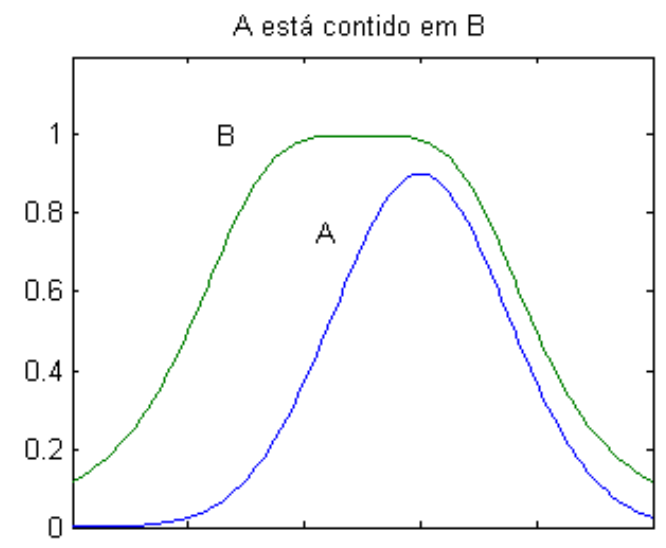

Figura 2.3: $\mathrm{O}$ conceito de $A \subseteq B$ (JANG; SUN; MIZUTANI, 1997).

União: representa a união de dois conjuntos fuzzy $A$ e $B$ que gera um outro conjunto fuzzy $C$. A operação de união é representada como $C=A \cup B$ ou $C=A \vee B$

$$
\mu_{C}(x)=\max \left(\mu_{A}(X), \mu_{B}(x)\right)=\mu_{A}(x) \vee \mu_{B}(x) .
$$

Interseção: quando o conjunto fuzzy $A$ interseção com o conjunto fuzzy $B$ resulta em um conjunto fuzzy $C$, escrito como $C=A \cap B$ ou $C=A \wedge B$. Sua função de pertinência é denotada como

$$
\mu_{C}(x)=\min \left(\mu_{A}(X), \mu_{B}(x)\right)=\mu_{A}(x) \wedge \mu_{B}(x) .
$$

Complemento ou negação: é o complemento do conjunto fuzzy $A$, denotado por $\bar{A}$ ou $\neg A$, é definido como

$$
\mu_{\bar{A}(x)}=1-\mu_{A}(X) .
$$

A figura 2.4 demonstra as três operações básicas aplicadas aos conjuntos fuzzy: figura 2.4(a) ilustra dois conjuntos fuzzy $A$ e $B$; figura 2.4(b) é o complemento do conjunto fuzzy $A$; figura 2.4(c) é a união dos conjuntos fuzzy $A$ e $B$; e a figura $2.4(\mathrm{~d})$ representa a intersecção entre os conjuntos fuzzy $A$ e $B$. 

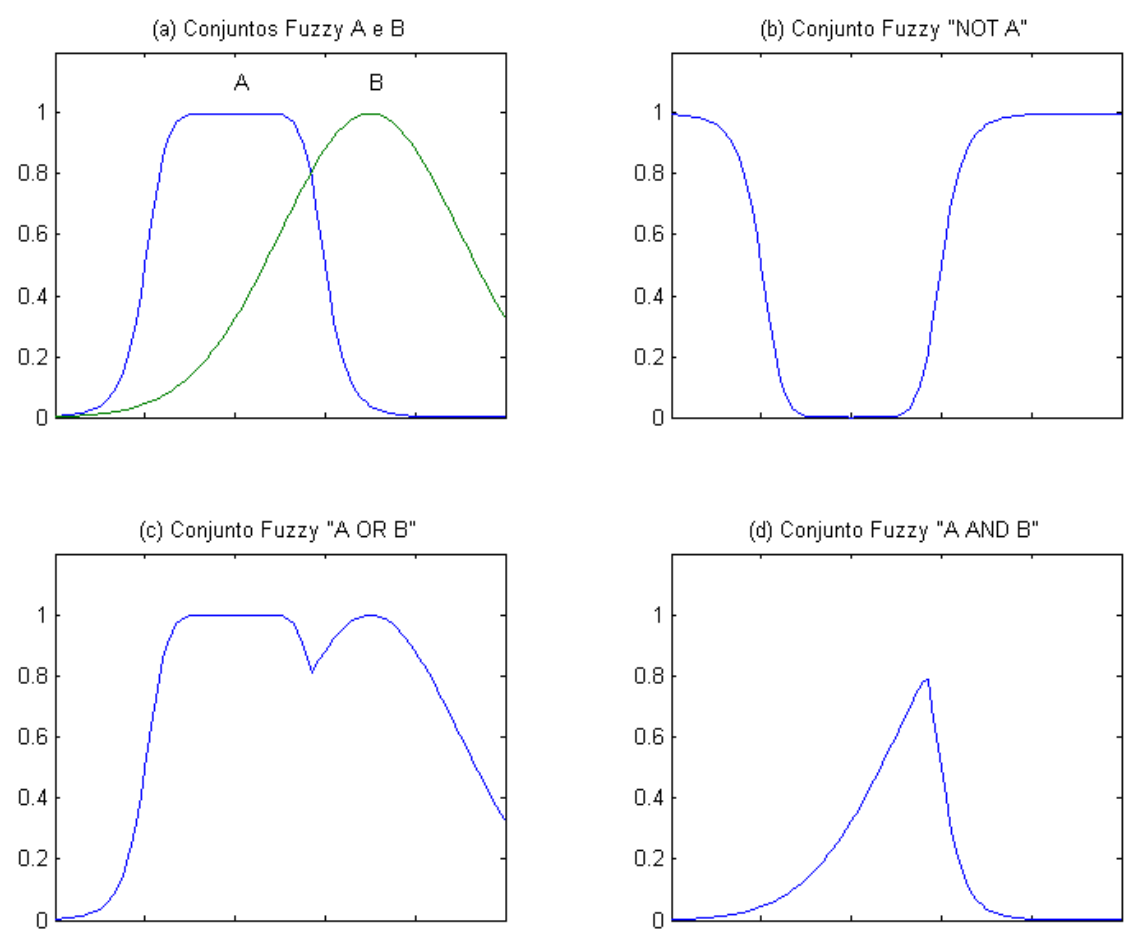

Figura 2.4: Operações lógicas em conjuntos fuzzy: (a) dois conjuntos fuzzy $A$ e $B$; (b) $\bar{A}$; (c) $A \cup B$; (d) $A \cap B$. (JANG; SUn; MIZUTANI, 1997).

Com a possibilidade de realizar operações lógicas simples com conjuntos fuzzy, torna-se possível definir operações mais robustas, como o produto cartesiano e o co-produto em conjuntos fuzzy.

Produto cartesiano: dado $A$ e $B$ estarem nos conjuntos $X$ e $Y$, respectivamente. Dessa forma, o produto cartesiano entre os dois é denotado como $A \times B$, que é o conjunto fuzzy do produto do espaço $X \times Y$. Sua função de pertinência é dada por

$$
\mu_{A \times B}(x, y)=\min \left(\mu_{A}(x), \mu_{B}(y)\right) .
$$

Co-produto cartesiano: é um conjunto fuzzy simular, ou seja, um conjunto formado pela maximização de dois pontos de pertinência, cujo conjunto fuzzy $A+B$ é dado pela função de pertinência

$$
\mu_{A+B}(x, y)=\max \left(\mu_{A}(x), \mu_{B}(y)\right) .
$$

Uma operação de produto, ou co-produto cartesiano, é caracterizada pelo uso de, pelo menos, duas variáveis fuzzy, tornando sua intersecção uma relação com, no mínimo, duas dimensões. 


\subsubsection{Regras IF-THEN Fuzzy}

Ao longo deste capítulo é introduzido o conceito de variável lingüística. Em (ZADEH, 1973), Zadeh propõe o conceito do uso de variáveis lingüísticas fuzzy como uma alternativa aproximada para modelar o pensamento humano, de maneira a sumarizar e expressar informações em termos de conjuntos fuzzy, ao invés de números discretos precisos (JANG; SUN; MIZUTANI, 1997). Trabalhar com conjuntos fuzzy facilita a manipulação de informações que possuem características de rotulação qualitativa, como as variáveis linguísticas no contexto do mundo real.

Através da possibilidade de manipular variáveis lingüísticas, torna-se possível criar regras lógicas para processar essas variáveis. A equação a seguir demonstra uma simples dedução realizada por uma regra fuzzy, na qual é possível realizar um processamento

$$
\text { if } x \text { is } A \text { then } y \text { is } B \text {, }
$$

em que $A$ e $B$ são rótulos das funções de pertinência de duas variáveis fuzzy definidas previamente. $\operatorname{Logo} x$ e $y$ são inferências de elementos no universo de discurso das funções de pertinência das respectivas variáveis fuzzy. Usualmente, o termo " $x$ é $A$ "é chamado de antecedente ou premissa, enquanto o termo " $y$ é $B$ "é chamado de conseqüência ou conclusão. Em uma forma abreviada é comum encontrar essa notação como

$$
A \rightarrow B
$$

ou seja, dado $A$, por conseqüência, temos $B$.

Esse tipo de expressão é conhecida como regra if-then fuzzy. Com esse tipo de expressão lógica simples é possível começar uma discussão de raciocínio fuzzy (JANG; SUN; MIZUTANI, 1997; ZADEH, 1996; KOSKO, 1992). Esse raciocínio origina uma expressão 2.8 que descreve a relação entre as duas variáveis $x$ e $y$ de maneira lingüística, ao mesmo tempo que permite um processamento da informação contida nas mesmas.

A seguir é apresentado um sistema que faz uso dos conceitos de relações entre conjuntos fuzzy e das regras IF-THEN fuzzy para gerar uma engenharia de processamento de variáveis fuzzy de forma genérica. 


\subsection{Sistema de Inferência Fuzzy}

Um Sistema de Inferência Fuzzy - ou do termo em inglês Fuzzy Inference Systems (FIS) - é um framework que trabalha com conjuntos fuzzy e permite a implementação de aplicações com relações de conjuntos e regras IF-THEN fuzzy.

Um FIS funciona como um sistema de controle que recebe informações em valores numéricos de conjuntos clássicos, ou valores numéricos crisp, e transforma esses valores em inferências de variáveis lingüísticas. Para fazer essa transformação o sistema faz uso das funções de pertinência contidas em cada variável fuzzy do sistema. Ao realizar essa operação o sistema passa a operar com rótulos lingüísticos no lugar de valores dos conjuntos clássicos. Esse processo de transformação é conhecido como fuzificação.

Conforme apresentado na seção 2.1.2 é possível realizar operações com variáveis lingüísticas através da aplicação de regras IF-THEN fuzzy. O FIS faz uso deste recurso após a transformação das variáveis para o universo fuzzy, além de realizar operações que processam essas variáveis de forma lingüística, produzindo na saída uma outra variável ligüística.

Esse processamento lingüístico é baseado em uma base de dados e regras que representam o conhecimento do especialista que elaborou o conhecimento a ser aplicado pelo FIS.

Para que o valor do processo retorne ao sistema externo é necessário interpretar e transformar novamente o valor da variável ligüística em um valor dos conjuntos clássicos. Esse processo de transformação de uma variável fuzzy para uma variável dos conjuntos clássicos é conhecido como processo de defuzificação (LEE, 1990a; LEE, 1990b).

A figura 2.5 ilustra a arquitetura padrão de um FIS. Os dados de entrada em valores dos conjuntos clássicos alimentam o sistema. Em seguida, esses valores são transformados em valores de pertinência fuzzy (fuzificação). Só então a variável fuzzy é processada por um tomador de decisões que faz uso das regras IF-THEN fuzzy criadas pelo especialista. Ao final do processo a variável fuzzy resultante é novamente transformada em uma variável dos conjuntos clássicos e, subsequentemente, é utilizada pelo sistema externo.

O FIS estabelece um esquema de funcionamento básico para implementações de soluções fuzzy nas mais diversas áreas: controle, classificação de padrões, tomadas de decisões, predição de séries temporais, entre outras (LEE, 1990a; LEE, 1990b; DUBOIS; PRADE; YAGER, 1996). 


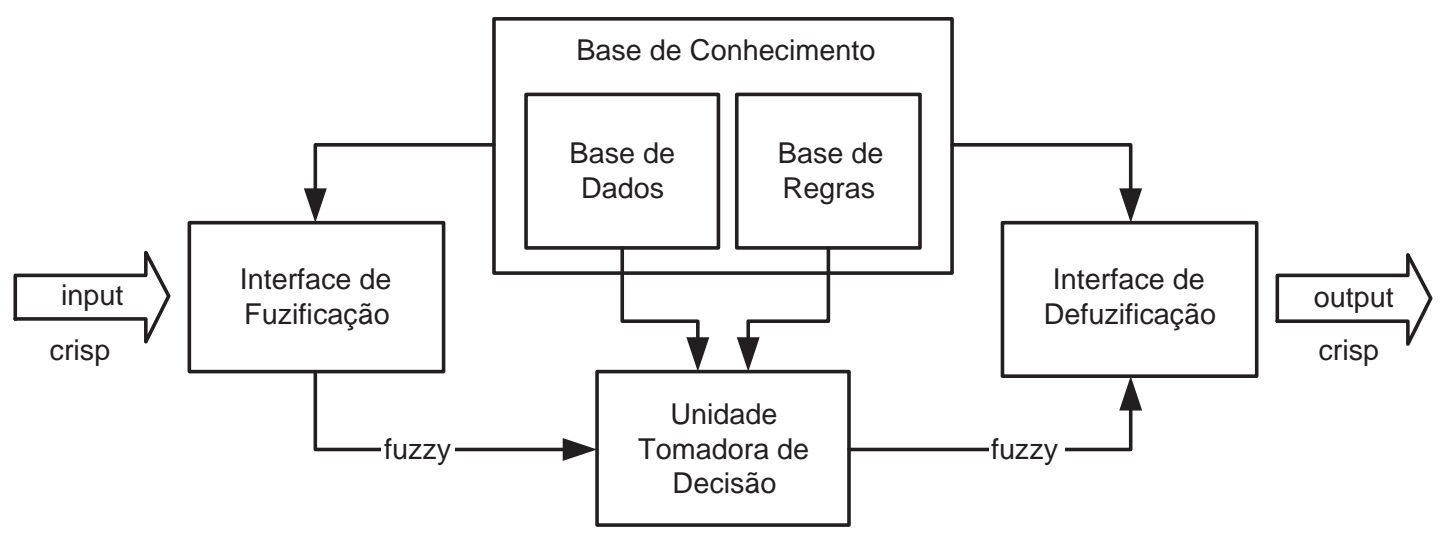

Figura 2.5: Sistema de Inferência Fuzzy (FIS) (JANG, 1993).

Existem basicamente três implementações de modelos FIS: modelo Mamdani, Takagi-Sugeno e Tsukamoto. Basicamente, estes modelos diferem entre si na forma de operar os parâmetros conseqüentes e na forma de realizar o processo de defuzificação (LEE, 1990b; DUBOIS; PRADE; YAGER, 1996).

A seguir são apresentadas as três implementações dos modelos que implementam o FIS e seus processos de defuzificação .

\subsubsection{Modelo Fuzzy Mamdani}

O primeiro modelo a implementar um FIS foi o modelo proposto por Mamdani. Este sistema utiliza operações de regras IF-THEN fuzzy que foram criadas previamente por um especialista para realizar os processamentos de regras fuzzy.

A figura 2.6 ilustra o processo de inferência no modelo Mamdani dado pelas regras

$$
\begin{aligned}
& \text { if } x \text { is } A_{1} \text { and } y \text { is } B_{1} \text { then } z \text { is } C_{1} \\
& \text { if } x \text { is } A_{2} \text { and } y \text { is } B_{2} \text { then } z \text { is } C_{2} \text {. }
\end{aligned}
$$

Na figura 2.6, as duas primeiras colunas são variáveis de entradas $x$ e $y$ respectivamente, sendo que cada linha representa uma regra da equação 2.10 a ser aplicada. Já cada linha destas colunas representam as funções de pertinência das variáveis fuzzy de entrada, onde $A_{1}$ e $A_{2}$ pertencem à variável fuzzy $A$, e $B_{1}$ e $B_{2}$ pertencem à variável fuzzy $B$.

Ao executar as regras if-then fuzzy, o sistema realiza uma operação de intersecção entre os valores das funções de pertinência obtidas para cada regra; essa intersecção minimiza os valores obtidos como uma função and (ver seção 2.1.1). Na figura 2.6 essa operação pode ser observada pelos pontos tracejados que são 


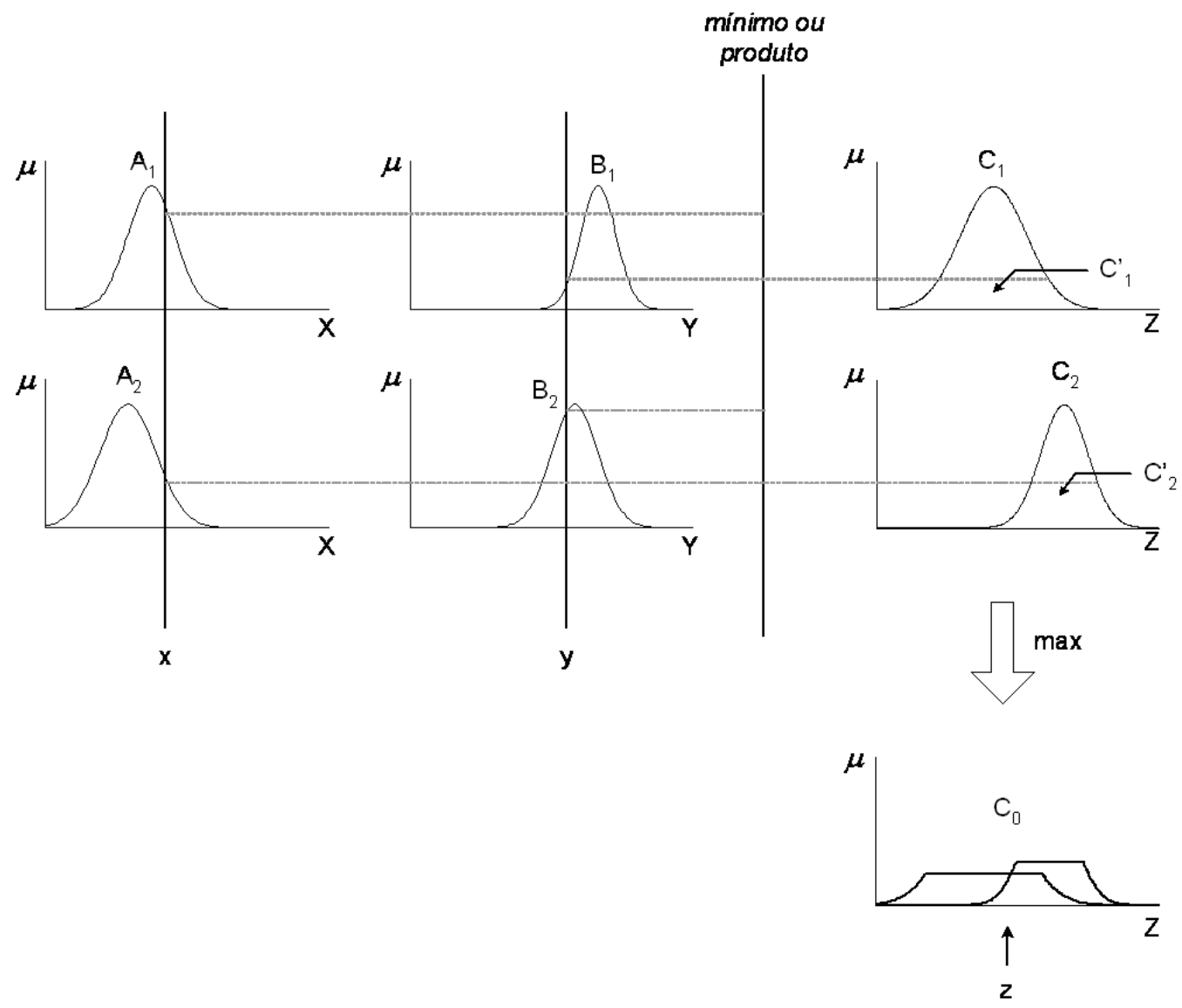

Figura 2.6: Modelo fuzzy Mamdani (JANG; SUN; MIZUTANI, 1997).

comparados, a seguir é executada a operação and.

Obtido um valor de pertinência para cada função da variável fuzzy $C$ de saída, o sistema realiza uma operação de união entre a área dada por $C_{1}$ e $C_{2}$. A área obtida pela união de todos os resultados das regras aplicadas sobre as variáveis fuzzy representa o valor numérico dos conjuntos clássicos da saída do sistema (ou processo de defuzificação), dado por $z$.

Logo, o processo de defuzificação pode ser feito pelo cálculo do centro da área obtida por $z$; analogicamente, a saída em valores dos conjuntos clássicos é produzida pelo cálculo do centro de gravidade do conjunto. A expressão a seguir realiza o cálculo de centro de gravidade para a saída de um FIS.

$$
z=\frac{\sum_{i=0}^{m} \mu_{C}\left(z_{i}\right) z_{i}}{\sum_{i=0}^{m} \mu_{C}\left(z_{i}\right)}
$$

onde $m$ é o número de intervalos de quantização da saída, $z_{i}$ é o valor da variável de saída para o intervalo de quantização $i$ e $\mu_{C}\left(z_{i}\right)$ é seu grau de pertinência. 


\subsubsection{Modelo Fuzzy Takagi-Sugeno}

O modelo fuzzy Takagi-Sugeno, conhecido também apenas por Sugeno, utiliza uma função de mapeamento para cada saída de regra IF-THEN fuzzy. Esta função mapeia a entrada e a saída da regra por uma combinação linear das entradas, como por exemplo $z_{1}=p x_{1}+q y_{1}+r$ (no caso de $p=q=0$, $\operatorname{logo} z=r$, temos uma função singleton). Dessa maneira, os valores de $z_{1}$ e $z_{2}$ são dados por funções lineares que representam as funções de pertinência de uma análoga variável fuzzy $C$ de saída. A figura 2.7 ilustra o processo do modelo de Takagi-Sugeno.

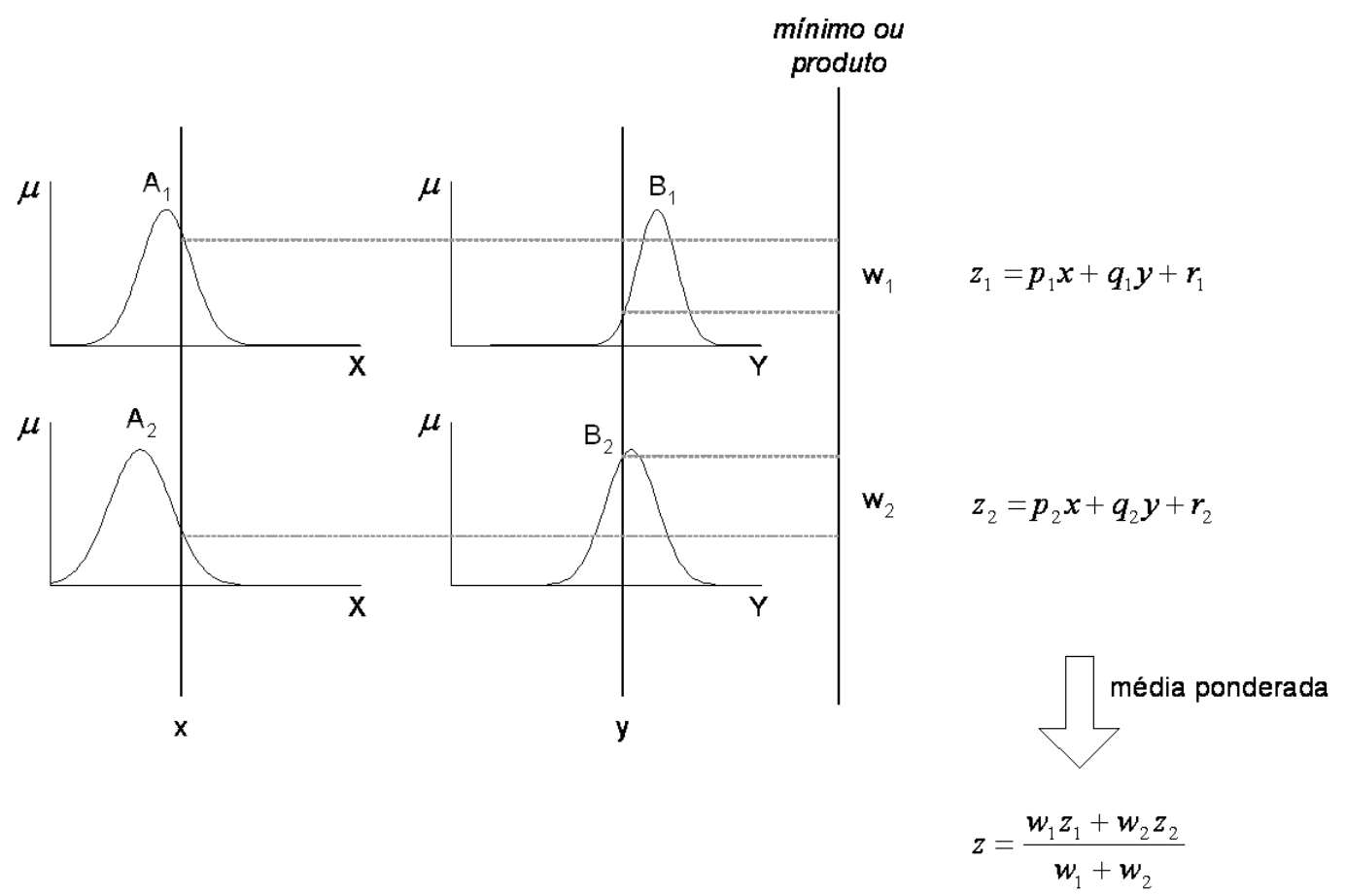

Figura 2.7: Modelo fuzzy Takagi-Sugeno (JANG; SUN; MIZUTANI, 1997).

Neste caso, o processo de defuzificação é realizado através da média ponderada da pertinência de saída na variável $C$. De forma genérica, $z$ é obtido por

$$
z=\frac{\sum_{i=1}^{n} \mu_{i} z_{i}}{\sum_{i=1}^{n} \mu_{i}}
$$

na qual $n$ é o número de regras fuzzy, $\mu_{i}$ é seu grau de pertinência da regra $i$, e $z_{i}$ é o valor da função de pertinência de $i$.

\subsubsection{Modelo Fuzzy Tsukamoto}

No modelo FIS de Tsukamoto o conseqüente de cada regra é representado por um conjunto fuzzy com uma função de pertinência monotônica. A figura 2.8 a seguir, ilustra este modelo (JANG; SUN; MIZUTANI, 1997). 


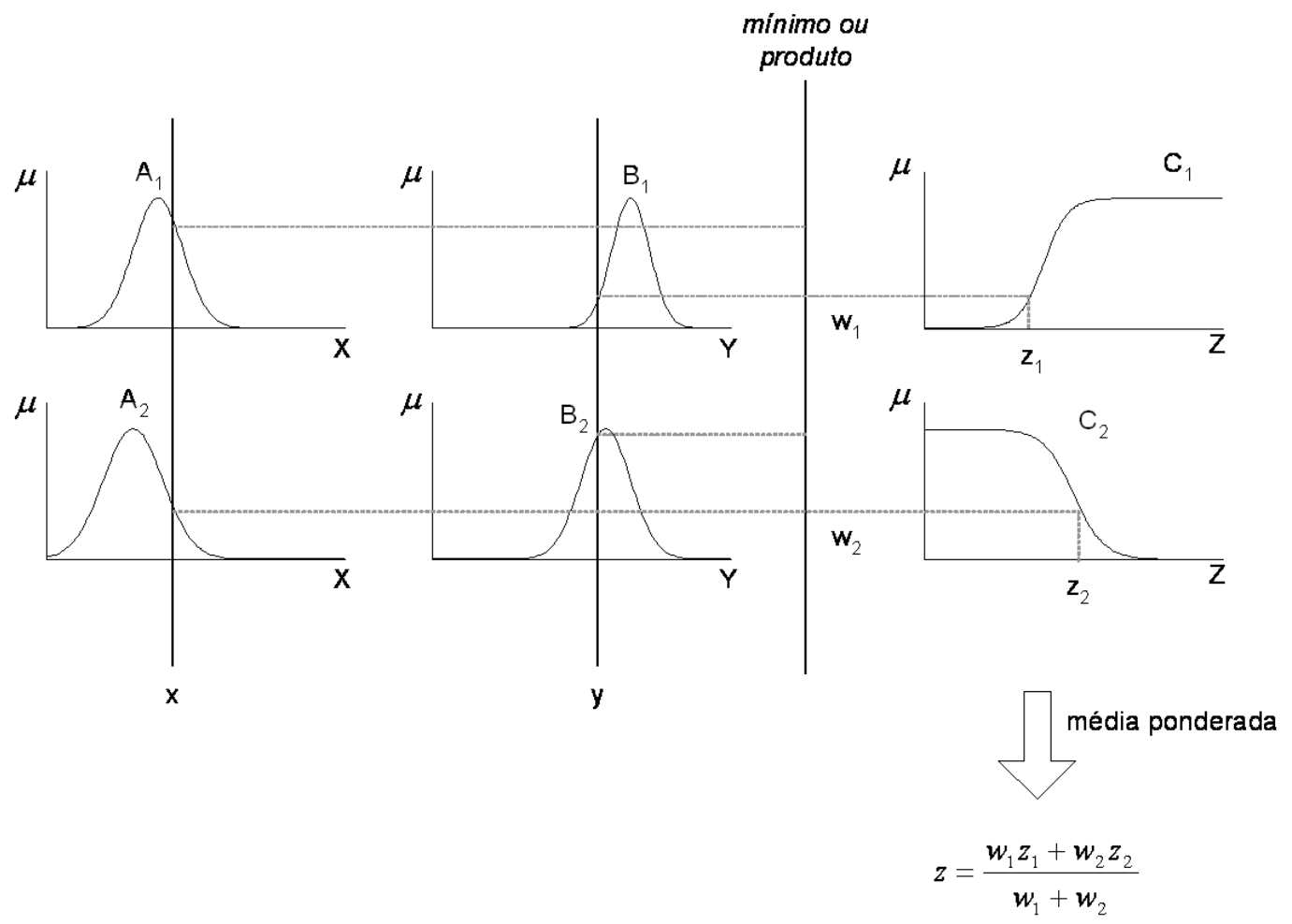

Figura 2.8: Modelo fuzzy Tsukamoto (JANG; SUN; MIZUTANI, 1997).

Neste processo, o cálculo fuzzy é realizado pela simples inferência do min das funções de pertinências avaliadas sob uma função de pertinência da variável de saída $Z$. Neste caso, o processo de defuzificação é semelhante ao utilizado pelo método Takagi-Sugeno e também é dado pela equação 2.12 .

\subsubsection{Espaço de Particionamento das Variáveis Fuzzy}

O processamento das variáveis fuzzy de entrada por regras IF-THEN fuzzy gera um espaço de particionamento entre cada variável (ver seção 2.1.2). A interseç̧ão de possibilidades entre as variáveis fuzzy cria um particionamento do espaço de entrada que indica a forma como as regras fuzzy estão sendo relacionadas neste espaço. Um exemplo de espaço gerado pela intersecção de duas variáveis pode ser ilustrado pela figura 2.9 , onde cada eixo indica uma variável fuzzy distinta.

Já o particionamento da variável de saída de um FIS está associado aos parâmetros de conseqüência das regras.

O particionamento do espaço das variáveis fuzzy de entrada e de saída está diretamente ligado à compreensão do problema. Um relacionamento possível entre todas as variáveis de um FIS acaba por causar um problema de alta dimensionalidade no sistema, o que eleva o custo de processamento e implementação do mesmo. É para otimizar o relacionamento entre as variáveis de um FIS que entra 


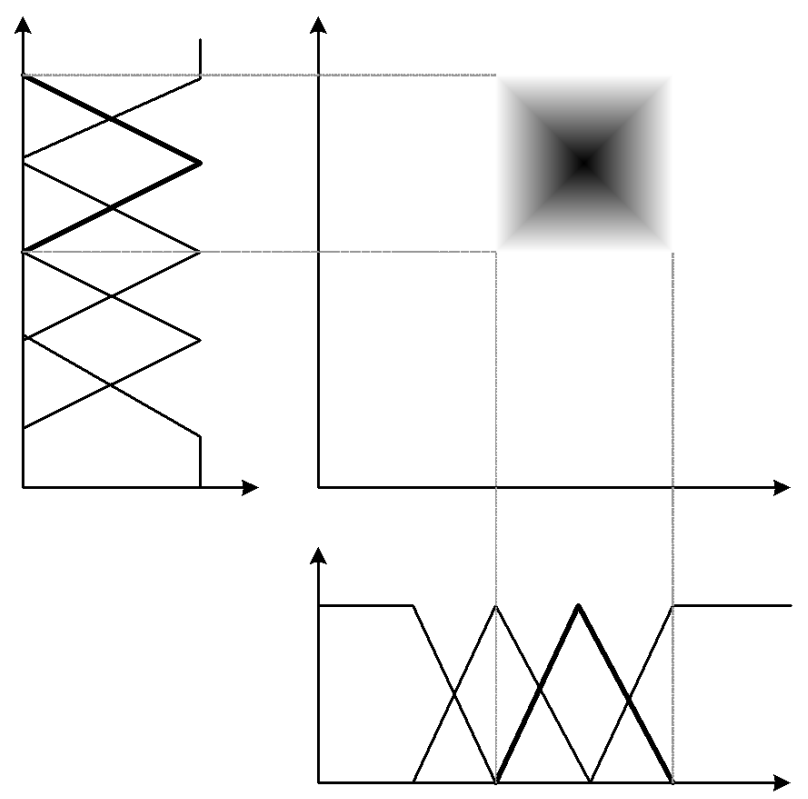

Figura 2.9: Espaço gerado pela intersecção de duas funções de pertinência de duas variáveis fuzzy distintas (DUDA; HART; STORK, 2000).

a função de um especialista.

A figura 2.10 mostra outros tipos de particionamentos de espaços para variáveis fuzzy de entrada e saída para um FIS. Essas formas podem ser generalizadas e são encontradas na literatura como processo de geração de regras (MITRA; HAYASHI, 2000).

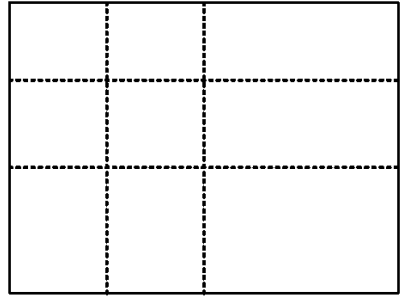

(a) Fuzzy Grid

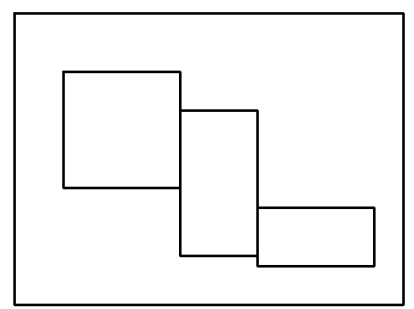

(c) Fuzzy Boxes

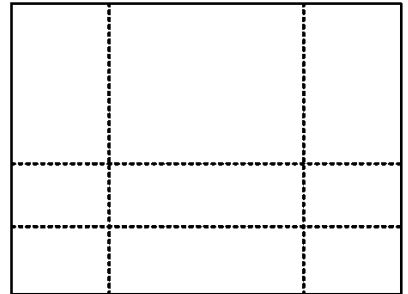

(b) Adaptive Fuzzy Grid

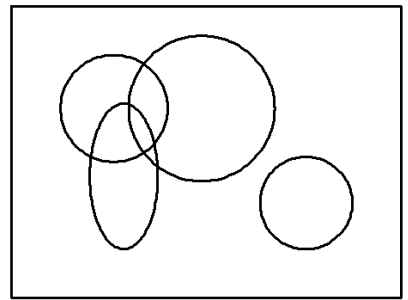

(d) Fuzzy Clusters

Figura 2.10: Particionamentos possíveis para o espaço de duas variáveis (AURÉLIO; VELLASCO; LOPES, 1999).

A figura 2.10(a) ilustra uma típica grid partition. Neste espaço, os limites entre cada particionamento são fixos e definidos pela combinação de cada variável e suas funções de pertinências com todas as outras variáveis e suas pertinências. Isso torna o universo de possibilidades muito grande caso o número de variáveis 
seja grande. Por exemplo, no caso de haver 10 variáveis e 2 funções de pertinências para cada, o número de espaços de regras possíveis seria de $2^{10}=1024$ regras if-then fuzzy. Este número de regras restringe esse particionamento apenas para problemas com baixo número de variáveis, afim de evitar a maldição da dimensionalidade.

O espaço da figura 2.10(a) como seu próprio nome diz, adaptive grid partition, é semelhante ao anterior, porém, seus limites são adaptivos. Neste modelo, ainda existe o problema de alta dimensionalidade.

Nas figuras 2.10(c) e 2.10(d) são mostradas, respectivamente, um particionamento do tipo fuzzy boxes e outro do tipo fuzzy clusters. Esses particionamentos utilizam outras técnicas para melhor mapear as regras do sistema (MITRA; HAYASHI, 2000). O primeiro, da figura 2.10(c), utiliza redes neurais ART, ou processo também chamado FSOM de Fuzzy Self-Organized Map. Na segunda figura as regras são geradas por redes neurais RBF de Radial Basis Function (ver seção 3.2). Em ambas as técnicas o objetivo é estimar os centros das pertinências das funções. Esta estratégia diminui o número de possibilidades de regras, suportando assim um número maior de variáveis.

\subsection{Sumário}

Neste capítulo foram abordados alguns conceitos de teoria fuzzy e suas operações. Foi apresentado também um modelo de framework para processar informações com as funções de pertinência das variáveis fuzzy, sendo este modelo implementado em três formatos: Mamdani, Takagi-Sugeno e Tsukamoto.

O processamento fuzzy gera durante a interpretação das regras IF-THEN espaços de particionamentos possíveis. Os espaços gerados são listados e sua relação com o problema de dimensionalidade que uma lista regras pode gerar é também abordada. 


\section{$3 \quad$ Redes Neurais Artificiais}

Neste capítulo é apresentada uma breve introdução às redes neurais artificiais. $\mathrm{Na}$ primeira parte é apresentado o processamento realizado por um único neurônio e suas similaridades com os neurônios encontrados no universo biológico. Em seguida são apresentadas redes mais robustas, ou seja, redes que possuem um poder de processamento maior, como as redes de perceptrons de múltiplas camadas (MLP) e as redes de função de base radial (RBF). No final do capítulo é apresentado um sumário com a relevância dessas arquiteturas para o trabalho.

As redes neurais artificiais têm suas origens nas pesquisas de modelagem do funcionamento dos neurônios biológicos. Partindo da observação da organização e funcionamento do sistema neural biológico, foram propostas arquiteturas matemáticas formais com o objetivo de tentar simular o comportamento de processamento paralelo eficaz encontrado nas arquiteturas biológicas. A terminologia rede neural utilizada neste trabalho refere-se apenas às redes neurais artificiais, já queo mesmo é baseado em formalidade matemática.

O neurônio é a unidade básica de processamento dos sistemas de redes neurais biológicas (BEAR; CONNORS; PARADISO, 2001) e também é a unidade básica de processamento nos modelos artificiais propostos. Um neurônio biológico contém dentritos, uma soma e um axônio (BEAR; CONNORS; PARADISO, 2001). Esse protótipo biológico é interpretado analogamente pelo modelo artificial como sensores de entrada, processamento dos sinais de entrada e sinal de saída gerado pelo processamento do neurônio ${ }^{1}$. A figura 3.1 ilustra a representação matemática de um neurônio biológico.

O neurônio artificial tem como função reproduzir o comportamento de disparos encontrado nos neurônios biológicos. Os neurônios biológicos disparam ou não disparam em respostas aos estímulos recebidos por seus dentritos; esses dis-

\footnotetext{
${ }^{1}$ A modelagem de um neurônio biológico não é tão simples. Devido a sua alta complexidade se torna viável apenas a reprodução de alguns comportamentos. Neste trabalho assim como na maioria da literatura matemática a respeito do assunto, a visão de funcionamento do neurônio biológico é simplificada. Para um aprofundamento no estudo do comportamento do neurônio são aconselháveis outras bibliografia específicas da área de neurociências.
} 


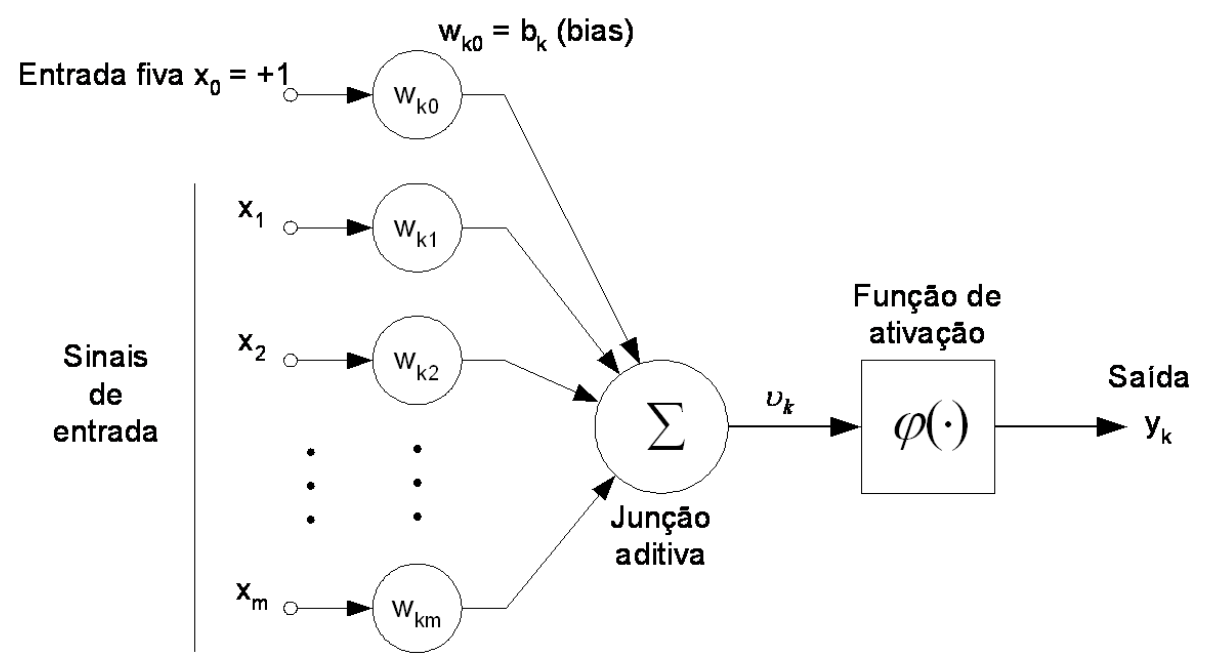

Figura 3.1: Modelo de um neurônio artificial (HAYKIN, 1999).

paros são interpretados como sinais digitais de 1 e 0 nos modelos matemáticos. A interpretação desse comportamento do universo biológico permite a criação de sistemas artificiais que atuam em diversas áreas, como classificação e reconhecimento de padrões.

O perceptron é a forma mais simples de uma rede neural usada para a classificação de padrões ditos linearmente separáveis² (HAYKIN, 1999), ilustrado na figura 3.1. O perceptron recebe os sinais do mundo externo através da camada de entrada. Esses sinais são somados para se calcular o estímulo aplicado ao neurônio. O perceptron aplica uma função com o papel de limitador abrupto à soma resultante dos sinais de entrada ponderados, representada na figura 3.1 pela caixa de função aditiva. Esta função abrupta simula o limiar de disparo do neurônio biológico e é conhecida também como função de ativação, denotada na figura 3.1 por $\varphi$.

Transcrevendo a figura 3.1 em termos matemáticos temos

$$
\nu_{k}=\sum_{j=0}^{m} w_{k j} x_{j}
$$

na qual $x$ representa o vetor de entrada de sinais. A matriz $w$ é o peso dado para cada valor de sinal de entrada; os pesos $w$ podem ser interpretados como o grau de acoplamento ou relevância daquela dimensão da matriz $x$ para o perceptron. O termo $m$ é o tamanho do vetor $x$ de entrada. O somatório de todos os sinais é representado por $\nu_{k}$, em que $k$ é um índice para o neurônio. A saída do neurônio $k$ é calculada através da função de ativação, generalizada na equação 3.2.

\footnotetext{
${ }^{2}$ Padrões linearmente separáveis podem ser interpretados como padrões que se encontram em lados opostos de um hiperplano.
} 


$$
y_{k}=\varphi\left(\nu_{k}\right)
$$

na qual $\varphi$ representa a função de ativação. Existem diversos tipos e finalidades de funções de ativação, sendo que maiores detalhes a respeito podem ser encontrados em Haykin (1999) e Muller e Reinhardt (1990). A escolha de uma função de ativação afere o modo de disparo e intrepretação dos sinais de entrada. Logo, o termo $y_{k}$ representa a saída do neurônio $k$.

As redes neurais, quando aplicadas em sistemas inteligentes, tornam estes dinâmicos (MULLER; REINHARDT, 1990). Essa dinâmica é resultado da capacidade de aprendizado das redes neurais, proporcionado basicamente por um algoritmo de ajuste nos pesos $w$ do perceptron na equação 3.1. Por conseguinte, quando uma rede neural aprende (em termos matemáticos), ela apenas está ajustando os pesos de conexões dos sinais de entrada. No caso da figura 3.1, a matriz $w$.

Como cada rede neural apresentada neste trabalho possui uma topologia distinta, nas próximas seções são abordadas algumas topologias e algoritmos de aprendizados que também são utilizados ao longo do trabalho.

\subsection{Perceptrons de Múltiplas Camadas (MLP)}

Uma rede de perceptrons de múltiplas camadas consiste em um conjunto de unidades de entrada conhecido por camada de entrada. Esta camada de entrada é seguida por uma ou mais camadas ocultas de neurônios; após as camadas ocultas existe a camada de saída. Por esta topologia ter múltiplas camadas, esta rede é conhecida como rede de perceptrons de múltiplas camadas, ou simplesmente MLP. Uma MLP é uma generalização do perceptron. A figura 3.2 ilustra uma topologia de uma rede MLP.

Numa rede MLP, o sinal de entrada representado pelo $x$ se propaga da camada de entrada $i$ para a primeira camada oculta, e desta para a próxima camada oculta, até atingir a camada de saída $k$. À medida que o sinal de entrada avança, este alimenta os neurônios da camada seguinte com seus valores de saída. Na camada subseqüente, cada neurônio pondera os valores recebidos, isso faz com que estes disparem ou não dependendo da soma dos valores ponderados das saídas dos neurônios da camada anterior. Na figura 3.2 os neurônios da camada $j$ são alimentados pelos neurônios da camada $i$, e os neurônios da camada $k$ são alimentados pelos neurônios da camada $j$. Este processo é conhecido como propagação. 


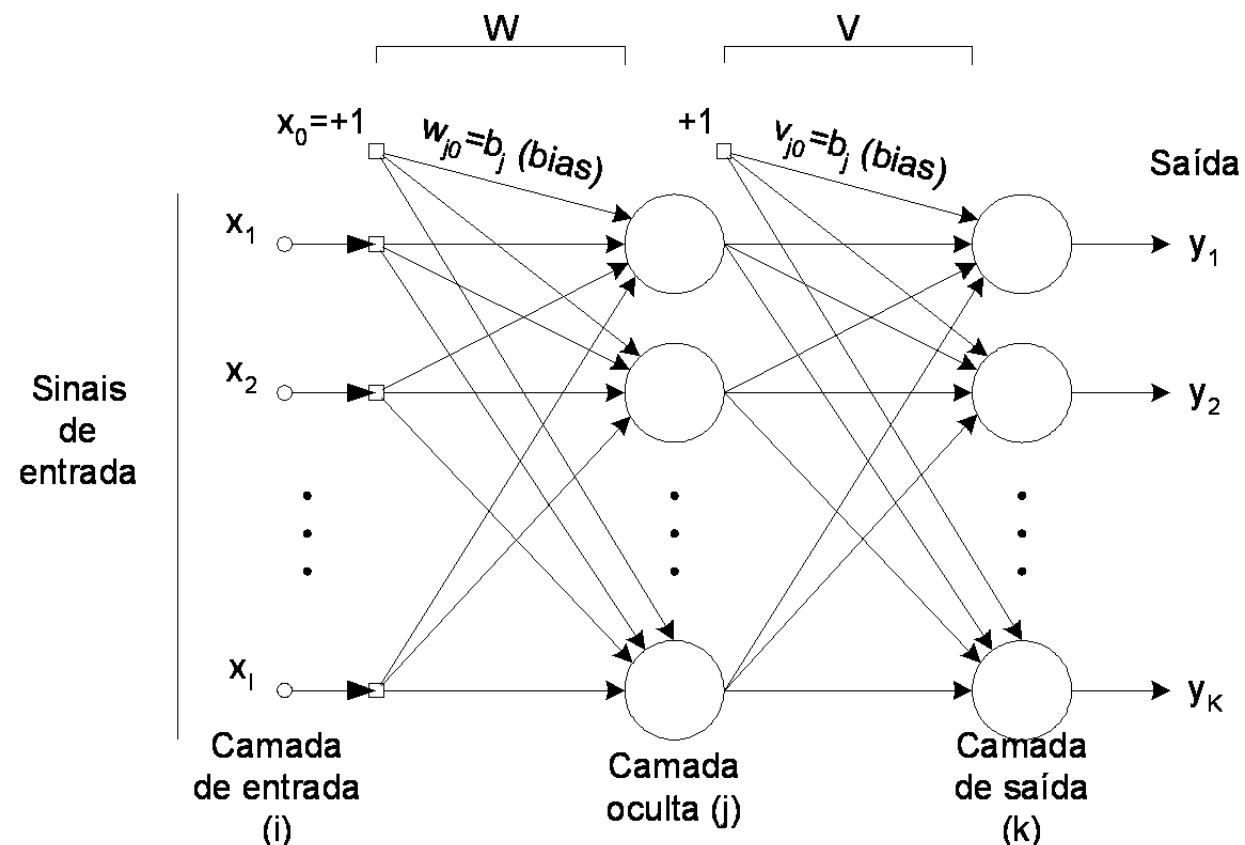

Figura 3.2: Topologia de uma Rede de Perceptrons de Múltiplas Camadas (MLP).

Ao final do processo de propagação a rede utiliza o valor de saída para estimar, classificar ou processar algo sobre o sinal de entrada. Como os valores dos nós em cada camada são calculados dinamicamente, não é possível manipular os valores de saída realizando ajustes nos nós. A única possibilidade de ajuste de valores em uma rede neural está nos pesos que ligam os nós de uma camada à outra. No caso da figura 3.2 os pesos são representados pelas matrizes $w$ e $v$. Onde $w$ são os pesos dos nós das camadas $i$ para os nós da camada $j$ e $v$ denota os pesos da camada $j$ para camada de saída $k$.

O ajuste de pesos tem como referência o erro de saída da rede neural. O erro da rede é calculado pela diferença entre o valor desejado para a rede e o valor que a rede está proporcionando. Essa diferença é retropropagada para todos os pesos do sistema. O algoritmo mais utilizado para esta correção dos pesos é o algoritmo de retropropagação do erro. O algoritmo de retropropagação utiliza a regra de aprendizagem por correção de erro, e é discutido na próxima seção.

O número de camadas ocultas de uma MLP pode variar de uma implementação para outra. Uma MLP com apenas uma camada oculta pode funcionar como um aproximador universal de funções (HAYKIN, 1999). Logo, não é necessário na grande maioria das aplicações, o uso de mais camadas. Porém, um número reduzido de camadas ocultas pode ocasionar um aumento no número de nós da camada oculta, gerando um problema de alta dimensionalidade. Um estudo sobre a correlação de camadas e do número de nós da camada oculta com 
a capacidade de generalização da rede neural MLP é encontrada em Muller e Reinhardt (1990).

Adiante é apresentado o algoritmo de aprendizagem por retropropagação de para uma MLP.

\subsubsection{Algoritmo de Retropropagação}

O algoritmo de retropropagação utiliza a regra de aprendizagem por correção de erro; nesta regra os valores de treinamentos são processados um por um na rede, e esta, na medida de uma estratégia de correção, ajusta seus pesos para obter uma saída desejada para cada amostra (DUDA; HART; STORK, 2000).

Em uma rede MLP o sinal de entrada percorre a rede da esquerda para a direita, propagando os valores calculados em cada neurônio até a camada de saída. A equação 3.3 apresenta o cálculo realizado em uma rede neural MLP no processo conhecido como propagação. O termo $x$ representa o vetor de entrada de sinais na rede e cada elemento do vetor é indexado por $i$.

O sinal de entrada é propagado para os neurônios da camada oculta; nela, cada neurônio realiza a soma ponderada dos sinais e aplica uma função de ativação, exatamente como descrita para o perceptron (ver equação 3.1). Cada neurônio da camada oculta é indexado por $j$ e a matriz $w$ correlaciona os pesos que são dados pelos respectivos sinais de entrada.

Através do cálculo dos neurônios na camada oculta, a rede utiliza os valores de saída da camada para alimentar os neurônios da próxima camada, no caso, os neurônios da camada de saída da rede. A topologia desse acoplamento pode ser vizualizada na figura 3.2 e descrita matematicamente por

$$
y_{k}=\varphi\left(\sum_{j=0}^{N_{j}} v_{k j} \varphi\left(\sum_{i=0}^{N_{k}} w_{j i} x_{i}\right)\right),
$$

na qual y representa o vetor de saída da rede e $k$ um elemento desse vetor. A matriz $v$ correlaciona os pesos dos neurônios da camada oculta com os neurônios da camada de saída.

Com o processo de propagação concluído, a rede obtém os valores de saída no vetor $y$. O cálculo do erro em cada neurônio de saída $y_{k}$ é calculado pela diferença entre o valor desejado $d_{k}$ para o neurônio e o valor obtido.

$$
e_{k}=d_{k}-y_{k},
$$


$\mathrm{Na}$ equação 3.4 de erro por neurônio, cada $e_{k}$ é um valor do erro calculado para o neurônio $k$ da atual amostra.

O erro de cada amostra, ou vetor de entrada $\boldsymbol{x}$, é dado pelo cálculo do erro médio quadrático de todos os neurônios de saída. Em termos matemáticos é representado por $J$.

$$
J=\frac{1}{2} \sum_{k=1}^{N_{k}} e^{2}
$$

Conseqüentemente, o erro médio para o conjunto de treinamento pode ser calculado como a média de erro por amostra, conforme mostrado na equação 3.6.

$$
J_{\text {med }}=\frac{1}{N} \sum_{n=1}^{N} J(n)
$$

sendo que $N$ representa o número total de amostras e $J_{n}$ representa o erro individual para cada amostra $n$.

Com o cálculo do erro é possível aplicar uma correção sobre os pesos entre os neurônios, representados pelas matrizes $w$ e $v$. O erro para cada neurônio é proporcional à derivada parcial $\partial J(n) \partial w_{j i}(n)$. De acordo com a regra da cadeia podemos expressar o gradiente pela equação 3.7.

$$
\frac{\partial J(n)}{\partial w_{j i}(n)}=\frac{\partial J(n)}{\partial e_{j}(n)} \frac{\partial e_{j}(n)}{\partial y_{j}(n)} \frac{\partial y_{j}(n)}{\partial \nu_{j}(n)} \frac{\partial \nu_{j}(n)}{\partial w_{j i}(n)}
$$

Sendo que a derivada parcial $\partial J(n) / \partial w_{j i}(n)$ representa um fator de sensibilidade. Essa sensibilidade determina a direção vetorial da busca da correção no espaço de pesos para o peso sináptico $w_{j i}$.

Assim, é possível definir uma correção a ser aplicada em $w_{i j}$ por $\delta w_{j i}$, que é obtido pela derivada parcial do erro retropropagado por $\partial J(n) / \partial w_{j i}(n)$. O $\delta w_{j i}$ é calculado pela equação 3.8 .

$$
\Delta w_{j i}=-\eta \frac{\partial J(n)}{\partial w_{j i}(n)}
$$

Na equação 3.8, o $\eta$ é o parâmetro de taxa de aprendizagem do algoritmo de retropropagação. O uso do sinal negativo na equação 3.8 indica a descida do gradiente no espaço de pesos. 


\subsection{Redes de Função de Base Radial (RBF)}

Diferentemente do projeto de um perceptron de múltiplas camadas, o enfoque dado nesta seção é de uma rede neural como um problema de ajuste de curva ou aproximação em um espaço de alta dimensionalidade (HAYKIN, 1999). Nesse sentido, aprender para uma rede de função de base radial (RBF) é buscar um melhor ajuste dos dados de treinamento por uma matriz de interpolação. Esse ponto de vista é a motivação por trás do método das funções de base radial, no sentido de que essa motivação aproxima essa topologia com os trabalhos de pesquisa em interpolação estrita tradicional em um espaço multidimensional. No contexto de uma rede neural, as unidades ocultas fornecem um conjunto de funções que constituem uma base arbitrária de padrões de base radial (HAYKIN, 1999).

As redes de base radial, ou RBF (Radial Basis Function), são geralmente projetadas com três camadas de neurônios. A primeira camada é a de entrada, ou seja, a camada por onde a rede recebe os valores do ambiente na qual está inserida. A segunda camada é uma camada oculta que aplica uma transformação não-linear do espaço de entrada. É nesta camada que se encontra a função de base radial a ser aplicada no sistema. A terceira camada é a camada de saída da rede; nela é realizada uma soma ponderada dos valores da segunda camada. A figura 3.3 ilustra a topologia de uma RBF.

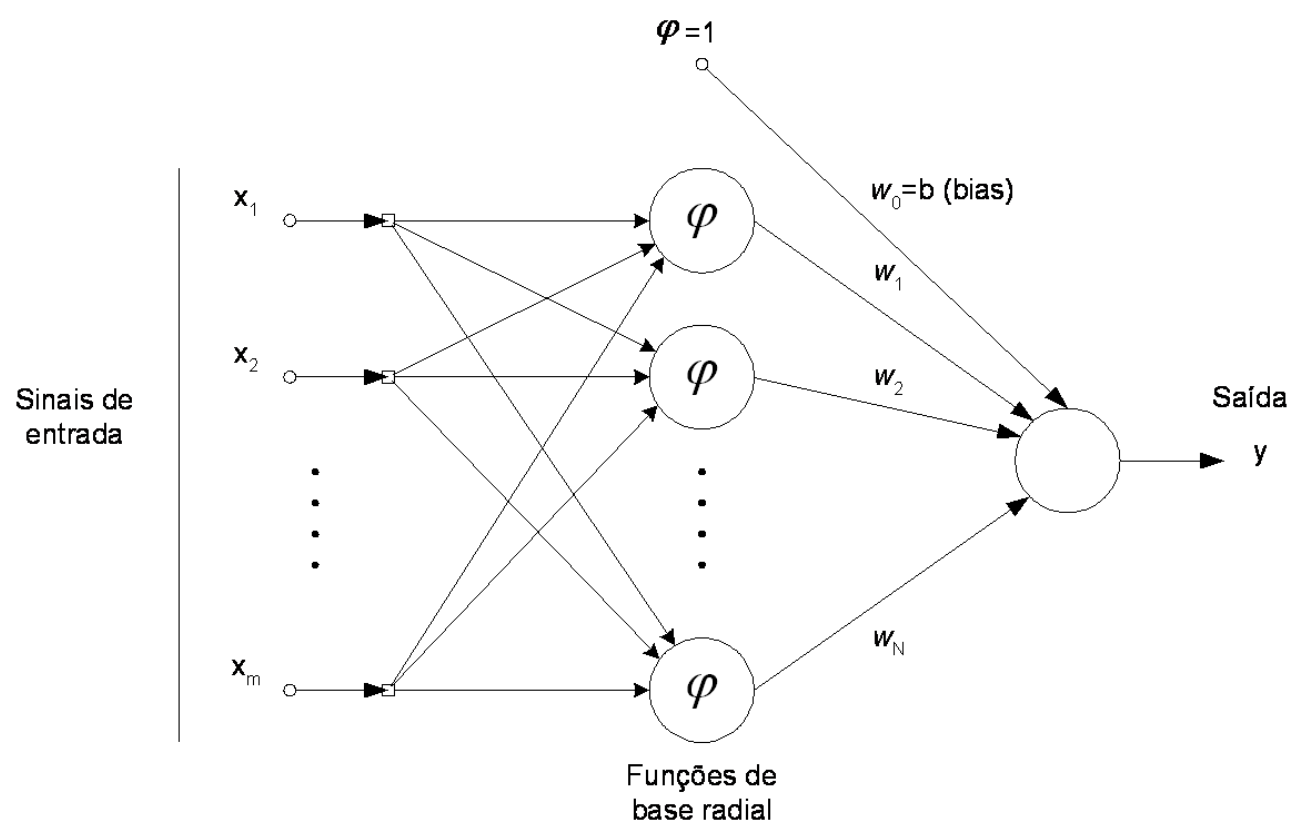

Figura 3.3: Rede de Função de Base Radial (HAYKIN, 1999).

Os valores de entradas são dados pelo vetor $\mathbf{x}$, onde $i$ representa um elemento do vetor $\mathbf{x}$. Nos neurônios da segunda camada ficam as funções de base radial representadas por $\varphi$. Existe uma função para cada centro de agrupamento espacial 
de dados, portanto, esta camada pode ser uma camada com alta dimensionalidade, já que o número de nós pode tender ao número do tamanho do conjunto das amostras de treinamento representado por $N$. A primeira função da camada de bases radiais é dada por $\varphi=1$, que é um ajuste para a inclusão do valor de bias $w_{0}$. Na última camada da rede é realizada uma ponderação linear da segunda camada. Uma forma de expressar matematicamente a saída de uma rede RBF é dada pela equação 3.9 .

$$
f(\mathbf{x})=\mathbf{d}=\sum_{i=1}^{N} w_{i} \varphi\left(\left\|\mathbf{x}-\mathbf{x}_{i}\right\|\right)
$$

Na equação 3.9, $\left\{\varphi\left(\left\|\mathbf{x}-\mathbf{x}_{i}\right\|\right) \mid i=1,2, \ldots, N\right\}$ é um conjunto de $N$ funções (geralmente não-lineares) arbitrárias. Essas funções são conhecidas como funções de base radial e o termo $\|$.$\| representa a norma da distância entre os pontos$ $\mathbf{x}$ e $\mathbf{x}_{i}$, que geralmente é euclidiana. Os pontos de dados $\mathbf{x}_{i}$ são os centros das respectivas funções $i$ de base radial. O $w_{i}$ representa o peso da função de base radial $i$ na soma ponderada final.

Expandindo a equação 3.9 são os seguintes conjuntos de equações lineares

$$
\left[\begin{array}{cccc}
\varphi_{11} & \varphi_{12} & \ldots & \varphi_{1 N} \\
\varphi_{21} & \varphi_{22} & \ldots & \varphi_{2 N} \\
\vdots & \vdots & \vdots & \vdots \\
\varphi_{N 1} & \varphi_{N 2} & \ldots & \varphi_{N N}
\end{array}\right]\left[\begin{array}{c}
w_{1} \\
w_{1} \\
\vdots \\
w_{N}
\end{array}\right]=\left[\begin{array}{c}
d_{1} \\
d_{1} \\
\vdots \\
d_{N}
\end{array}\right]
$$

considerando que

$$
\Phi=\left(\varphi_{j i} \mid(j, i)=1,2, \ldots, N\right)
$$

Os vetores

$$
\begin{gathered}
\mathbf{d}=\left[d_{1}, d_{2}, \ldots, d_{N}\right]^{T} \\
\mathbf{w}=\left[w_{1}, w_{2}, \ldots, w_{N}\right]^{T}
\end{gathered}
$$

são o vetor de saída desejada e o vetor de peso linear, respectivamente. O termo $N$ é o número de funções de base radial possíveis no conjunto de amostras de treinamento. Considerando que $\Phi$ representa uma matriz de $N$ por $N$ com elementos $\varphi_{j i}$, temos:

$$
\Phi=\left\{\varphi_{j i} \mid(j, i)=1,2, \ldots, N\right\}
$$

Assim, o vetor desejado d pode ser escrito como:

$$
\Phi \mathbf{w}=\mathbf{d}
$$


Com base na equação 3.15 é possível calcular os valores de peso de ponderação linear w pela equação

$$
\mathbf{w}=\Phi^{-1} \mathbf{d}
$$

Para que o cálculo cálculo de w na equação 3.16 seja possível, torna-se necessário garantir que a matriz de interpolação $\Phi$ seja não-singular, ou seja, que exista uma inversa $\Phi^{-1}$. Para isso, a função $\varphi$ tem que ser coberta pelo Teorema de Micchelli ${ }^{3}$. Como o cálculo de $w$ das redes RBF é feito por de com uma única iteração para todas as representações de possíveis amostras, elas não precisam necessariamente de um grande número de iterações para aprender.

Os centros das funções de base radial são geralmente estimados pelas amostras de treinamento por meio do uso de diversas técnicas de pré-processamentos, como o agrupamento de classes, algum outro processo classificatório supervisionado ou não-supervisionado.

\subsection{Sumário}

Este capítulo apresenta uma breve introdução a algumas topologias de redes neurais, como topologias do tipo MLP e RBF. Ambas são utilizadas ao longo do trabalho como pontos de referência para implementação dos sistemas neurofuzzy e em alguns testes comparativos. Mais detalhes sobre o funcionamento das redes neurais podem ser encontrados nas referências citadas, como Haykin (1999), Duda, Hart e Stork (2000) e Muller e Reinhardt (1990).

\footnotetext{
${ }^{3}$ Considere que $\left\{x_{i}\right\}_{i=1}^{N}$ seja um conjunto de pontos distintos em $R^{m_{0}}$. Então, a matriz de interpolação $\Phi, N$ por $N$, cujo elemento $j i$ é $\varphi_{j i}=\varphi\left(\left\|\mathbf{x}-\mathbf{x}_{i}\right\|\right)$, é não singular (HAYKIN, 1999).
} 


\section{Sistemas Neuro-Fuzzy}

Sistemas de engenharia fuzzy são aplicados a um grande número de problemas, mas métodos fuzzy puros não são utilizados em sistemas dinâmicos, ou seja, sistemas onde se torna essencial um treinamento ou ajuste de seus parâmetros para melhor interagir com o ambiente no qual esta inserido (DUDA; HART; STORK, 2000). Um FIS (ver capítulo 2.2) basicamente é projetado para trabalhar com variáveis de entradas e saídas fuzzy muito bem definidas, assim sendo não possui artifícios para possíveis ajustes em suas variáveis ou correções em seus parâmetros.

Por outro lado, as redes neurais possuem uma grande capacidade de adaptação ao ambiente, através dos ajustes aplicados em seus parâmetros. Essa adaptação é ocasionada por sua capacidade de aprendizado e generalização. Uma rede neural passa por uma etapa de treinamento; nessa etapa, aprende (com ajustes em seus parâmetros) a melhor maneira para interagir com as variáveis do ambiente, pertindo assim uma atuação precisa e otimizada para a solução de um problema. Ao mesmo tempo, trabalhar com sistemas de redes neurais não proporciona quase nenhuma facilidade para o processamento de variáveis lingüísticas, dominantes no mundo real (JANG; SUN; MIZUTANI, 1997).

Os sistemas híbridos são sistemas que fazem uso de pelo menos dois paradigmas de processamentos de informações sob um único sistema. No caso de sistemas híbridos que fazem uso de engenharia fuzzy e redes neurais, o grande objetivo é unir as vantagens do processamento lingüístico de um FIS com a capacidade de adaptação e aprendizagem das redes neurais (ABRAHAM, 2001; MITRA; HAYASHI, 2000).

Na seção a seguir são apresentados maiores detalhes e descrições de algumas topologias para modelos híbridos, além de exemplos de modelos de sistemas híbridos. 


\subsection{Modelos Híbridos}

Quando um modelo é projetado com dois ou mais paradigmas diferentes é conhecido como modelo híbrido. O principal objetivo de projetar modelos híbridos é tentar minimizar falhas de um determinado paradigma colocando um outro em conjunto. Esse acomplamento serve para suprimir ou otimizar as desvantagens existentes no primeiro paradigma ou até mesmo no sistema todo.

Existem basicamente três formas de acoplamento de modelos híbridos: concorrente, cooperativo e incorporado. Essas formas descrevem a maneira como dois paradigmas distintos se relacionam. A seguir é feita uma breve descrição de cada forma de acoplamento ou modelo híbrido (JANG; SUN; MIZUTANI, 1997; NAUCK et al., 2003).

\subsubsection{Modelo Concorrente}

O modelo concorrente ou híbrido seqüencial é caracterizado por apresentar um subsistema projetado com a tecnologia de um paradigma que atua sobre os dados de entrada de sistema e outro subsistema com outro paradigma que atua sobre a saída do primeiro. Assim, o primeiro subsistema processa e prepara os dados de entrada para uma aquisição seqüencial do segundo subsistema, sendo que o segundo subsistema possui um paradigma de tratamento da informação diferenciado do primeiro.

Esse modelo de sistema híbrido pode ser claramente divido em duas partes distintas, como ilustrado pela figura 4.1 (ABRAHAM, 2001).

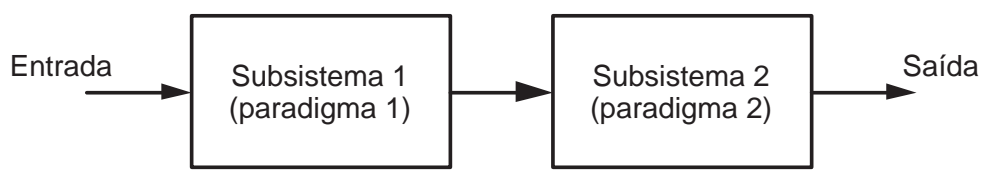

Figura 4.1: Modelo Neuro-Fuzzy Concorrente, ou Híbrido Seqüencial (AURÉLIO; VELLASCO; LOPES, 1999).

Um exemplo de modelo concorrente por ser descrito por um sistema de redes neurais que processam os dados de algum tipo de sensor, e então, com os valores de sua saída, realiza inferências em sistemas fuzzy. Neste exemplo, o primeiro paradigma pode ser visto como um pré-processamento dos dados de entrada para o segundo paradigma. Modelos desse tipo também são comuns em redes neurais que fazem uso de técnicas de pré-processamento para redução de dimensionalidade em sua camada de entrada. 


\subsubsection{Modelo Cooperativo}

O modelo cooperativo ou híbrido auxiliar tem como característica o uso de um subsistema auxiliar projetado com um paradigma diferente do subsistema principal. Geralmente esse tipo de modelo é utilizado para a otimização de um processo no qual o paradigma principal seja deficiente, ou então, em uma situação em que o paradigma do subsistema auxiliar seja mais ótimo que no subsistema principal. A figura 4.2 ilustra este modelo, onde o subsistema 1 utiliza o paradigma 1, e este invoca em seu processo interno o subsistema 2, que utiliza o paradigma 2.

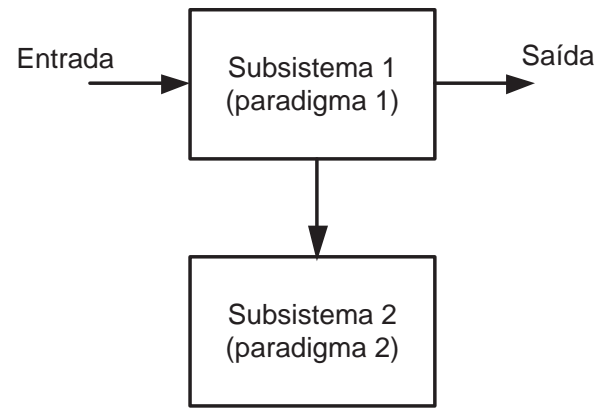

Figura 4.2: Modelo Neuro-Fuzzy Cooperativo, ou Híbrido Auxiliar (AURÉLIO; VELLASCO; LOPES, 1999).

Um exemplo de uso do modelo cooperativo são redes neurais que fazem uso de sistemas fuzzy para auxiliar no ajuste de seu parâmetro de taxa de aprendizado $\eta$ (ver seção 3.1.1). Dessa maneira é possível incorporar inteligência de processamento de variáveis lingüísticas no aprendizado de uma rede neural. Ainda nesse modelo é possível traçar ou desacoplar um paradigma de outro (ABRAHAM, 2001).

\subsubsection{Modelo Incorporado}

Já o modelo híbrido incorporado é representado por sistemas que possuem um alto grau de acoplamento entre os paradigmas utilizados. Esse alto grau de acoplamento não permite distinguir com clareza onde começa e onde termina o acoplamento. Esse modelo é utilizado para projetar sistemas que suprem as falhas de um paradigma com as qualidades de outros. A figura 4.3 ilustra o modelo de um sistema incorporado.

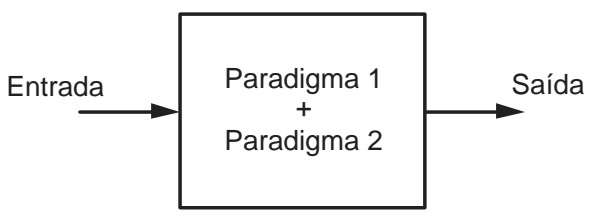

Figura 4.3: Modelo Neuro-Fuzzy Fused, ou Híbrido Incorporado (AURÉLIO; VELLASCO; LOPES, 1999). 
Este trabalho tem foco neste tipo de sistemas; ao projetar um FIS com redes neurais é possível fazer com que o sistema adquira a capacidade de adaptatividade e aprendizado, e ainda mantenha seu poder de processamento de variáveis lingüísticas encontrado nos sistemas fuzzy. Dessa forma, um modelo híbrido de FIS projetado com redes neurais e sistemas fuzzy torna sua aplicabilidade em ambiente de comportamentos dinâmicos. 


\section{Adaptive Neuro-Fuzzy Inference System (ANFIS)}

O Adaptive Neuro-Fuzzy Inference System (ou ANFIS), proposto por Jang (1992), foi uma das primeiras arquiteturas neuro-fuzzy. Esta arquitetura tem, como principal objetivo, a atuação na área de predição de funções não-lineares e controle inteligente (ZHOU; JAGANNATHAN, 1996).

O ANFIS funciona como um FIS (veja seção 2.2), ou seja, sua função consiste em processar variáveis lingüísticas, como o processamento encontrado nos sistemas de engenharia fuzzy. Apesar desta característica, o ANFIS é implementado sob o paradigma de redes neurais; por conseqüencia, ele está categorizado como um sistema híbrido incorporado, conforme descrito na seção 4.1.3.

A principal vantagem de sua implementação sob o domínio da arquitetura de redes neurais está em incorporar a capacidade de aprendizado, função que justifica sua atuação em controle inteligente. Assim como uma rede neural se adapta ao ambiente, o ANFIS faz uso de técnicas de aprendizado e pode aprender também.

Conseqüentemente, ANFIS é um sistema que pode processar variáveis lingüísticas com a capacidade de aprendizado de uma rede neural. Assim como a maioria dos sistemas inteligentes, o ANFIS pode se ajustar e otimizar uma solução qualquer para o ambiente no qual esta foi inserido.

Na próxima seção é apresentada uma arquitetura de funcionamento para um ANFIS. Estão expostas também algumas outras formas de implementação do ANFIS, que buscam uma aproximação com outros modelos de implementação fuzzy, como o Mamdami e Tsukamoto (ver seção 2.2). Denifidos os modelos ANFIS, são apresentados processos e estratégias utilizadas na etapa de aprendizagem do sistema. 


\subsection{Arquitetura}

A ANFIS tem a função de implementar um FIS sob o domínio das redes neurais. Assim como um FIS, a ANFIS possui modelos que implementam formas diferentes para o processamento dos parâmetros conseqüentes e defuzificação dos dados de entrada. Neste trabalho, o ANFIS é referenciado no modelo FIS Sugeno (ver seção 2.2.2), enquanto outros modelos são citados adiante. O modelo ANFIS Sugeno foi escolhido por tornar a interpretação do funcionamento do sistema ANFIS mais simples (JANG, 1992).

Uma arquitetura ANFIS típica possui cinco camadas de neurônios. Cada camada realiza um processamento específico sobre os dados da camada anterior a ela. A figura 5.1 ilustra um exemplo de arquitetura ANFIS.

Camada 1

Camada 4

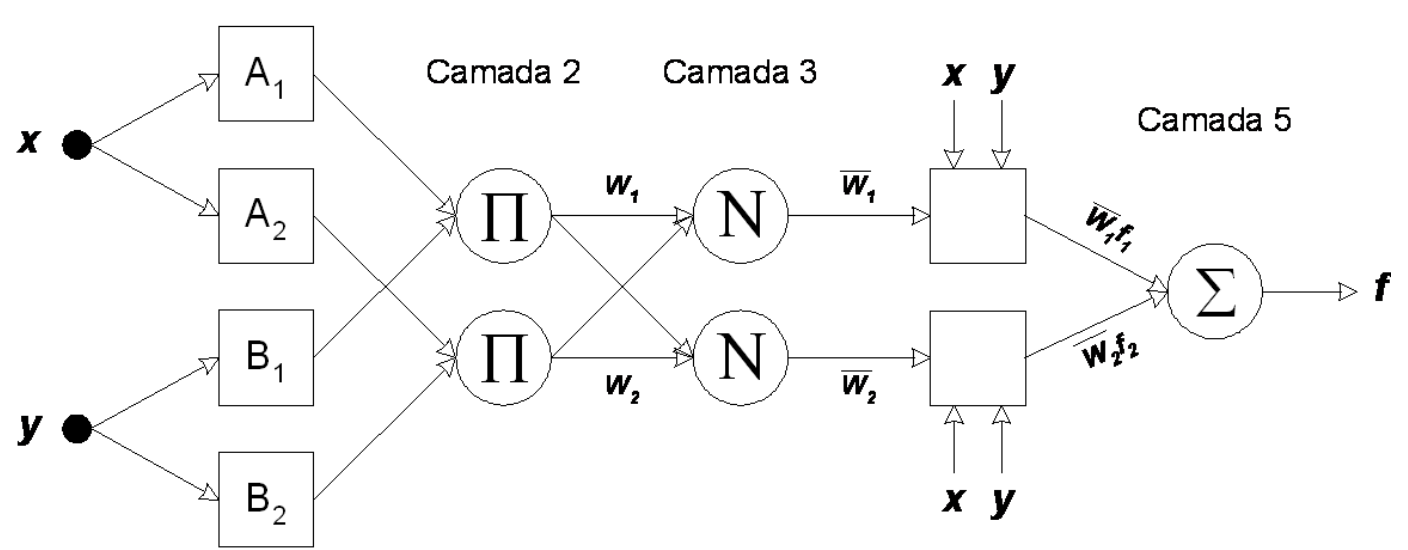

Figura 5.1: Arquitetura ANFIS Sugeno com suas cinco camadas (JANG, 1992).

Como em um típico FIS, a ANFIS recebe as variáveis do mundo real no formato dos conjuntos clássicos. Através de iterações em suas camadas, os dados de entrada são transformados em variáveis lingüísticas, ao final retornando à variável em formato dos conjuntos clássicos.

Assim como nas redes neurais, cada neurônio do ANFIS possui uma função de ativação. Essa função de ativação é específica para a atuação do neurônio sobre a funcionalidade da camada ao qual este pertence.

Para exemplificar o funcionamento de um ANFIS estão apresentados a seguir os processos realizados em cada camada de processamento. Sendo as variáveis de entrada $x$ e $y$ (variáveis do mundo real no formato dos conjuntos clássicos), a variável de saída do sistema é dada pela função $f(x, y)$. É importante notar que, apesar das duas variáveis de entrada estarem no formato dos conjuntos clássicos, elas possuem funções de pertinência para melhor classificá-las no uni- 
verso lingüístico, o que as torna variáveis do universo fuzzy.

Para notação, cada camada é indexada por $l$ e cada nó da camada $l$ é indexado por $i$. Assim, a função realizada por um nó pode ser denotada como $f_{l, i}$.

Camada 1: Esta camada é responsável por transformar cada variável de entrada em variáveis do universo fuzzy, por exemplo, as variáveis de entrada $x$ e y. Em resumo, esta camada é responsável pelo processo de fuzificação.

Cada neurônio nesta camada representa uma função de pertinência das diversas variáveis fuzzy. Logo, a função de saída de cada neurônio é dada por:

$$
\mu_{j}^{i}\left(x_{i}\right),
$$

onde o índice $j$ representa uma variável lingüística de entrada. Na figura 5.1, este índice é representado por $A$ e $B$ para cada variável. Por conseqüência, o índice $i$ representa cada função de pertinência da respectiva variável fuzzy. Ainda no caso da figura 5.1, a primeira camada pode ser expressa por:

$$
\begin{gathered}
\mu_{A_{i}}(x) \\
\mu_{B_{i}}(y) .
\end{gathered}
$$

Na equação 5.2, o termo $A$ é a variável lingüística da entrada $x$ e o termo $i$ indexa as funções de pertinências para esta variável. Respectivamente, $B$ é a variável lingüística da entrada $y$ e o termo $i$ desta variável indexa as suas funções de pertinência.

No exemplo foi utilizada como função de pertinência uma função trapeizoidal, tanto para $x$ quanto para $y$. O uso dessa função tem como objetivo facilitar a explicação do processo de aprendizado.

A função trapeizoidal é dada por:

$$
\mu(x)=\frac{1}{1+\left(\left(\frac{x-c}{a}\right)^{2}\right)^{b}},
$$

onde $a, b$ e $c$ são parâmetros de ajuste da curva. Sobre estes parâmetros são realizados os ajustes que ocorrem durante o processo de aprendizado descrito adiante neste capítulo.

Esse tipo de operação realizada nesta camada sobre as variáveis lingüísticas são equivalentes às que ocorrem sobre um FIS Sugeno, ilustrado pela figura 2.7. Assim como no FIS Sugeno, esses graus de pertinência são denominados parâmetros de premissa de entrada do sistema FIS (ver seção 2.1.2). 
Camada 2: Com base nos parâmetros de premissas obtidos na primeira camada, na segunda camada são realizadas as operações da base de conhecimento FIS; logo, é nesta camada que se encontram as regras de conhecimento do especialista fuzzy. A camada 2 equivale à aplicação das operações IF-THEN ao FIS Sugeno, ilustrado de forma similar pela figura 2.7 pela linha vertical.

$$
f_{2, i}=w_{i}=\mu_{A_{i}}(x) \mu_{B_{i}}(y), i=1,2
$$

Cada neurônio da camada 2 representa uma operação da regra IF-THEN fuzzy (ver seção 2.1.2). É nesta camada que as variáveis fuzzy se relacionam e geram os parâmetros de $w$ para os parâmetros de conseqüência do FIS.

Normalmente existe uma $f_{2, i}$ correspondente para cada parâmetro de premissa gerado, o que torna o número de nós da camada 2 relativamente grande devido ao número de entrada e funções de pertinência existentes por variáveis fuzzy. Quando não existe a interferência de um especialista para a definição das regras dessa camada, o ANFIS sofre uma explosão de particionamentos fuzzy possíveis (ver seção 2.2.4). Logo, o sistema cai no problema da maldição da dimensionalidade. Para evitar esse tipo de comportamento são realizados pré-processamentos nos dados de entrada, visando a redução de regras fuzzy a serem aplicadas. Esse problema de dimensionalidade é levantado ao longo do capítulo.

Camada 3: Esta camada é responsável pela normalização dos valores gerados pelas regras IF-THEN, evitando assim uma distorção nos parâmetros de conseqüência do sistema. Para a figura 5.1, essa normalização é dada pela equação:

$$
f_{3, i}=\bar{w}_{i}=\frac{w_{i}}{w_{1}+w_{2}}, i=1,2
$$

De forma genérica, a função pode ser descrita como:

$$
\bar{w}_{i}=\frac{w_{i}}{\sum_{k=1}^{K} w_{k}},
$$

na qual $K$ é o número total de regras IF-THEN da segunda camada.

Camada 4: Cada nó $i$ é um nó adaptativo, por conter uma função adaptativa $f_{i}$.

$$
f_{3, i}=\bar{w}_{i} f_{i}=\bar{w}_{i}\left(p_{i} x+q_{i} y+r_{i}\right)
$$

Na equação da camada 4 - equação 5.7 - é realizada o cálculo com os parâmetros de conseqüência do sistema, $p_{i}, q_{i}$ e $r_{i}$. De forma equivalente ao que ocorre no FIS Sugeno, cada neurônio desta camada pode ser comparado com 
as equações das lineares que geram os parâmetros $z$ encontrados na figura 2.7.

Camada 5: A camada 5 finaliza o processo. Esta camada transforma as variáveis fuzzy de conseqüência obtidas na camada 4 em um único valor dos conjuntos clássicos. Em resumo, a camada 5 realiza o processo de defuzificação de um FIS. Este processo é realizado pela soma de todos os valores obtidos na camada 4 ,

$$
f_{5,1}=\sum_{i} \bar{w}_{i} f_{i}=\frac{\sum_{i} w_{i} f_{i}}{\sum_{i} w_{i}}
$$

Ao final deste processo, o ANFIS equivale a um FIS, com a mesma vantagem de incorporar ao seu processo o conhecimento aproximado de um especialista.

Existem algumas variações de estruturas para o ANFIS; algumas vezes estas variações podem ser encontradas com apenas 4 camadas, na qual as camada 3 e 4 são reduzidas a apenas uma ponderação média realizada diretamente na última camada (JANG; SUN; MIZUTANI, 1997).

Além dessas, existem outras variantes de ANFIS que suprem outros métodos de implementações FIS, como a Tsukamoto (ver seção 2.2.3). A figura 5.2 ilustra uma arquitetura ANFIS que realiza a operação FIS seguindo a seqüência de um FIS Tsukamoto.

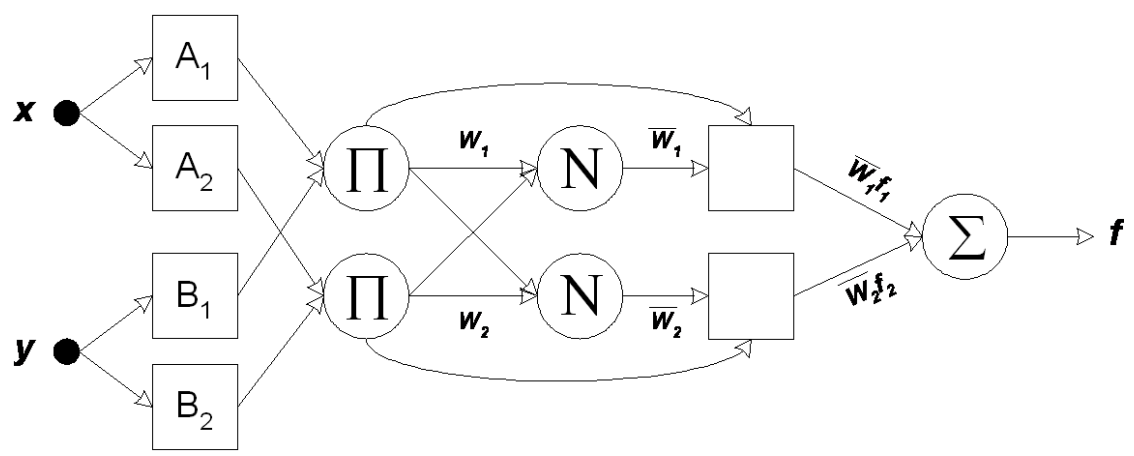

Figura 5.2: Modelo ANFIS equivalente ao FIS Tsukamoto (JANG; SUN; MIZUTANI, 1997).

À medida que aumenta o número de variáveis de entrada em uma ANFIS, o número de neurônios aumenta em proporção exponencial, dado pelo número de funções de pertinência de cada variável de entrada e o número de variáveis de entrada. A figura 5.3 ilustra uma arquitetura ANFIS Sugeno com três variáveis de entrada. Cada uma delas possui duas funções de pertinência dentro do universo fuzzy. Note que o número de regras possíveis são combinatórias, de acordo com o particionamento de regiões fuzzy grid (ver seção 2.2.4). Isso torna o sistema ANFIS lento para o processo de aprendizagem e também pouco viável para sistemas com muitas variáveis de entradas. 


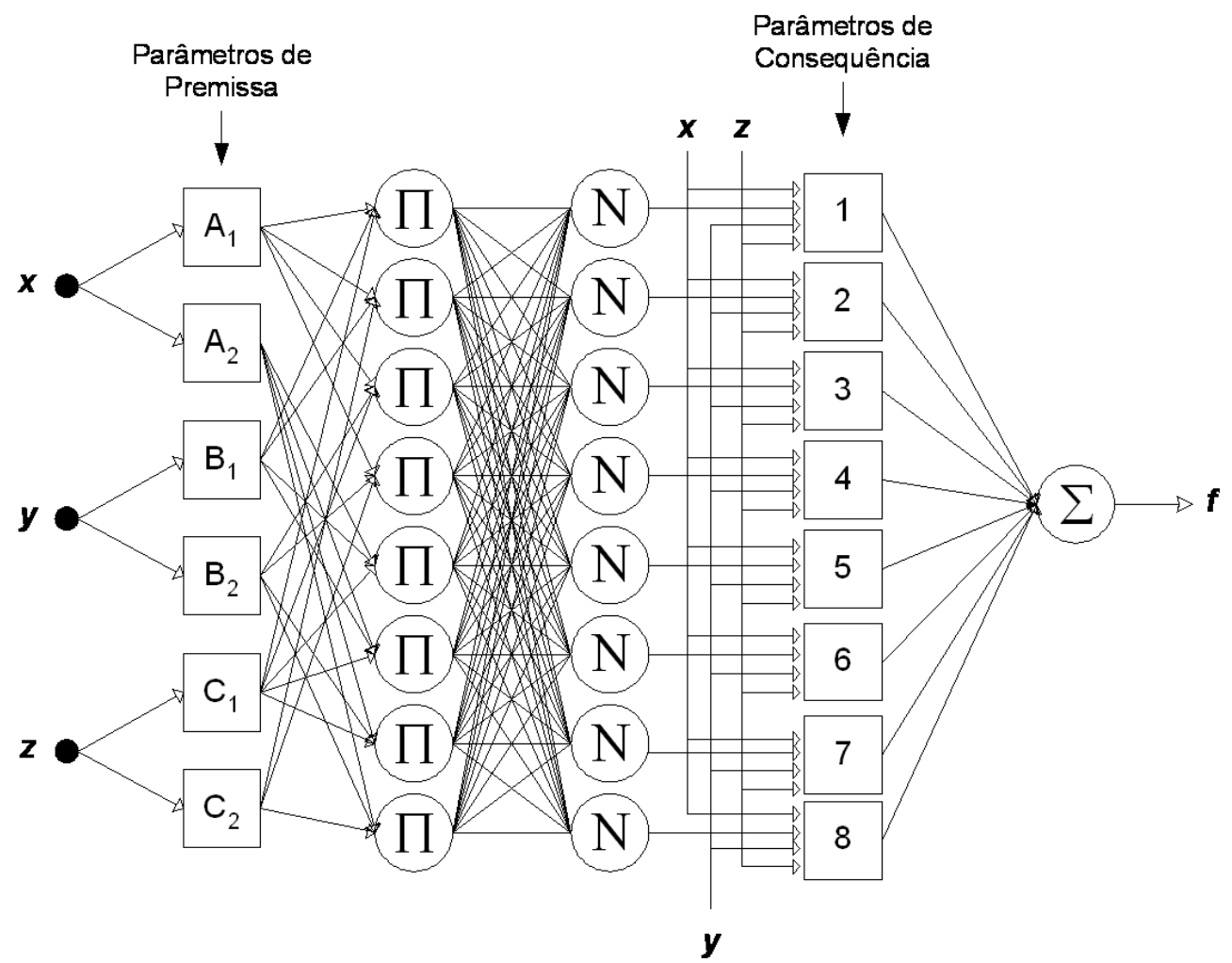

Figura 5.3: Modelo ANFIS, equivalente ao FIS Sugeno, com 3 variáveis de entrada, sendo que cada uma possui 2 funções de pertinência. Gerando assim uma lista de regras com 8 combinações.

Para evitar um problema de dimensionalidade na camada 2, alguns préprocessamentos podem ser feitos nas variáveis de entrada, para que sejam identificadas as regras e funções de pertinência realmente são significativas, ou até mesmo válidas no processo. Esse pré-processamento é estudado em (MITRA; HAYASHI, 2000). Outra solução é a aplicação de técnicas de particionamento, como fuzzy boxes ou cluters (ver seção 2.2.4, figuras 2.10(c) e 2.10(d) respectivamente). Estas tentativas para diminuir o número de regras IF-THEN fuzzy possíveis tentam suprir a necessidade de um especialista durante o processo de aprendizagem.

Na próxima seção são tratados os aspectos de aprendizagem em uma ANFIS Sugeno, assim como formas de ajustes em seus parâmetros de premissas.

\subsection{Aprendizado}

A possibilidade de aprendizado, como encontrado nas redes neurais, é o que torna o ANFIS um sistema diferenciado dos demais. É através do aprendizado que o ANFIS ajusta seus pesos e otimiza sua atuação sobre os dados de treinamento do ambiente. Essa otimização permite que o ANFIS passe a processar as variáveis lingüísticas com mais customização para o contexto. 
Em uma rede neural, o aprendizado é dado pelos ajustes dos pesos que interligam os neurônios. Já em um ANFIS, o aprendizado atua sobre os parâmetros ajustáveis das funções de pertinência das variáveis fuzzy de entrada do sistema - os parâmetros de premissa. De certa maneira, é correto pensar que o ANFIS afere as curvas dadas pelo especialista apoiando-se nos dados de treinamento e nas regras IF-THEN utilizadas em sua construção. Este aferimento acaba por melhorar o funcionamento do sistema como um todo. Porém, deve-se evitar problemas de overfitting, o qual representa um treinamento viciado que acaba com o poder de generalização do sistema. Maiores informações sobre overfitting podem ser encontradas em Haykin (1999), Muller e Reinhardt (1990) e Jordan e Bishop (1996).

Assim como na rede neural, o ANFIS possui uma certa heterogeneidade de métodos para o seu processo de aprendizado. O método mais utilizado é implementado por um algoritmo de aprendizado híbrido, como nomeado por Jang em (JANG, 1992). Este algoritmo realiza um aprendizado matricial para calcular os valores de ajuste até uma determinada camada. Este método é similar ao encontrado em uma RBF (ver seção 3.2). Na seqüência, o algoritmo executa uma retropropagação para ajustar os parâmetros de premissa. Esta retropropagação é encontrada na MLP (ver seção 3.1.1).

O erro em um ANFIS pode ser calculado através do erro médio quadrado da diferença entre valor desejado e o valor de saída do sistema (DENÄ̈; PALIS; ZEGHBIB, 2004), descrito como:

$$
E=\frac{1}{2}(d-f)^{2}
$$

O primeiro passo do ajuste do erro em um ANFIS está no cálculo do erro da matriz de soma realizada na quarta e na quinta camada da rede. O cálculo da função resultante dessas camadas é dado como:

$$
\begin{aligned}
f & =\frac{w_{1}}{w_{1}+w_{2}} f_{1}+\frac{w_{2}}{w_{1}+w_{2}} f_{2} \\
& =\bar{w}_{1} f_{1}+\bar{w}_{2} f_{2} \\
& =\left(\bar{w}_{1} x\right) p_{1}+\left(\bar{w}_{1} y\right) q_{1}+\left(\bar{w}_{1}\right) r_{1}+\left(\bar{w}_{2} x\right) p_{2}+\left(\bar{w}_{2} y\right) q_{2}+\left(\bar{w}_{2}\right) r_{2} .
\end{aligned}
$$

Dessa forma é possível colocar todos os parâmetros de conseqüência em uma única matriz linear $X$ e os valores de $w$ em uma outra matriz $W$. Logo, de forma linear, é possível:

$$
f=X W .
$$


Sendo $X$ uma matriz inversível, então:

$$
W=X^{-1} f
$$

ou através de uma pseudo-inversa é possível resolver $W$ como

$$
W=\left(X^{T} X\right)^{-1} X^{T} f
$$

Com a equação 5.13 é possível calcular os valores de $w$ para o valor desejado. Essa solução permite calcular os valores de $w$ desejados. Logo, a diferença entre o $w$ desejado e o obtido é propagado para as demais camadas da rede (ver equação 5.9). Esta técnica é a mesma aplicada no processo de aprendizagem de uma RBF, como demonstrado na seção 3.2.

Com o valor de $W$ obtido para o vetor da camada 4 , onde cada elemento é dado por $w_{i}$, é possível retropropagar o erro para as demais camadas do sistema. Para isso, o processo de aprendizagem utiliza a técnica de retropropagação encontrada em uma MLP. O valor de correção para cada parâmetro da curva de pertinência da variável fuzzy de entrada pode ser dado por $\Delta \rho$, que é expresso por:

$$
\Delta \rho=\frac{\partial E}{\partial \rho}=\sigma \frac{\partial E}{\partial f} \frac{\partial f}{\partial f_{i}} \frac{\partial f_{i}}{\partial w_{i}} \frac{\partial w_{i}}{\partial \mu_{i j}} \frac{\partial \mu_{i j}}{\partial \rho}
$$

como

$$
\begin{gathered}
E=\frac{1}{2}\left(f-f^{t}\right), \log \frac{\partial E}{\partial f}=\left(f-f_{t}\right)=e, \\
f=\sum_{i=1}^{n} f_{i}, \log \frac{\partial f}{\partial f_{i}}=1, \\
f_{i}=\frac{w_{i}}{\sum_{n=1}^{n} w_{i}}\left(p_{i} x+q_{i} y+r_{i}\right), \log \mathrm{O} \frac{\partial f_{i}}{\partial w_{i}}=\frac{\left(p_{i} x+q_{i} y+r_{i}\right)-f}{\sum_{i=1}^{n} w_{i}},
\end{gathered}
$$

$\mathrm{e}$

$$
w_{i}=\prod_{j=1}^{m} \mu_{A_{j i}}, \log \mathrm{o} \frac{\partial w_{i}}{\partial \mu_{i j}}=\frac{w_{i}}{\mu_{i j}},
$$

onde o parâmetro $\rho$ representa o termo função de pertinência. Logo, no caso do uso da função traipezoidal utilizada no exemplo, é necessário ajustar os três parâmetros da equação 5.2, onde a derivada parcial para o ajuste de cada parâmetro pode ser calculado por

$$
\begin{aligned}
\frac{\partial \mu_{i j}}{\partial a} & =-\frac{\mu_{i j}\left(x_{i}\right)^{2}}{a}\left(\frac{\left(x_{i}-c\right)^{2}}{a}\right)^{b} \\
\frac{\partial \mu_{i j}}{\partial b} & =-b \mu_{i j}\left(x_{i}\right)^{2}\left(\frac{\left(x_{i}-c\right)^{2}}{a}\right)^{(b-1)}
\end{aligned}
$$




$$
\frac{\partial \mu_{i j}}{\partial c}=\frac{2 b \mu_{i j}\left(x_{i}\right)^{2}}{x_{i}-c}\left(\frac{\left(x_{i}-c\right)^{2}}{a}\right)^{b},
$$

para $a, b$ e $c$ respectivamente.

\subsection{Aproximador Universal de Funções}

A maior utilização de um ANFIS está em explorar a sua capacidade de aproximação para funções não lineares. Essa capacidade existe devido ao número de regras IF-THEN, que podem ser relativamente grandes. Esse número pode ser tão grande ao ponto de atender o teorema de aproximação universal $^{1}$ (JANG; SUN; MIZUTANI, 1997; NAUCK et al., 2003).

A possibilidade de estimar uma função é muito utilizada na área de controle inteligente, onde é possível definir futuras possibilidades de cenários para o sistema (ZHOU; JAGANNATHAN, 1996; JORDAN; BISHOP, 1996).

Este trabalho trata da predição de séries temporais com o uso de um ANFIS. Mais adiante, no capítulo 6, são propostos experimentos que tentam modelar alguns funções matemáticas, muitas vezes as funções apresentadas neste trabalho são funções com comportamento caótico, o que torna a modelagem da função um tanto quanto complexa. Ao utilizar um ANFIS, este último tem que ser capaz de realizar predições dessas funções ao ponto de provar ser um bom estimador de funções.

\subsection{Sumário}

Neste capítulo foi apresentada uma arquitetura de sistema neuro-fuzzy conhecida como ANFIS. A ANFIS tem como objetivo trabalhar como um FIS, porém, sua implementação é feita sobre uma arquitetura de redes neurais. Esse diferencial permite que um ANFIS tenha a capacidade de aprendizado. Assim, o ANFIS pode ao mesmo tempo processar variáveis lingüísticas e aprender com o ambiente no qual está inserido. Dessa forma, um ANFIS pode unir aos dois grandes paradigmas do processamento fuzzy e neural.

Ainda neste capítulo, foi abordado o processamento de um ANFIS, assim como seu processo de aprendizado híbrido. Este processo possui este nome porque

\footnotetext{
${ }^{1} \mathrm{O}$ teorema de aproximação universal pode ser visto como uma extensão natural do Teorema de Weierstrass. Este teorema afirma que qualquer função contínua sobre um intervalo fechado no eixo real pode ser expressa naquele intervalo como uma série de polinômios absolutamente e uniformemente convergente (HAYKIN, 1999)
} 
a primeira etapa do processo é dada por uma inversão de matriz a qual permite o cálculo do erro a ser propagado pela segunda etapa do processo de aprendizagem.

Essa arquitetura de sistema neuro-fuzzy é utilizada ao longo do trabalho para demonstrar sua capacidade de predição de funções. 


\section{Experimentos}

Este capítulo descreve os experimentos realizados para testar a capacidade de predição de funções descrita em um ANFIS. São abordadas duas funções de séries temporais: uma função logística simples e uma função de Mackey-Glass. Estas funções foram escolhidas por possuírem a característica de apresentar comportamentos caóticos com a simples alteração de um termo de sua composição.

Uma série temporal é basicamente definida por uma variável cuja o valor futuro pode ser calculado levando em conta seu valor atual, ou um determinado período de valores de seu histórico (ROSS, 1970; BROCKWELL; DAVIS, 1991). Logo, uma função de série temporal pode ser dada como $x(t)=f(x(t-1))$, em que o termo $t$ representa o instante de tempo da variável $x$.

Analisando os valores gerados por uma série temporal é notável que alguns valores não mudam ao longo do tempo, fazendo com que a função opere sempre com o mesmo valor, esse tipo de comportamento denota uma convergência da função a longo prazo para um estado estacionário (também chamado ponto de equilíbrio ou ponto fixo) (GLASS; MACKEY, 1997). Este estado é sempre alcançado pela função a longo prazo, independente de seu valor inicial.

Outras vezes, essa função converge para mais de um ponto fixo, ou seja, o valor passa a oscilar entre dois ou mais pontos. Essa oscilação gera um padrão de repetição de visitação a estes valores de forma estável; mesmo que haja uma pertubação no sistema a longo prazo, a função volta ao plano de fase da oscilação. Como o estado não é imutável (como no caso do estado estacionário), esse comportamento é denominado como estado oscilatório, e suas oscilações ocorrem em períodos de ciclos-limites superior à 1 .

Uma característica encontrada nessas equações é uma tendência por comportamentos instáveis - sensíveis aos parâmertos iniciais do sistema e que não permitem uma dinâmica de estado estacionário ou ciclo-limite. Este estado é denominado instável ou estado de caos $^{1}$.

\footnotetext{
${ }^{1}$ Este trabalho apresenta uma breve introdução a alguns conceitos de caos apenas para tornar familiar os termos aqui utilizados. Para maiores detalhes é aconselhavél uma consulta
} 
Nas duas funções abordadas é possível navegar por estados estacionários, de ciclo-limite e caótico, apenas com um ajuste em alguns dos termos da equação. Este termo ajuste é conhecimento por parâmetro de bifurcação.

Os experimentos aqui descritos buscam reproduzir as funções em seus comportamentos caóticos, como uma forma de estimar de uma função não-linear. A seguir são tratados os experimentos para cada uma das funções e suas predições em ANFIS e MLP.

\subsection{Função Logística}

A função logística é uma simples função de grau 2 que utiliza seu estado de tempo anterior para calcular seu estado atual. Essa relação entre o estado de tempo anterior e o atual possibilita a criação de uma série temporal. A variável de tempo tratada nesta função é de domínio discreto, logo, para notação, o deslocamento do seu valor em função do tempo é dado como $f(x(n))$, onde $n$ é o instante de tempo da variável $x$.

Os experimentos com a função logística foram realizados utilizando o estado de tempo $n+1$ como valor desejado e o estado $n$ como valor de entrada. Desta maneira, o ANFIS é utilizado para estimar a função que leva do estado $n$ para o estado $n+1$, ou seja, a função $x(n+1)=f(x(n))$. A função logística utilizada neste trabalho é dada por:

$$
x(n+1)=f(x(n))=\mu x(n)(1-x(n)),
$$

na qual o parâmetro $\mu$ é o parâmetro de bifurcação da função que permite assim um controle sobre o comportamento da função a longo prazo. Uma simples variação no parâmetro de bifurcação $\mu$ gera uma variação de comportamento estacionário para um ciclo-limite ou até mesmo caótico, como ilustrado na figura 6.1 .

Uma forma de ilustrar o comportamento de uma função a longo prazo para uma grande abrangência de valores do parâmetro de bifurcação é através da montagem de um mapa de bifurcação, que permite uma melhor visualização e tomada de decisão para a escolha do valor. A figura 6.2 ilustra o mapa de bifurcação da função logística 6.1. O ponto onde ocorre a mudança de comportamento da função é chamado de ponto de bifurcação.

Para a montagem do mapa de bifurcação foram realizados experimentos com ao material específico da área. 

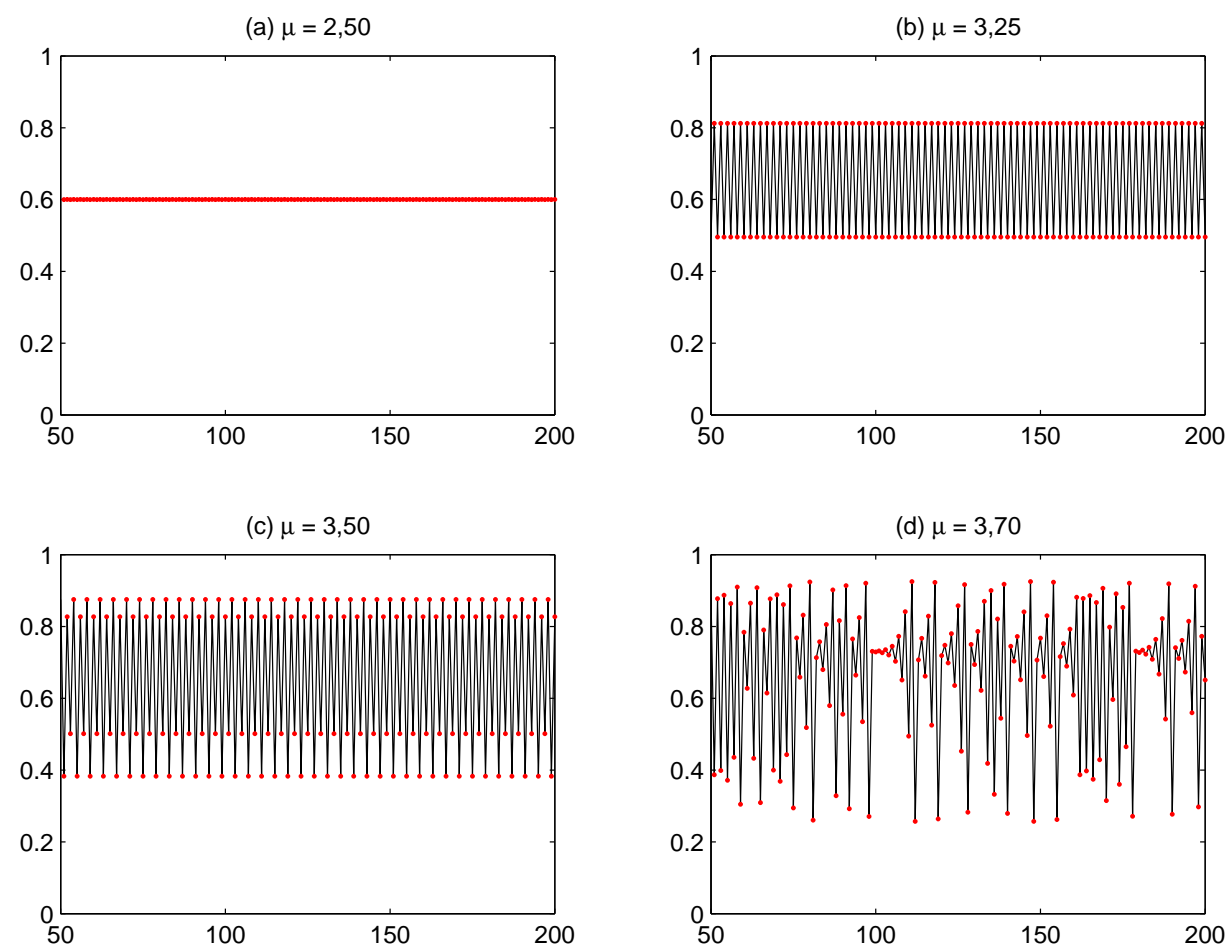

Figura 6.1: Com uma simples variação no parâmetro de bifurcação $\mu$ da função logística $x(n+1)=f(x(n))=\mu x(n)(1-x(n))$ é possível navegar entre comportamentos distintos da função: (a) é o período com apenas um ponto de convergência assintótico (estado estacionário); (b) é o período com dois pontos de oscilação (estado de ciclo-limite com periodicidade 2); (c) é o período com quatro pontos de oscilação (estado de ciclo-limite com periodicidade 4) e (d) é o período com comportamento caótico (estado instável). 


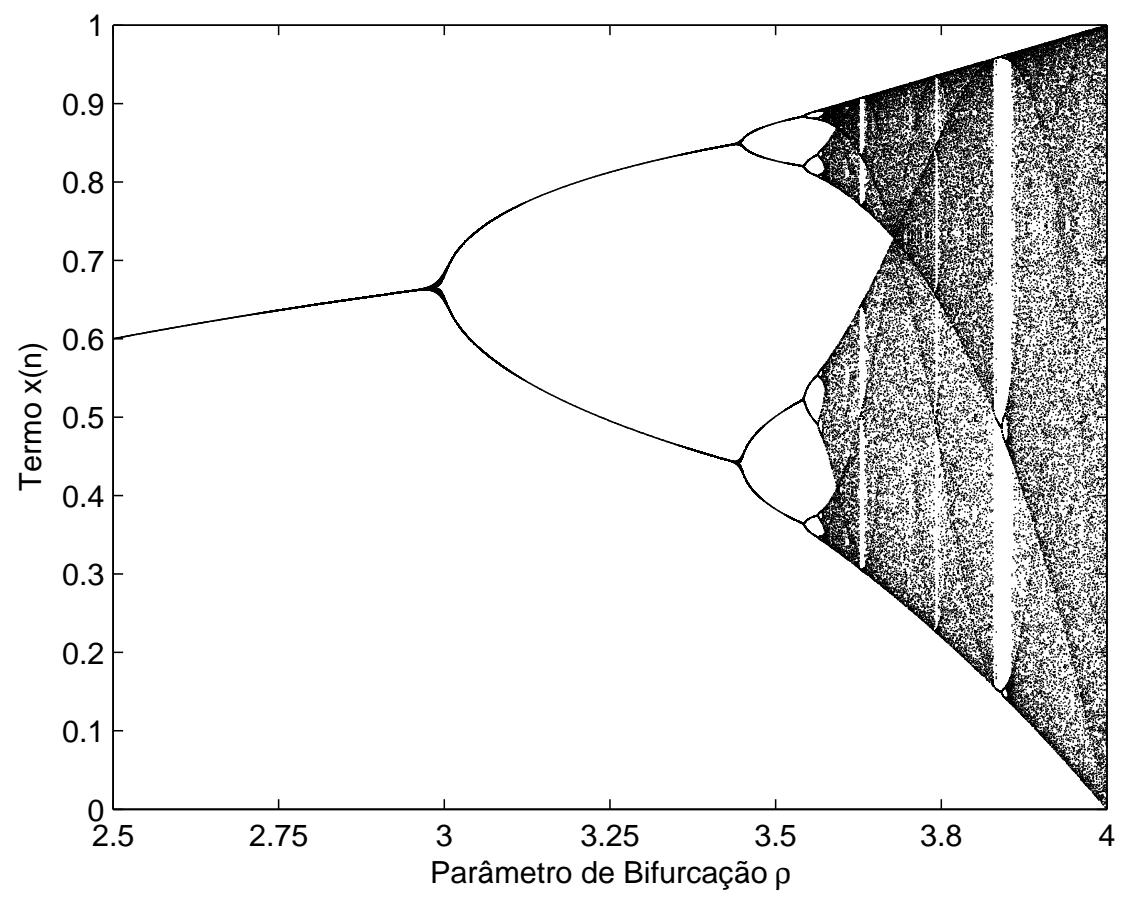

Figura 6.2: Mapa de bifurcação da função logística 6.1

(DEL-MORAL-HERNANDEZ, 2003; DEL-MORAL-HERNANDEZ; SANDMANN; SILVA, 2004; GLASS; MACKEY, 1997; BEUTER et al., 2003).

a função logística por um período de 250 iterações. Destas, foram descartadas as primeiras 100 iterações, evitando assim o período de convergência da função.

Na geração dos dados foram utilizados 850 pontos de uma série temporal gerada pela função logística 6.1 com o valor inicial de $x(0)=0,1$. Destes pontos foram descartados os 50 primeiros afim de evitar o uso de um período de convergência da função. Dos 800 pontos restantes, os 400 primeiros foram utilizados na fase de treinamento do ANFIS e da MLP, e os demais pontos foram utilizados para o teste do processo.

Foram escolhidos três valores para o parâmetro de bifurcação $\mu: 3,25,3,50$ e 3,70 . Para cada um deles a função logística apresenta um comportamento a logo prazo, sendo respectivamente, um ciclo-limite de período 2 , de período 4 e outro de período caótico.

Os experimentos realizados foram divididos em duas partes: na primeira foi utilizado um ANFIS para estimar a função logística; e na segunda, foi utilizada uma rede neural MLP.

A tabela 6.1 apresenta os resultados obtidos com o experimento em um ANFIS. Estes variam de acordo com o número de funções de pertinência impostas à variável de entrada. Na tabela a primeira coluna indica a quantidade de 


\begin{tabular}{|c|c|c|c|c|c|c|c|c|c|}
\cline { 2 - 10 } \multicolumn{1}{c|}{} & \multicolumn{3}{|c|}{3,25} & \multicolumn{3}{c|}{3,50} & \multicolumn{3}{c|}{3,70} \\
\hline $\begin{array}{c}\text { no. } \\
\text { FPs }\end{array}$ & $\begin{array}{c}\text { erro } \\
\text { médio }\end{array}$ & var. & $\begin{array}{c}\text { desvio } \\
\text { padrão }\end{array}$ & $\begin{array}{c}\text { erro } \\
\text { médio }\end{array}$ & var. & $\begin{array}{c}\text { desvio } \\
\text { padrão }\end{array}$ & $\begin{array}{c}\text { erro } \\
\text { médio }\end{array}$ & var. & $\begin{array}{c}\text { desvio } \\
\text { padrão }\end{array}$ \\
\hline 2 & $1,8 \mathrm{e}-9$ & 0,00 & $1,0 \mathrm{e}-9$ & $8,6 \mathrm{e}-9$ & 0,00 & $3,1 \mathrm{e}-9$ & $5,9 \mathrm{e}-4$ & $9,9 \mathrm{e}-8$ & $3,2 \mathrm{e}-4$ \\
\cline { 2 - 10 } & $1,8 \mathrm{e}-9$ & 0,00 & $1,0 \mathrm{e}-9$ & $8,6 \mathrm{e}-9$ & 0,00 & $3,1 \mathrm{e}-9$ & $5,8 \mathrm{e}-4$ & $9,9 \mathrm{e}-8$ & $3,2 \mathrm{e}-4$ \\
\hline \multirow{2}{*}{3} & $1,9 \mathrm{e}-9$ & 0,00 & $1,0 \mathrm{e}-9$ & $3,8 \mathrm{e}-9$ & 0,00 & $3,6 \mathrm{e}-9$ & $1,5 \mathrm{e}-4$ & $6,9 \mathrm{e}-9$ & $8,3 \mathrm{e}-5$ \\
\cline { 2 - 10 } & $1,9 \mathrm{e}-9$ & 0,00 & $1,0 \mathrm{e}-9$ & $3,8 \mathrm{e}-9$ & 0,00 & $3,6 \mathrm{e}-9$ & $1,4 \mathrm{e}-4$ & $6,1 \mathrm{e}-9$ & $7,8 \mathrm{e}-5$ \\
\hline \multirow{2}{*}{5} & $1,9 \mathrm{e}-9$ & 0,00 & $1,0 \mathrm{e}-9$ & $4,4 \mathrm{e}-9$ & 0,00 & $2,8 \mathrm{e}-9$ & $6,2 \mathrm{e}-5$ & $2,1 \mathrm{e}-9$ & $4,6 \mathrm{e}-5$ \\
\cline { 2 - 10 } & $1,9 \mathrm{e}-9$ & 0,00 & $1,0 \mathrm{e}-9$ & $4,4 \mathrm{e}-9$ & 0,00 & $2,8 \mathrm{e}-9$ & $5,9 \mathrm{e}-5$ & $1,9 \mathrm{e}-9$ & $4,4 \mathrm{e}-5$ \\
\hline
\end{tabular}

Tabela 6.1: Resultados da estimação da função logística 6.1 em um ANFIS.

(a) erro médio $=0.0005827330$

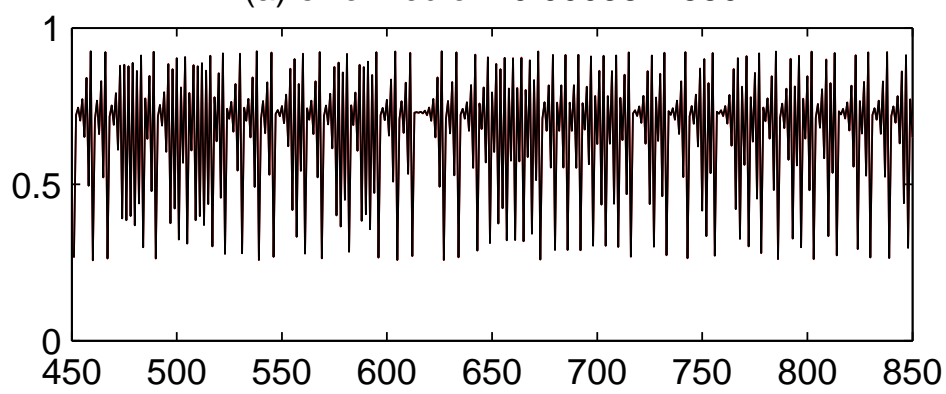

(b) erro médio $=0.0001440157$

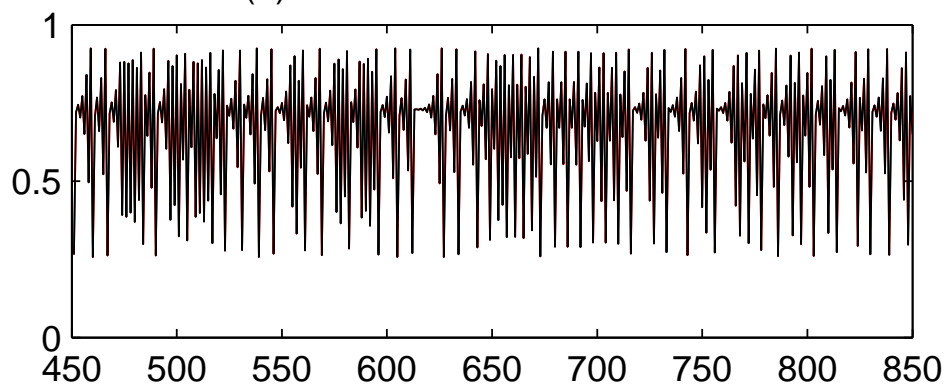

(c) erro médio $=0.0000596428$

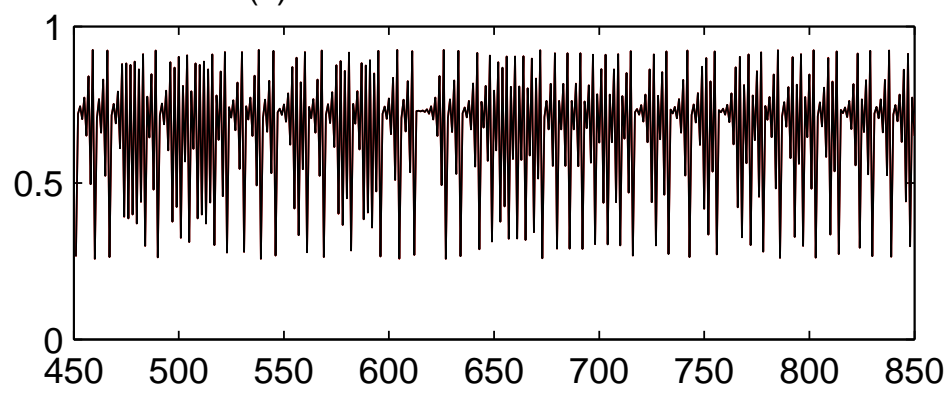

Figura 6.3: Estimação da função logística 6.1 com parâmetro de bifurcação $\mu=3,70$ (período caótico) por um ANFIS com números de funções de pertinência por variável de entrada: (a) 2, (b) 3 e (c) 5 . 
funções de pertinência utilizada por variável de entrada; logo, a primeira linha de cada experimento aponta os resultados do conjunto de treino e a segunda linha, os resultados do conjunto de teste.

Já a figura 6.3 ilustra a função logística em comportamento caótico com $\mu=3,70$, sendo que cada gráfico possui um número de funções de pertinência diferente para cada variável de entrada do sistema.

A rede neural MLP utilizada não implementa nenhuma estratégia de aprendizado, portanto, seu valor padrão para aprendizado é fixo, sendo $\eta=0,07$. O número máximo de iterações para a MLP foi definido em 500 (definido como critério de parada). Este número de iterações foi definido porque durante os testes foi observado que este número de iterações foi suficiente para atingir valores de erros estáveis, ou seja, cuja a variação do erro entre uma iteração e outra é quase desprezível.

Outro fator de influência sobre a elaboração de uma rede neural MLP são seus valores de pesos iniciais. Para minimizar essa influência a rede neural foi inicializada com pesos aleatórios, treinada e executada para medição durante um ciclo de 150 iterações. Dessa maneira, os valores obtidos levam em conta a média de acerto de todos os ciclos para a rede neural.

A tabela 6.2 exibe os resultados obtidos através da MLP. A primeira coluna indica a quantia de neurônios presentes na camada oculta da rede; assim, a primeira linha de cada experimento aponta os resultados dos dados de treinamento e a segunda, os resultados dos dados de teste.

\begin{tabular}{|c|c|c|c|c|c|c|c|c|c|}
\cline { 2 - 10 } \multicolumn{1}{c|}{} & \multicolumn{3}{c|}{3,25} & \multicolumn{3}{c|}{3,50} & \multicolumn{3}{c|}{3,70} \\
\hline \multirow{2}{*}{$\begin{array}{c}\text { no. } \\
\text { NO }\end{array}$} & $\begin{array}{c}\text { erro } \\
\text { médio }\end{array}$ & var. & $\begin{array}{c}\text { desvio } \\
\text { padrão }\end{array}$ & $\begin{array}{c}\text { erro } \\
\text { médio }\end{array}$ & var. & $\begin{array}{c}\text { desvio } \\
\text { padrão }\end{array}$ & $\begin{array}{c}\text { erro } \\
\text { médio }\end{array}$ & var. & $\begin{array}{c}\text { desvio } \\
\text { padrão }\end{array}$ \\
\hline 2 & 0,0634 & 0,0056 & 0,0750 & 0,0882 & 0,0074 & 0,0862 & 0,0826 & 0,0071 & 0,0844 \\
\cline { 2 - 11 } & 0,0634 & 0,0056 & 0,0750 & 0,0882 & 0,0074 & 0,0862 & 0,0807 & 0,0070 & 0,0838 \\
\hline \multirow{2}{*}{3} & 0,0268 & 0,0031 & 0,0557 & 0,0543 & 0,0009 & 0,0294 & 0,0842 & 0,0039 & 0,0627 \\
\cline { 2 - 10 } & 0,0268 & 0,0031 & 0,0557 & 0,0543 & 0,0009 & 0,0294 & 0,0828 & 0,0039 & 0,0626 \\
\hline \multirow{2}{*}{5} & 0,0002 & 0,0000 & 0,0014 & 0,0363 & 0,0007 & 0,0261 & 0,0471 & 0,0018 & 0,0419 \\
\cline { 2 - 10 } & 0,0002 & 0,0000 & 0,0014 & 0,0363 & 0,0007 & 0,0261 & 0,0467 & 0,0017 & 0,0408 \\
\hline
\end{tabular}

Tabela 6.2: Resultados da estimação da função logística 6.1 com uma MLP.

As figuras 6.4, 6.5 e 6.6 ilustram, respectivamente, o melhor e o pior resultado dos dados de testes utilizando a MLP com 2, 3 e 5 neurônios da camada oculta. 
(a) melhor caso (erro médio $=0.0400)$

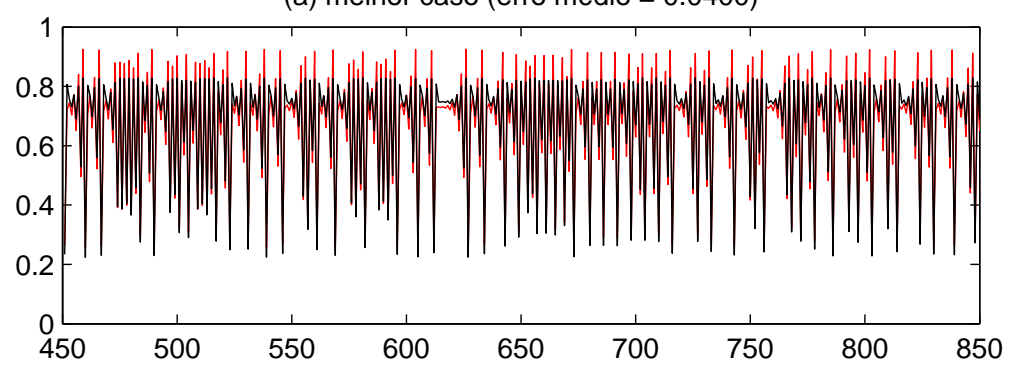

(b) pior caso (erro médio $=0.1756$ )

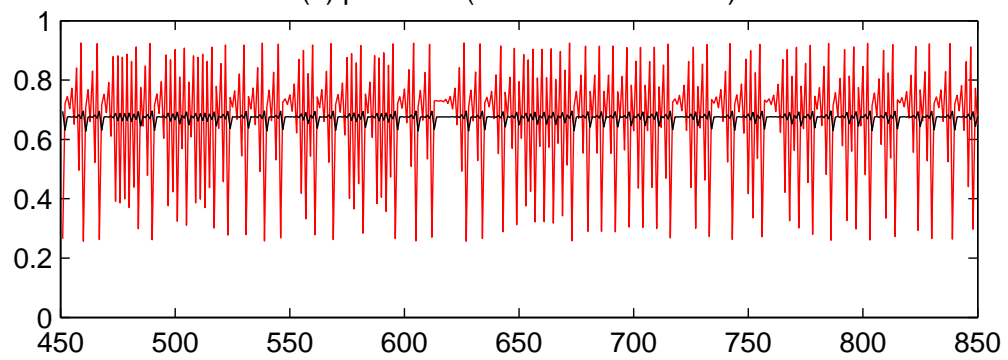

Figura 6.4: Estimação da função logística 6.1 por em rede neural MLP com 2 neurônios na camada oculta.

(a) melhor caso (erro médio $=0.0566$ )

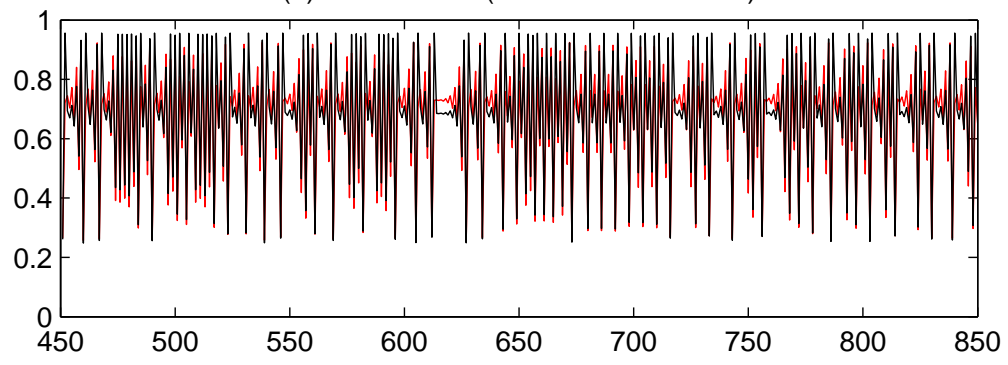

(b) pior caso (erro médio $=0.1535$ )

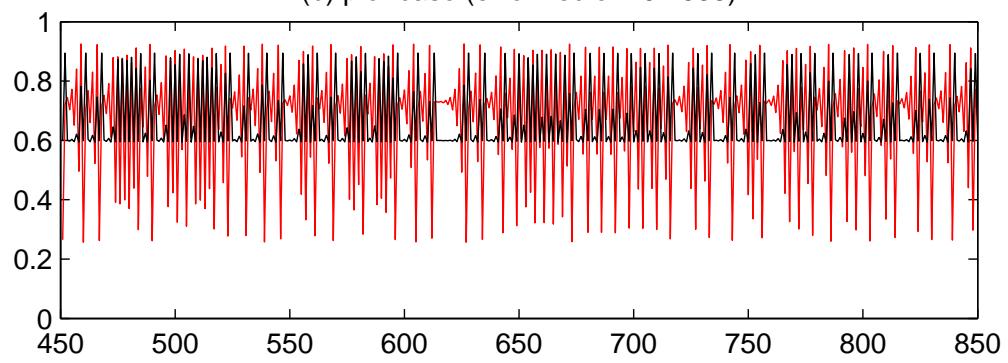

Figura 6.5: Estimação da função logística 6.1 por uma rede neural MLP com 3 neurônios na camada oculta. 
(a) melhor caso (erro médio $=0.0233$ )

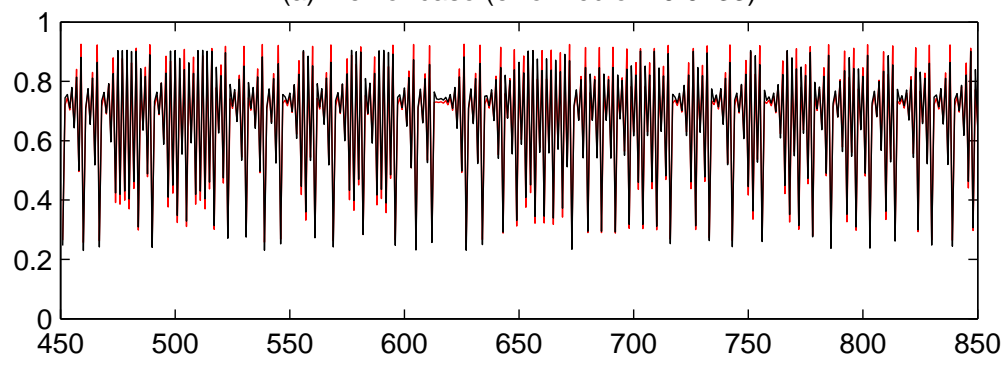

(b) pior caso (erro médio $=0.0654$ )

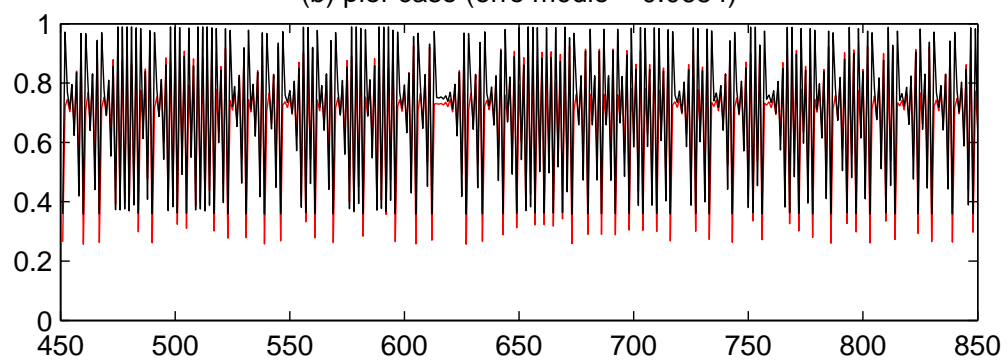

Figura 6.6: Estimação da função logística 6.1 por uma rede neural MLP com 5 neurônios na camada oculta.

\subsection{Série de Mackey-Glass}

A série de Mackey-Glass, assim como a função logística, apresenta comportamentos caóticos de acordo com seu parâmetro de bifurcação. Esta função tem suas origens na observação e pesquisa de Glass e Mackey (1997), Beuter et al. (2003) sobre a modelagem de alguns comportamentos atípicos do sistema biológico. A partir daí, foram observados comportamentos com estados estacionários, de ciclolimite e instáveis.

A série de Mackey-Glass pode ser descrita pela equação 6.2, onde o termo $\tau$ é o parâmetro de bifurcação da função.

$$
\frac{d(x)}{d t}=\frac{\beta \theta^{m} x(t-\tau)}{x(t-\tau)^{m}+\theta^{m}}-\gamma x
$$

A função de Mackey-Glass é uma função de valores contínuos; sendo assim, referência ao estado da variável no instante de tempo $t$ é dado por $x(t)$. Logo, na equação 6.2 o instante de tempo de $\tau$ é dado pelo termo $x(t-\tau)$. Os termos $\beta, \omega, \gamma$ e $m$ são ajustes da função, sendo que seus valores para este trabalho são $\beta=0,2, \omega=1, \gamma=0,1$ e $m=10$.

O parâmetro de bifurcação $\tau$ da função de Mackey-Glass permite a navegação do valor da função entre estados estáveis, de ciclo-limite e instáveis. Essa variedade de estados pode ser observada na figura 6.7. 

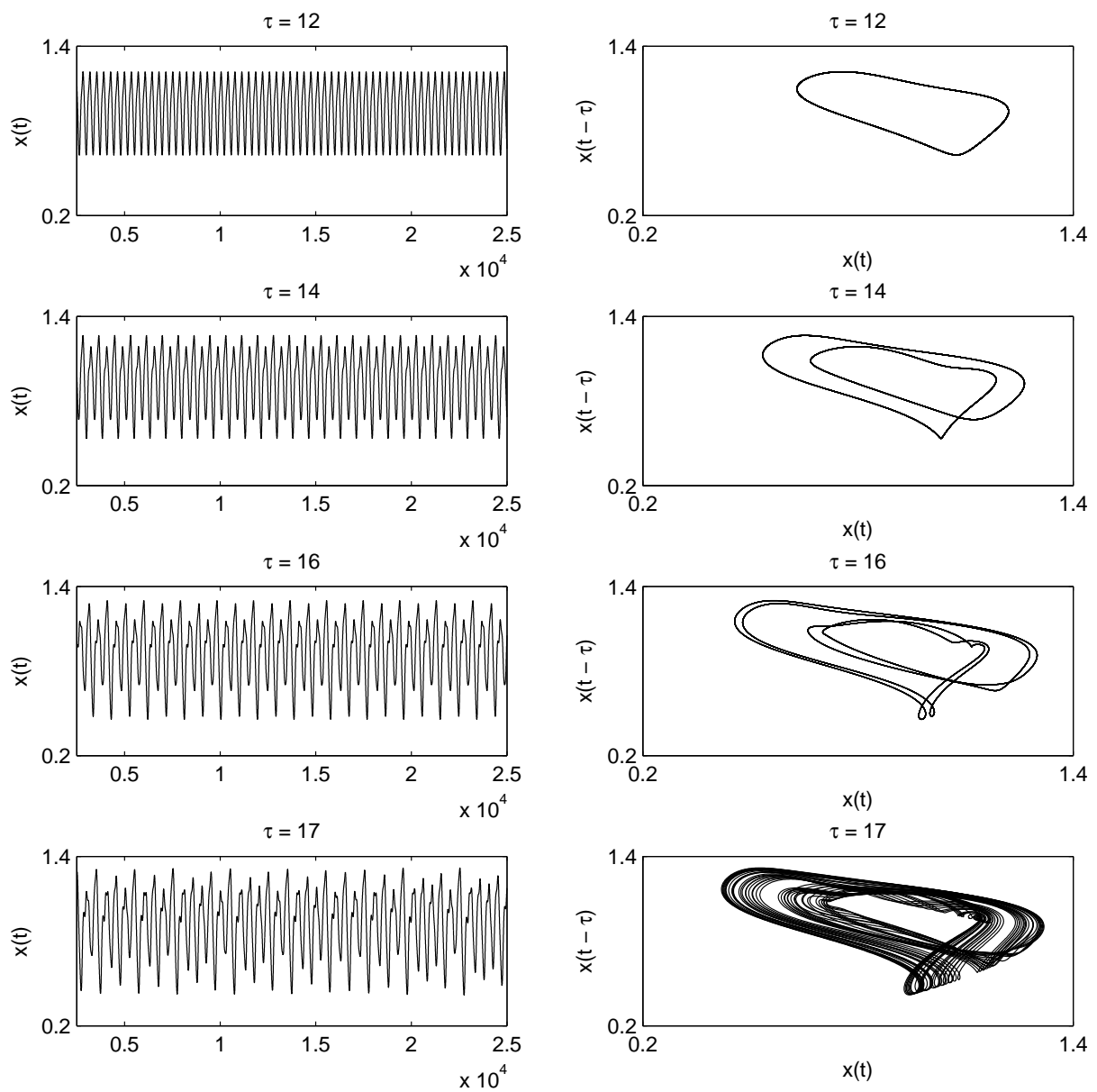

Figura 6.7: Uma simples variação no parâmetro de bifurcação $\tau$ da função de Mackey-Glass permite navegar entre comportamentos distintos da função. A coluna da esquerda apresenta a evolução da função ao longo do tempo $(t)$ e a da direita apresenta um diagrama de teia, no qual é notável o número de períodos da função e a evolução entre $x(t)$ e $x(t-\tau)$. A última linha exibe uma função em comportamento caótico. 
Os experimentos realizados com a função de Mackey-Glass foram separados em dois grupos: o primeiro trabalha apenas com ciclos-limites de periodicidade definida; já o segundo trabalha com estado instável.

O grupo de dados com periodicidade definida foi gerado com 25.000 iterações, das quais as 5.000 iniciais foram descartadas para evitar a influência de uma possível estabilização da variável. Os próximos 10.000 dados foram utilizados como dados de treinamento e os 10.000 últimos como dados de testes. O número máximo de iterações foi restrito a 200 ou valor de erro 0 (o que não ocorreu durante o treinamento).

\begin{tabular}{|c|c|c|c|c|c|c|c|c|c|}
\cline { 2 - 10 } \multicolumn{1}{c|}{} & \multicolumn{3}{c|}{12} & \multicolumn{3}{c|}{14} & \multicolumn{3}{c|}{16} \\
\hline $\begin{array}{c}\text { no. } \\
\text { FPs }\end{array}$ & $\begin{array}{c}\text { erro } \\
\text { médio }\end{array}$ & var. & $\begin{array}{c}\text { desvio } \\
\text { padrão }\end{array}$ & $\begin{array}{c}\text { erro } \\
\text { médio }\end{array}$ & var. & $\begin{array}{c}\text { desvio } \\
\text { padrão }\end{array}$ & $\begin{array}{c}\text { erro } \\
\text { médio }\end{array}$ & var. & $\begin{array}{c}\text { desvio } \\
\text { padrão }\end{array}$ \\
\hline 2 & 0,1413 & 0,0051 & 0,0716 & 0,1467 & 0,0063 & 0,0792 & 0,1384 & 0,0079 & 0,0888 \\
\cline { 2 - 11 } & 0,1422 & 0,0051 & 0,0718 & 0,1466 & 0,0063 & 0,0793 & 0,1372 & 0,0081 & 0,0897 \\
\hline 3 & 0,1407 & 0,0052 & 0,0718 & 0,1453 & 0,0059 & 0,0769 & 0,1383 & 0,0078 & 0,0884 \\
\cline { 2 - 10 } & 0,1416 & 0,0052 & 0,0720 & 0,1451 & 0,0059 & 0,0769 & 0,1372 & 0,0079 & 0,0894 \\
\hline \multirow{2}{*}{5} & 0,1407 & 0,0052 & 0,0718 & 0,1448 & 0,0062 & 0,0785 & 0,1345 & 0,0085 & 0,0921 \\
\cline { 2 - 10 } & 0,1416 & 0,0052 & 0,0721 & 0,1446 & 0,0062 & 0,0785 & 0,1334 & 0,0087 & 0,0931 \\
\hline
\end{tabular}

Tabela 6.3: Resultados obtidos com a estimação da função de Mackey-Glass por um ANFIS.
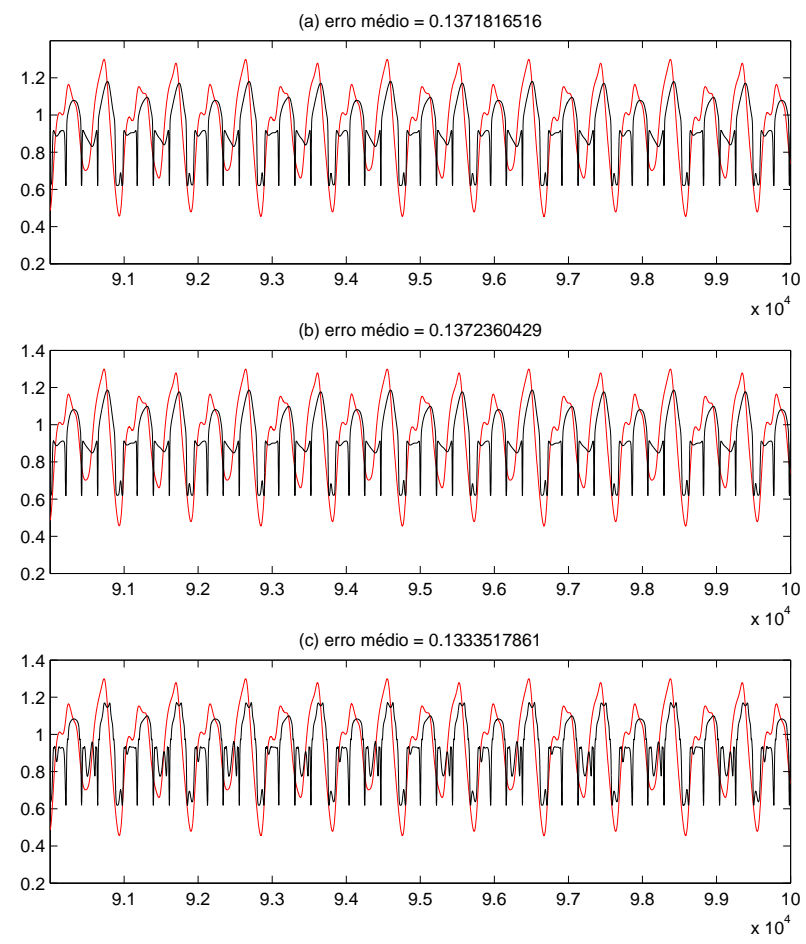

Figura 6.8: Estimação da função de Mackey-Glass 6.2 com parâmetro de bifurcação $\tau=16$ (ciclo-limite em período 4) por um ANFIS com números de funções de pertinência por variável de entrada: (a) 2, (b) 3 e (c) 5 . 
A tabela 6.3 apresenta os resultados obtidos do experimento com um ANFIS. Eles variam de acordo com o número de funções de pertinência imposto à variável de entrada. Na tabela, a primeira coluna indica a quantidade de funções de pertinência utilizada por variável de entrada. A primeira linha de cada experimento aponta o resultado do conjunto de treino, e a segunda linha, os resultados do conjunto de teste.

A figura 6.8 ilustra a estimação da função de Mackey-Glass 6.2 com parâmetro de bifurcação $\tau=16$ (ciclo-limite em período 4) e números de funções de pertinência por variável de entrada: (a) 2, (b) 3 e (c) 5 .

De forma semelhante aos experimentos com a função logística, a comparação foi realizada entre o ANFIS e uma rede MLP. Porém, a rede MLP utiliza no processo de aprendizagem apenas 250 iterações, e são realizados apenas 20 experimentos para se obter a média de erro da rede. Essa perda no número de experimentos é compensada em sua maioria pelo grande aumento de dados da função de Mackey-Glass.

A tabela 6.4 exibe os resultados obtidos com a rede MLP.

\begin{tabular}{|c|c|c|c|c|c|c|c|c|c|}
\cline { 2 - 10 } \multicolumn{1}{c|}{} & \multicolumn{3}{c|}{12} & \multicolumn{3}{c|}{14} & \multicolumn{3}{c|}{16} \\
\hline \multirow{2}{*}{$\begin{array}{c}\text { no. } \\
\text { NO }\end{array}$} & $\begin{array}{c}\text { erro } \\
\text { médio }\end{array}$ & var. & $\begin{array}{c}\text { desvio } \\
\text { padrão }\end{array}$ & $\begin{array}{c}\text { erro } \\
\text { médio }\end{array}$ & var. & $\begin{array}{c}\text { desvio } \\
\text { padrão }\end{array}$ & $\begin{array}{c}\text { erro } \\
\text { médio }\end{array}$ & var. & $\begin{array}{c}\text { desvio } \\
\text { padrão }\end{array}$ \\
\hline 2 & 0,1739 & 0,0076 & 0,0873 & 0,1812 & 0,0102 & 0,1008 & 0,1914 & 0,0137 & 0,1169 \\
\cline { 2 - 11 } & 0,1745 & 0,0076 & 0,0891 & 0,1818 & 0,0101 & 0,1005 & 0,1878 & 0,0132 & 0,1153 \\
\hline \multirow{2}{*}{3} & 0,1697 & 0,0074 & 0,0861 & 0,1815 & 0,0121 & 0,1099 & 0,1837 & 0,0137 & 0,1169 \\
\cline { 2 - 10 } & 0,1705 & 0,0074 & 0,0858 & 0,1819 & 0,0120 & 0,1097 & 0,1837 & 0,0134 & 0,1157 \\
\hline \multirow{2}{*}{5} & 0,1712 & 0,0079 & 0,0894 & 0,1765 & 0,0097 & 0,0984 & 0,1861 & 0,0147 & 0,1212 \\
\cline { 2 - 10 } & 0,1717 & 0,0079 & 0,0892 & 0,1770 & 0,0096 & 0,0981 & 0,1823 & 0,0143 & 0,1198 \\
\hline
\end{tabular}

Tabela 6.4: Resultados obtidos com a estimação da função de Mackey-Glass por uma rede MLP.

As figuras a seguir ilustram a estimação por uma rede MLP da função de Mackey-Glass com parâmetro de bifurcação $\tau=16$ (ver figura 6.7), com variações no número de neurônios da camada oculta de cada rede MLP.

O próximo passo é estimar a função de Mackey-Glass para períodos instáveis. Para isso, foram escolhidos os valores de 20, 25 e 30 para o parâmetro de bifurcação $\tau$.

Para esta estimação foi utilizada uma quatidade de dados diferente da primeira etapa. Visando a melhoria dos valores de erro médio, foi adicionada mais uma variável de entrada no sistema. Logo, o número de funções de pertinência dobraram. O número de regras também sofre alterações, uma vez que elas são 
(a) melhor caso (erro médio $=0.1847$ )

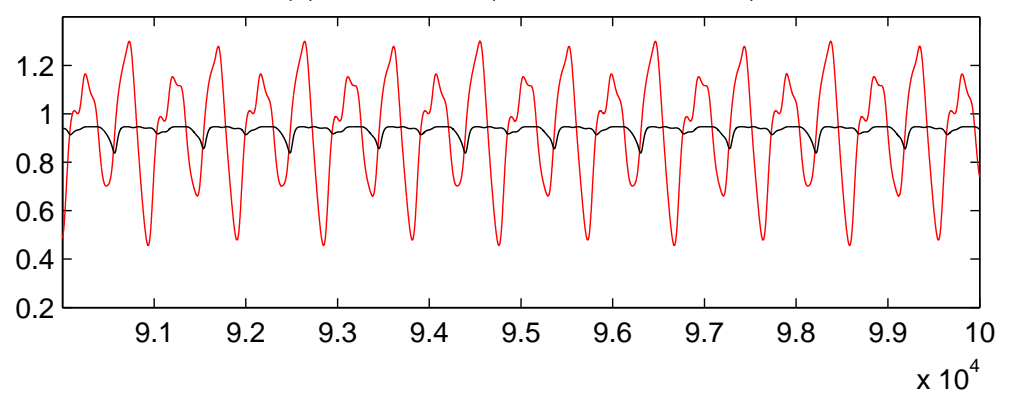

(b) pior caso (erro médio $=0.1897$ )

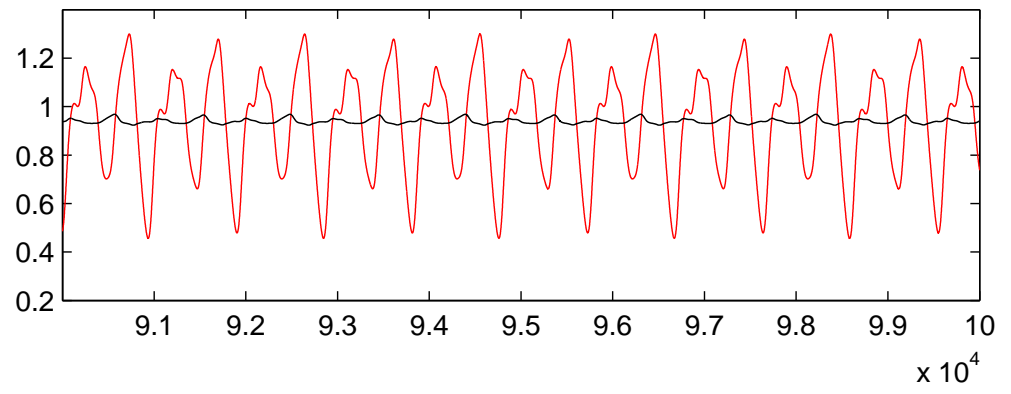

Figura 6.9: Estimação da função de Mackey-Glass 6.2 com parâmetro de bifurcação $\tau=16$ (ciclo-limite em período 4) em uma rede MLP com 2 neurônios na camada oculta.

(a) melhor caso (erro médio $=0.1742$ )

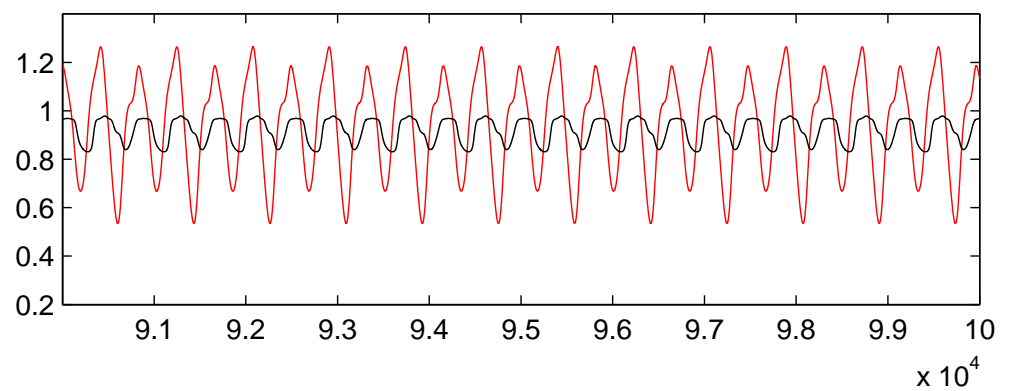

(b) pior caso (erro médio $=0.1852$ )

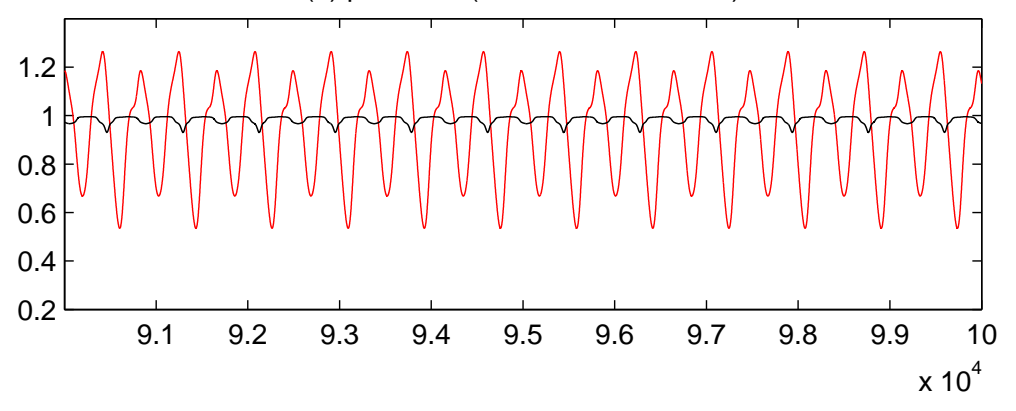

Figura 6.10: Estimação da função de Mackey-Glass 6.2 com parâmetro de bifurcação $\tau=16$ (ciclo-limite em período 4) em uma rede MLP com 3 neurônios na camada oculta. 
(a) melhor caso (erro médio $=0.1732$ )

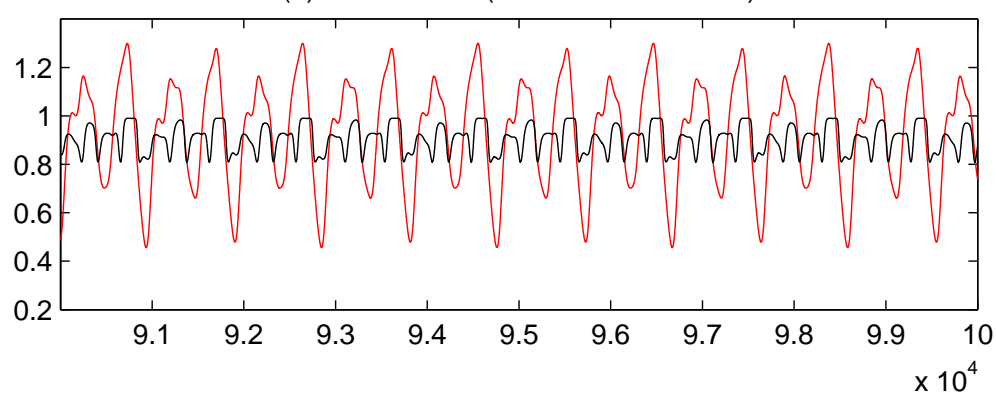

(b) pior caso (erro médio $=0.1874$ )

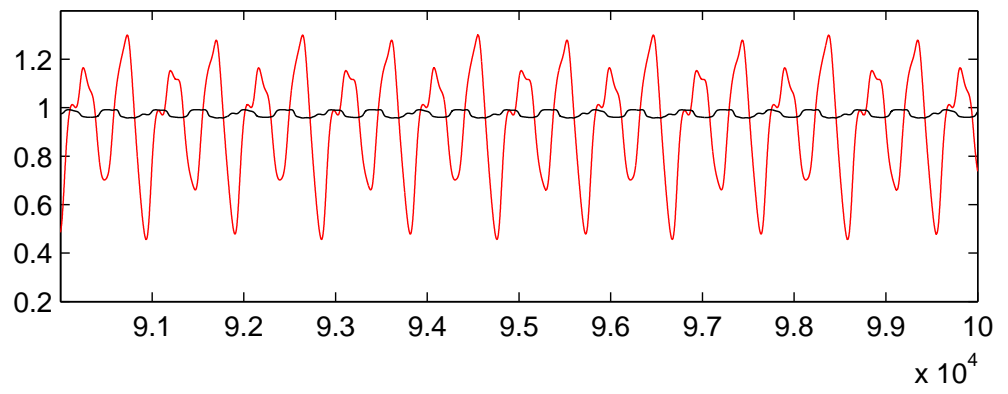

Figura 6.11: Estimação da função de Mackey-Glass 6.2 com parâmetro de bifurcação $\tau=16$ (ciclo-limite em período 4) em uma rede MLP com 5 neurônios na camada oculta.

combinações lineares dos valores de entrada e suas funções de pertinência. As novas amostras foram geradas com 25.000 pontos, sendo que foram descartados os 5.000 iniciais. Os restantes foram dividos igualmente em dados de treinamento e teste, respectivamente.

A nova entrada do sistema é o instante de tempo $t-1$ da variável $x$, logo, a função a ser estimada é calculada como $f(x(t))=f(x(t-\tau), x(t-1))$. O número de iterações para aprendizado também foi aumentado, já que o sistema possuí um número maior de graus de liberdade, passando para 300.

A tabela 6.5 mostra os resultados obtidos com o experimento.

\begin{tabular}{|c|c|c|c|c|c|c|c|c|c|}
\cline { 2 - 10 } \multicolumn{1}{c|}{} & \multicolumn{3}{c|}{20} & \multicolumn{3}{c|}{25} & \multicolumn{3}{c|}{30} \\
\hline $\begin{array}{c}\text { no. } \\
\text { FPs }\end{array}$ & $\begin{array}{c}\text { erro } \\
\text { médio }\end{array}$ & var. & $\begin{array}{c}\text { desvio } \\
\text { padrão }\end{array}$ & $\begin{array}{c}\text { erro } \\
\text { médio }\end{array}$ & var. & $\begin{array}{c}\text { desvio } \\
\text { padrão }\end{array}$ & $\begin{array}{c}\text { erro } \\
\text { médio }\end{array}$ & var. & $\begin{array}{c}\text { desvio } \\
\text { padrão }\end{array}$ \\
\hline 2 & 0,1676 & 0,0129 & 0,1135 & 0,1895 & 0,0160 & 0,1266 & 0,2009 & 0,0198 & 0,1409 \\
\cline { 2 - 11 } & 0,1746 & 0,0141 & 0,1188 & 0,1867 & 0,0162 & 0,1274 & 0,1961 & 0,0202 & 0,1419 \\
\hline \multirow{2}{*}{3} & 0,1669 & 0,0148 & 0,1217 & 0,1918 & 0,0166 & 0,1287 & 0,1982 & 0,0187 & 0,1366 \\
\cline { 2 - 10 } & 0,1734 & 0,0161 & 0,1268 & 0,1847 & 0,0163 & 0,1276 & 0,1958 & 0,0194 & 0,1391 \\
\hline 5 & 0,1641 & 0,0137 & 0,1169 & 0,1924 & 0,0159 & 0,1276 & 0,2030 & 0,0211 & 0,1455 \\
\cline { 2 - 10 } & 0,1732 & 0,0153 & 0,1239 & 0,1889 & 0,0162 & 0,1272 & 0,2017 & 0,0215 & 0,1468 \\
\hline
\end{tabular}

Tabela 6.5: Resultados obtidos com a estimação da função de Mackey-Glass por um ANFIS com duas variáveis de entrada.

A figura 6.12 ilustra a estimação da ANFIS para os dados de teste. 

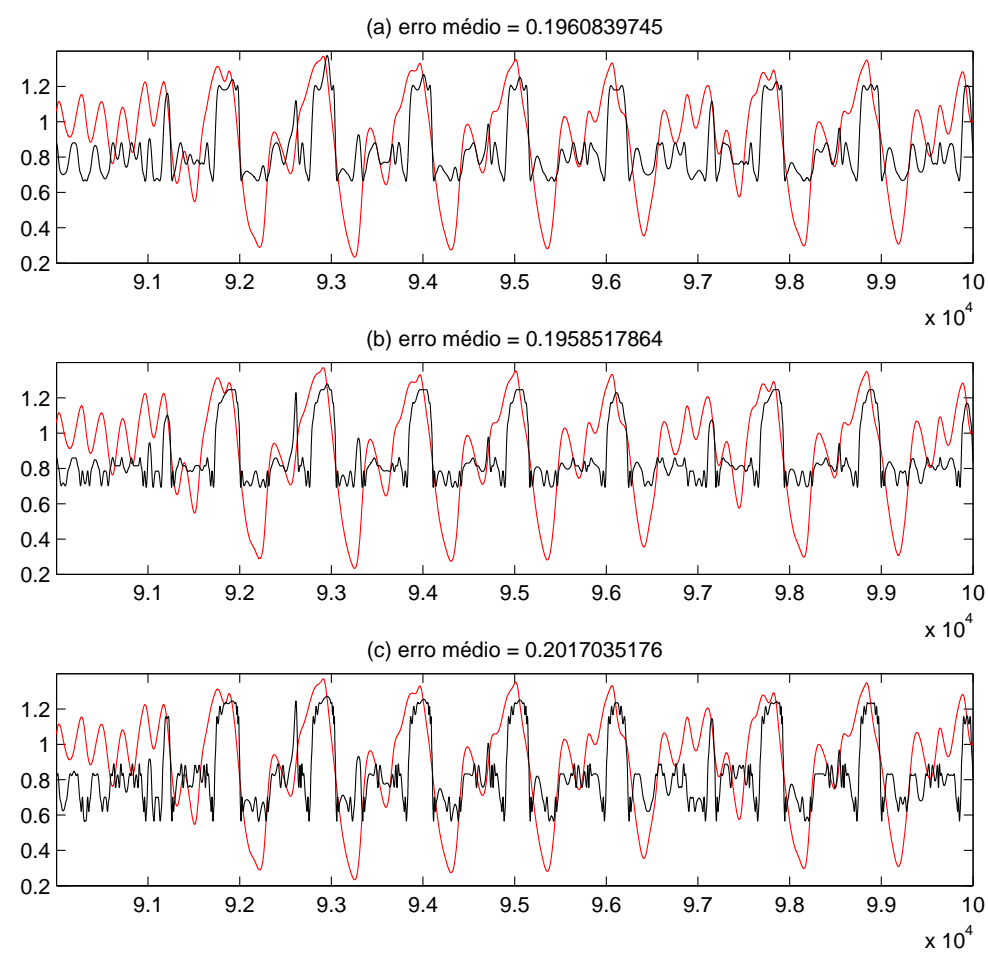

Figura 6.12: Estimação da função de Mackey-Glass 6.2 com parâmetro de bifurcação $\tau=30$ (período instável) por um ANFIS com 2 variáveis de entrada e números de funções de pertinência de entrada (a) 2, (b) 3 e (c) 5 por variável.

A tabela 6.6 exibe os resultados para a estimação utilizando uma rede MLP com duas variáveis de entrada.

\begin{tabular}{|c|c|c|c|c|c|c|c|c|c|}
\cline { 2 - 10 } \multicolumn{1}{c|}{} & \multicolumn{3}{c|}{20} & \multicolumn{3}{c|}{25} & \multicolumn{3}{c|}{30} \\
\hline $\begin{array}{c}\text { no. } \\
\text { FPs }\end{array}$ & $\begin{array}{c}\text { erro } \\
\text { médio }\end{array}$ & var. & $\begin{array}{c}\text { desvio } \\
\text { padrão }\end{array}$ & $\begin{array}{c}\text { erro } \\
\text { médio }\end{array}$ & var. & $\begin{array}{c}\text { desvio } \\
\text { padrão }\end{array}$ & $\begin{array}{c}\text { erro } \\
\text { médio }\end{array}$ & var. & $\begin{array}{c}\text { desvio } \\
\text { padrão }\end{array}$ \\
\hline 2 & 0,1956 & 0,0176 & 0,1327 & 0,2092 & 0,0238 & 0,1544 & 0,2288 & 0,0269 & 0,1639 \\
\cline { 2 - 10 } & 0,2081 & 0,0203 & 0,1425 & 0,2215 & 0,0264 & 0,1626 & 0,2269 & 0,0289 & 0,1702 \\
\hline \multirow{2}{*}{3} & 0,1941 & 0,0170 & 0,1304 & 0,2057 & 0,0234 & 0,1530 & 0,2272 & 0,0278 & 0,1668 \\
\cline { 2 - 10 } & 0,2065 & 0,0197 & 0,1405 & 0,2187 & 0,0259 & 0,1609 & 0,2264 & 0,0297 & 0,1726 \\
\hline \multirow{2}{*}{5} & 0,1917 & 0,0171 & 0,1309 & 0,2045 & 0,0233 & 0,1528 & 0,2256 & 0,0254 & 0,1592 \\
\cline { 2 - 10 } & 0,2050 & 0,0201 & 0,1418 & 0,2182 & 0,0258 & 0,1605 & 0,2243 & 0,0274 & 0,1656 \\
\hline
\end{tabular}

Tabela 6.6: Resultados obtidos com a estimação da função de Mackey-Glass por um ANFIS com duas variáveis de entrada. 
(a) melhor caso (erro médio $=0.1847$ )

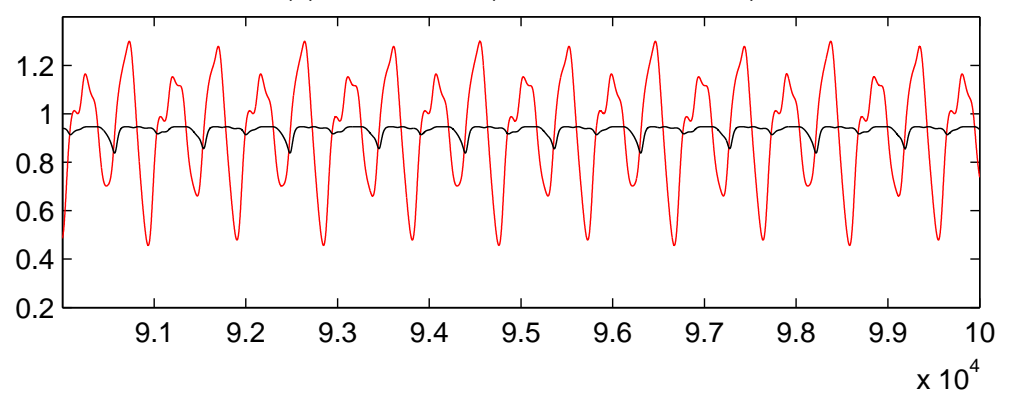

(b) pior caso (erro médio $=0.1897$ )

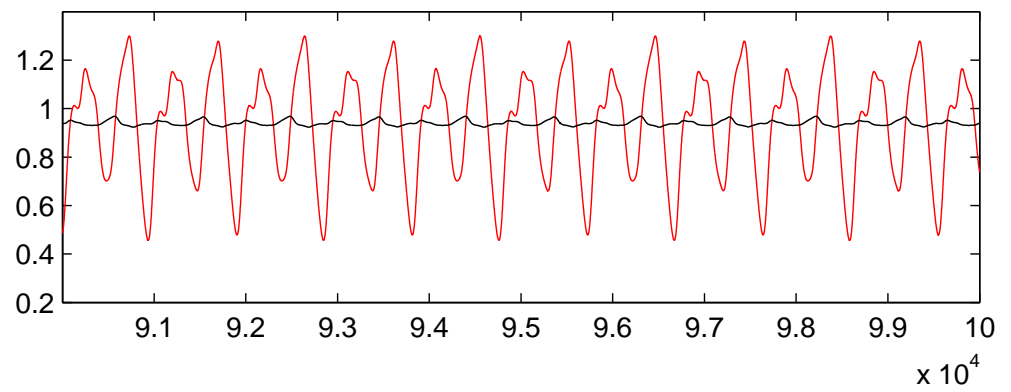

Figura 6.13: Estimação da função de Mackey-Glass 6.2 com parâmetro de bifurcação $\tau=16$ (ciclo-limite em período 4) em uma rede MLP com 2 variáveis de entrada e 2 neurônios na camada oculta.

(a) melhor caso (erro médio $=0.1742$ )

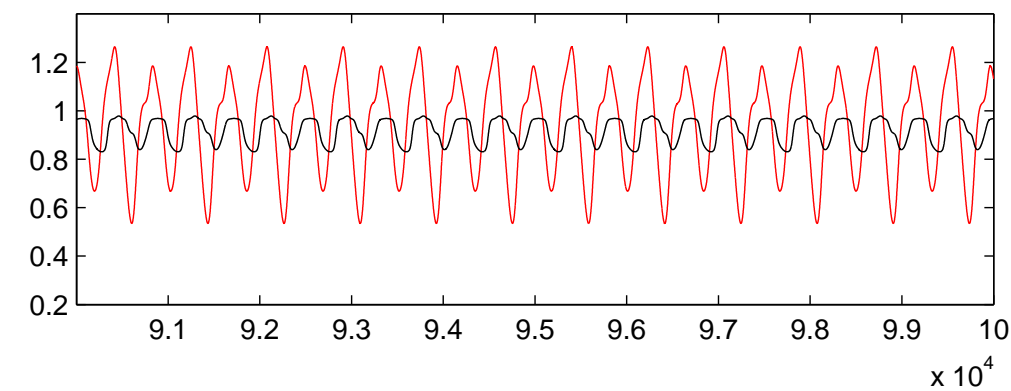

(b) pior caso (erro médio $=0.1852$ )

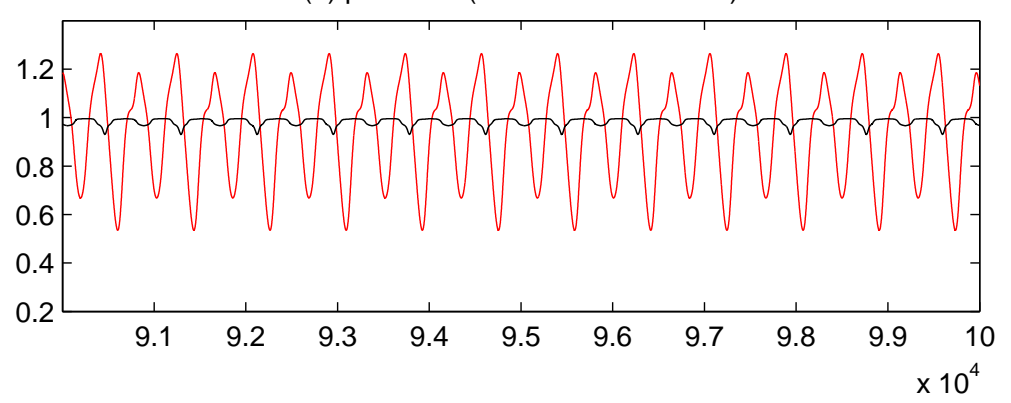

Figura 6.14: Estimação da função de Mackey-Glass 6.2 com parâmetro de bifurcação $\tau=16$ (ciclo-limite em período 4) em uma rede MLP com 2 variáveis de entrada e 3 neurônios na camada oculta. 
(a) melhor caso (erro médio $=0.1732$ )

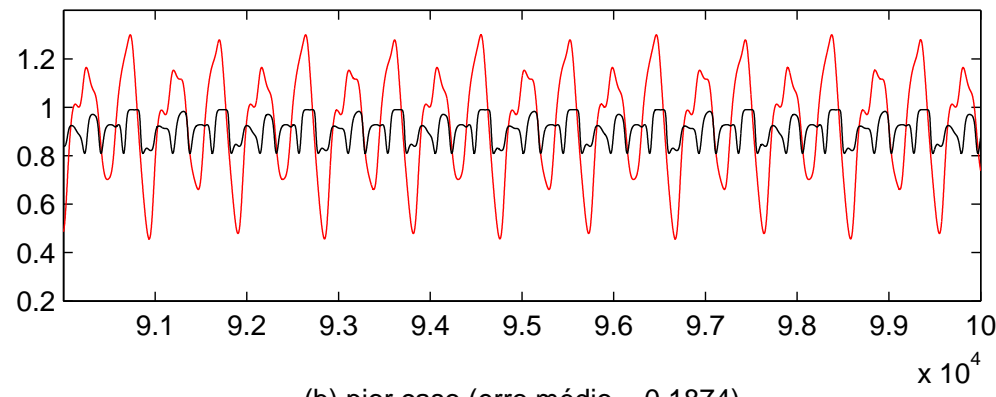

(b) pior caso (erro médio $=0.1874$ )

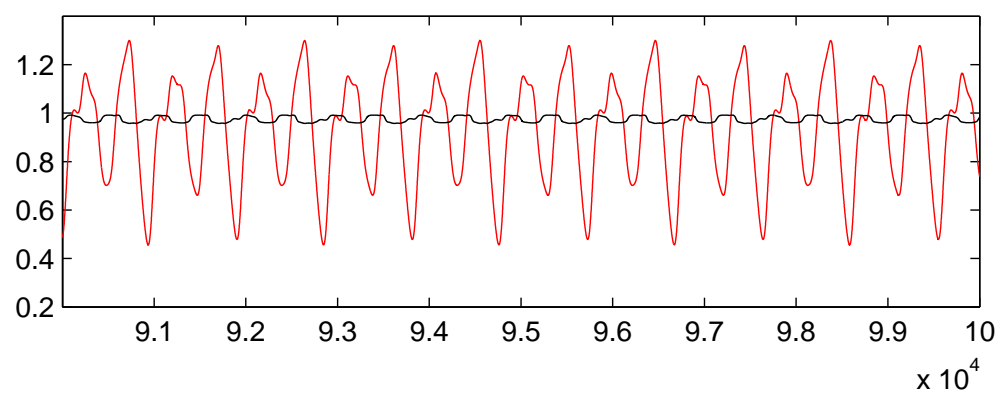

Figura 6.15: Estimação da função de Mackey-Glass 6.2 com parâmetro de bifurcação $\tau=16$ (ciclo-limite em período 4) em uma rede MLP com 2 variáveis de entrada e 5 neurônios na camada oculta. 


\section{Análise Comparativa e Discussões}

Neste capítulo são apresentadas algumas comparações, conclusões e discussões a respeito dos experimentos realizados e da finalização deste trabalho.

A predição de séries temporais possui as mais diversas áreas de aplicações. Neste trabalho foram utilizadas duas funções para a predição de funções. Essas funções foram especialmente escolhidas por apresentar um comportamento caótico de acordo com seus parâmetros de bifurcação: $\mu$ para a função logística e $\tau$ função de Mackey-Glass. Os resultados obtidos durante o processo de estimação das funções, tanto para o ANFIS quanto para a rede MLP, ajudam a mapear o uso apropriado de um ANFIS.

No caso da estimação da função logística, foram montadas duas tabelas comparativas, as tabelas 6.1 e 6.2. Na tabela 6.1, a estimativa é realizada através de um ANFIS que contém apenas uma variável de entrada e outra de saída, as quais são, respectivamento, os termos $x(t)$ e $x(t-1)$ da própria função logística.

Neste experimento é possível notar a grande discrepância da precisão quando um ANFIS é comparado com uma rede MLP, deixando nítida a vantagem do uso de um ANFIS sob o domínio desta função. Ao analisar os gráficos de testes gerados pelo ANFIS pode-se observar que a estimação se deu quase sem erro, e que o mesmo não aconteceu com a rede MLP. Este resultado em grande parte, pode ser atribuído ao fato de uma sensibilidade maior durante o processo de aprendizagem do ANFIS, uma vez que o número de graus de liberdade, ou seja, número de neurônios e parâmetros de influência, não é muito maior que os da rede MLP. Neste caso também, ANFIS apresentou um processo de aprendizagem com menos ciclos que a rede MLP, o que a torna mais adequada para a predição desta função.

Na tabela 6.2 está avaliado o desempenho da rede MLP para a predição da função logística. Observando a tabela é possível notar que, tanto a rede MLP quanto o ANFIS possuem dificuldades maiores para diagnosticar a função quando 
ela está em estado instável.

Já no caso da estimação da função de Mackey-Glass, os valores de erros médios das duas tabelas se mantiveram bastante próximos e altos. Mas, neste caso, a rede MLP leva vantagens pois apresenta um número de graus de liberdade bem menor que o ANFIS. Ao aumentar o número de variáveis de entrada, o número de regras para um ANFIS aumenta exponencialmente, o que torna o sistema mais robusto e complexo computacionalmente. Assim, para grandes processamentos em massas de dados, o ANFIS tem que ser aplicado com ajustes em seus parâmentros de conseqüência, o que geralmente é feito por um especialista.

Na função de Mackey-Glass o erro se manteve muito alto; alguns outros testes paralelos mostraram que mesmo aumentando o número de funções de pertinência, ou o número de neurônios ocultos (no caso da rede MLP), os valores sempre permaneceram imutáveis dentro de uma certa margem de erro. Acredita-se que isso tenha ocorrido pelo grande número de amostras geradas pela Mackey-Glass, uma vez que, para sua implementação foi necessário fazer uma discretização do instante $x(t)$.

Outro ponto de vista há avaliar é o aumento gradativo do erro em função do número de ciclos-limites que a função visita. Este aspecto torna o erro bem maior na medida que a função se encontra em estado instável. 


\section{Considerações Finais}

\subsection{Contribuições do Trabalho}

O trabalho permitiu a elaboração de um estimador para aproximação das funções logística e de Mackey-Glass utilizando técnicas de redes neurais e sistemas fuzzy. Essas técnicas foram empregadas cooperativamente através de uma arquitetura de sistemas neuro-fuzzy, propiciando assim uma melhor compreensão do uso e comportamento da série de Mackey-Glass, a qual se mostrou uma função complexa de ser estimada.

Com o trabalho também foi possível um aprofundamento da arquitetura e a implementação de um ANFIS, além da comprovação da superioridade para a predição de funções, mesmo que utilizando dados de entrada com funções de pertinência de espaço de variáveis geradas automaticamente. Durante o processo de aprendizagem, o algoritmo realizou o ajuste automático nas funções de pertinência.

\subsection{Trabalhos Futuros}

O trabalho permitiu uma boa visão do uso de um sistema híbrido de arquitetura neuro-fuzzy para predição de funções. Porém, alguns temas ainda permanecem em aberto, como por exemplo, uma forma de melhorar a perfomance de acerto de um ANFIS para a função de Mackey-Glass. Uma possibilidade seria incorporar técnicas de discretização na função, tornando-a mais abrupta. Dessa maneira, seriam necessários um número menor de graus de liberdade para representar a função.

Outra maneira de tornar o ANFIS uma arquitetura mais protegida contra o problema da dimensionalidade para sistemas macros é a redução de sua implementação para sistemas embarcados.

Outra interessante possibilidade seria tentar levantar uma curva do erro de 
predição em função do número de ciclos-limites do comportamento da função. Isso se mostra particularmente interessante pelo fato que é geralmente prévia uma estimativa do conhecimento do comportamento da função.

Uma comparação detalhada do ANFIS com outras arquiteturas de modelos neuro-fuzzy, como o NEFPROX por exemplo, seria de grande valia para uma tomada de decisão. 


\section{Referências}

ABRAHAM, A. Neuro fuzzy systems: State-of-the-art modeling techniques. In: Lecture Notes in Computer Science. [S.1.: s.n.], 2001. v. 2084, p. 269-276.

AURÉLIO, M.; VELLASCO, M.; LOPES, C. H. Descoberta de Conhecimento e Mineração de Dados. Rio de Janeiro, Brasil, Agosto 1999.

BEAR, M. F.; CONNORS, B. W.; PARADISO, M. A. Neuroscience: exploring the brain, 2/E. Providence, RI: Lippincott Willians \& Wilkins, 2001.

BEUTER, A.; GLASS, L.; MACKEY, M. C.; TITCOMBE, M. S. Nonlinear Dynamics in Physiology and Medicine. New York, NY: Springer-Verlag, Inc., 2003.

BROCKWELL, P. J.; DAVIS, R. A. Time series: theory and methods, 2/E. New York, NY: Springer-Verlag, Inc., 1991.

DEL-MORAL-HERNANDEZ, E. Neural networks with chaotic recursive nodes: techniques for the design of associative memories, contrast with hopfield architectures, and extensions for time-dependent inputs. In: Neural Networks, Elsevier. [S.l.: s.n.], 2003. v. 16, p. 675-682.

DEL-MORAL-HERNANDEZ, E.; SANDMANN, H.; SILVA, L. A. Pattern recovery in networks of recursive processing elements with continuous learning. In: IEEE Proceedings of International Joint Conference on Neural Networks (IJCNN). [S.l.: s.n.], 2004. v. 1, p. 98-103.

DENAï, M. A.; PALIS, F.; ZEGHBIB, A. Anfis based modelling and control of non-linear systems: A tutorial. In: IEEE International Conference on Systems, Man and Cybernetics. [S.l.: s.n.], 2004. p. 3433-3438.

DUBOIS, D.; PRADE, H.; YAGER, R. R. Fuzzy information engineering: a guided tour of applications. [S.l.]: John Wiley and Sons, Inc., 1996.

DUDA, R. O.; HART, P. E.; STORK, D. G. Pattern Classification 2/E. New York, NY: Wiley Interscience, 2000.

GLASS, L.; MACKEY, M. C. Dos Relógios ao Caos: Os Ritmos da Vida. Sao Paulo, SP: Editora da Universidade de São Paulo, 1997.

HAYKIN, S. Neural networks: a comprehensive foundation, 2/E. New York, NY: Prentice Hall, Inc., 1999.

JANG, J.-S. R. Neuro-Fuzzy Modeling: Architecture, Analyses and Applications (dissertation). Berkeley, CA: University of California, 1992.

JANG, J.-S. R. Anfis: Adaptive-network-based fuzzy inference system. In: IEEE Transactions on Systems, Man, and Cybernetics. [S.l.: s.n.], 1993. v. 23, n. 3, p. 665-685. 
JANG, J.-S. R.; SUN, C.-T.; MIZUTANI, E. Neuro-Fuzzy and Soft Computing. Upper Saddle River, NJ: Prentice Hall, 1997.

JORDAN, M. I.; BISHOP, C. M. Neural networks. In: CRC Handbook of Computer Science. [S.l.: s.n.], 1996.

KOSKO, B. Neural Networks and Fuzzy Systems. Englewood Cliffs, NJ: Prentice-Hall, 1992.

LEE, C. C. Fuzzy logic in control system: Fuzzy logic controller - part 1. In: IEEE Transactions on Systems, Man, and Cybernetics. [S.l.: s.n.], 1990. v. 20, n. 2 , p. 404-418.

LEE, C. C. Fuzzy logic in control system: Fuzzy logic controller - part 2. In: IEEE Transactions on Systems, Man, and Cybernetics. [S.l.: s.n.], 1990. v. 20, n. 2, p. 419-435.

MITRA, S.; HAYASHI, Y. Neuro-fuzzy rule generation: Survey in soft computing framework. In: IEEE Transactions on Neural Networks. [S.l.: s.n.], 2000. v. 11, n. 3, p. 748-768.

MULLER, B.; REINHARDT, J. Neural Networks: an introduction. Berlin Heidelberg: Springer-Verlag, 1990.

NAUCK, D.; KLAWONN, F.; KRUSE, R.; BORGELT, C. Neuro-Fuzzy-Systeme, 3/A. Wiesbaden: Fried. Wieweg \& Sohn Verlagsgessellschaft, 2003.

ROSS, S. M. Applied Probability Models with Optimization Applications. Toronto, Ontario: General Publishing Company, Ltd., 1970.

ZADEH, L. A. Fuzzy Sets. Berkeley, California, October 1965.

ZADEH, L. A. Outline of a new approach to the analysis of complex systems and decision processes. In: IEEE Transactions on Systems, Man, and Cybernetics. [S.l.: s.n.], 1973. v. 3, n. 1, p. 28-44.

ZADEH, L. A. Fuzzi logic = computing with words. In: IEEE Transactions on Systems, Man, and Cybernetics. [S.l.: s.n.], 1996. v. 4, n. 2, p. 103-111.

ZHOU, C.; JAGANNATHAN, K. Adaptive network based fuzzy control of a dynamic biped walking robot. In: . [S.l.: s.n.], 1996. p. 109-116. 